\title{
Decision-making Strategies and Self-regulated Learning: Fostering Decision-making Competence in Education for Sustainable Development
}

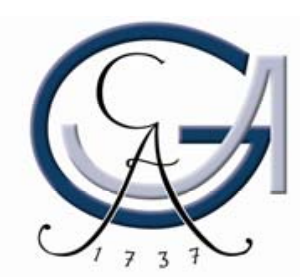

\section{Dissertation}

zur Erlangung des mathematisch-naturwissenschaftlichen Doktorgrades

$$
\text { „Doctor rerum naturalium” }
$$

der Georg-August-Universität Göttingen

vorgelegt von

Helge Gresch

aus Flensburg

Göttingen 2011 
Mitglieder des Betreuungsausschusses:

Referentin:

Koreferent:

Tag der mündlichen Prüfung:
Prof. Dr. Susanne Bögeholz

Prof. Dr. Marcus Hasselhorn

Prof. Dr. Susanne Bögeholz

Prof. Dr. Marcus Hasselhorn

06. Januar 2012 
Entscheidungsstrategien und selbstreguliertes Lernen:

Förderung von Bewertungskompetenz im Kontext Bildung für Nachhaltige Entwicklung 


\section{Acknowledgements}

During the last three years, I have been supported by many people, without whom this dissertation would not have been possible. Therefore, I would like to thank each one of them.

I cordially thank all of the students who took part in my study in a dedicated and concentrated way. Their contributions greatly supported my project. Furthermore, I am obliged to all of the teachers who participated despite their many other challenges, such as the new curricula and institutional reforms that coincided with my study. I greatly appreciate that many teachers offered to participate despite the scarce amount of time available in upper high school courses before the final high school exams.

In all phases of my $\mathrm{PhD}$ - from the first verbalization of the research questions until the publication of the results - my supervisors Prof. Dr. Susanne Bögeholz and Prof. Dr. Marcus Hasselhorn greatly and intensively supported my progress. I give my most cordial thanks to them for the enriching discussions. Moreover, I thank Prof. Dr. Dana Zeidler for his insights into the international discourse on socioscientific issues, which helped me considerably in presenting my study in an international context. In addition, I would like to warmly thank Dana and his amiable wife Patricia for the amazing stay in Tampa.

The idea of a computer-based intervention study could only be implemented thanks to the amazing support of Christian Rolfes, who programmed the learning environment and enduringly mastered the seemingly endless flood of requests to optimize the program. The server and the databank allowed for the efficient execution of the study and the evaluation of the results. I am especially grateful for his readiness to help even in the early morning in cases of emergency.

I am obliged to all my colleagues and professors of the graduate research program 1195 Enhancing Educational Congruence in Schools and 
the Department of Biology Education at the University of Göttingen for the intensive discussions during our internal retreats and for testing my computer-based training program. For the provision of the decision-making questionnaires, the introduction into the scoring guide and the discussions of my results, I especially thank Sabina Eggert. Moreover, I very much appreciate the help of Frauke Ostermeyer, Matthias Martens, Sonja Arens, Andju Labuhn and Stephan Teschner, who have proofread parts of my dissertation at different stages. Regarding our discussions in Göttingen and Frankfurt concerning sustainable development and empirical educational research, I immensely thank Matthias Martens, Lydia Wettstädt and Dorthe Petersen for the invaluable discourse.

I am grateful for the statistical advice of Dr. Wolfang Wörner of the German Institute for International Educational Research in Frankfurt, who helped me draw conclusions from my first study to improve the subsequent study. For their discussions of my first research results, I greatly thank the working group of Prof. Dr. Troy Sadler at the University of Florida in Gainsville.

Janis Evermann and Birgit Oelbermann supported me during the data collection phase of my project by printing the questionnaires, coordinating the schools and teachers and ensuring an adequate procedure for the study. For their endurance and thoroughness when recoding and discussing the open answers of half of my approximately 1800 questionnaires, I am obliged to Nathalie KohImann and Carina Meins. Most cordially, I would like to thank my friends Ingar Fröhlich, Ulrike Breuker and Marina Wrede for hosting me during the data collection phase and making this phase of my PhD as comfortable as possible.

Long before I began my PhD program, many people paved the way for this venture. I made my first contact in biology education during my community service, where I worked for Prof. Dr. Wilfried Probst, who taught me to value the diversity of nature. The discussions about sustainable 
development with my friend Ingar Fröhlich changed my world view and aroused my interest in this field. Moreover, I thank Prof. Dr. Corinna Hößle, Katja Reitschert, Julia Schwanewedel and Ulrike Breuker for laying the groundwork in biology education and advising me in the application process for a post as a PhD student.

For moral support throughout my degree process, I am obliged to my parents Eva and Wolfgang Gresch as well as Birthe, my sisters Ines, Ute and Dietlind and my brother Rüdiger. Without my stay at the English boarding school in Cheltenham, which my mother promoted, it would not have been possible to compose my dissertation in English. I thank my father for encouraging me to accept the challenge of beginning a PhD program. Moreover, I thank my nephew Max for pre-testing the learning program.

For financial support, I am grateful to the German taxpayers and the German Research Foundation (DFG), who financed the research program 1195 Enhancing Educational Congruence in Schools. The scholarship and the resources for my project enabled me to conduct this study with the proper scope and in a very constructive research environment. The stay abroad and the conferences broadened my horizon with regard to my project as well as empirical educational research as a whole.

Last but not least, I would like to thank the manager of the youth hostel, who waited for hours late at night until my train, which had become stuck in masses of snow, finally arrived at the location where I conducted my intervention the following day. 


\section{Danksagung}

In den letzten drei Jahren haben mich viele Menschen unterstützt, ohne die diese Dissertation nicht möglich gewesen wäre.

Besonders danke ich allen Schülerinnen und Schülern, die äußerst engagiert an meiner Studie teilnahmen und dieses Projekt durch ihre konzentrierte Mitarbeit und reflektierten Beiträge erst zu einem Erfolg gemacht haben. Genauso gilt mein Dank auch allen Lehrerinnen und Lehrern, welche in Zeiten des doppelten Abiturjahrgangs nach zwölf bzw. dreizehn Jahren und der Einführung eines neuen Kerncurriculums für die gymnasiale Oberstufe die ohnehin knappe Zeit ihrer Oberstufenkurse zur Verfügung gestellt haben.

In allen Phasen der Promotion - von der ersten Formulierung der Forschungsfragen bis zur Publikation der Ergebnisse - haben meine Doktoreltern Prof. Dr. Susanne Bögeholz und Prof. Dr. Marcus Hasselhorn den Fortschritt durch eine hervorragende, intensive Betreuung und anregende Diskussionen unterstützt. Hierfür gilt innen mein besonders herzlicher Dank. Prof. Dr. Dana Zeidler danke ich für die Einblicke in die USamerikanische Forschungstradition und die Diskussionen, die mir halfen, mein Forschungsprojekt in den internationalen Diskurs einzubetten. Außerdem möchte ich inm und seiner liebenswürdigen Frau Patricia herzlich für die vielen persönlichen Einladungen in meiner Zeit in Tampa danken.

Die Idee einer computergestützten Interventionsstudie war nur umsetzbar dank der hervorragenden Unterstützung von Christian Rolfes, der die Lernumgebung programmiert und die schier unendliche Flut an Optimierungswünschen kompetent und ausdauernd umgesetzt hat. Der von inm eingerichtete Server und die Datenbank haben eine effiziente Durchführung und Auswertung der Studie ermöglicht. Auch wegen der frühmorgendlichen Anrufe bei Störfällen bin ich Christian für sein Durchhaltevermögen und seine Hilfsbereitschaft sehr dankbar. 
Den Stipendiatinnen und Stipendiaten sowie den Hochschullehrerinnen und Hochschullehrern des Graduiertenkollegs 1195 Passungsverhältnisse schulischen Lernens und den Doktorandinnen und Doktoranden der Göttinger Biologiedidaktik danke ich sehr für die intensiven Diskussionen auf den internen Klausurtagungen und das Probetesten meines Lernprogramms. Insbesondere danke ich Sabina Eggert für die Bereitstellung der Fragebögen, die Einführung in das Kodiersystem und die Diskussion meiner Forschungsergebnisse sowie Frauke Ostermeyer, Matthias Martens, Sonja Arens, Andju Labuhn und Stephan Teschner für das Korrekturlesen in unterschiedlichen Stadien der Promotion. Besonders anregend waren die abendlichen Diskussionen über Nachhaltige Entwicklung und Grundlagen der empirischen Bildungsforschung mit Matthias Martens, Lydia Wettstädt und Dorthe Petersen in Göttingen und Frankfurt.

Dr. Wolfgang Wörner vom Deutschen Institut für Internationale Pädagogische Forschung danke ich für die intensive statistische Beratung bei meiner ersten Studie, aus der ich sehr gewinnbringende Schlüsse für die Folgestudie gezogen habe. Ebenso danke ich den Mitgliedern der Arbeitsgruppe von Prof. Dr. Troy Sadler an der University of Florida in Gainsville, mit denen ich die Ergebnisse meiner ersten Studie diskutieren konnte.

Für die Unterstützung bei der Durchführung der Studie, dem Fragebogendruck und der Organisation von Terminen an den teilnehmenden Schulen danke ich Janis Evermann und Birgit Oelbermann, die sich sehr dafür eingesetzt haben, einen reibungslosen Ablauf zu gewährleisten. Ganz besonders danke ich auch meinen Studienfreunden Ingar Fröhlich, Ulrike Breuker und Marina Wrede, die mich während der Datenerhebungsphasen bei sich zu Hause aufgenommen haben, um diese anstrengende Phase der Promotion so angenehm wie möglich zu gestalten. Für das Durchhalten und die Gründlichkeit beim Gegenscoren und Besprechen der offenen Schülerantworten von 50\% meiner etwa 1800 Fragebögen danke ich Nathalie KohImann und Carina Meins. 
Lange bevor meine Promotionszeit begann, hatten mich viele Menschen geprägt und den Weg für diese Arbeit bereitet. Den ersten Kontakt mit der Biologiedidaktik hatte ich während des Zivildienstes bei Prof. Dr. Wilfried Probst, durch den ich den Wert und die Vielfalt der Natur schätzen lernte. Die Diskussionen um Nachhaltige Entwicklung mit meiner Studienfreundin Ingar Fröhlich haben meine Weltsicht verändert und das Interesse an diesem Themenbereich geweckt. Für das fachliche Fundament zur Bewertungskompetenz und die Beratung bei der Bewerbung um meine Promotionsstelle danke ich Prof. Dr. Corinna Hößle, Katja Reitschert, Julia Schwanewedel und Ulrike Breuker.

Für die moralische Unterstützung während der gesamten Promotionszeit danke ich meinen Eltern Eva und Wolfgang Gresch sowie Birthe und meinen Geschwistern Ines, Ute, Dietlind und Rüdiger. Ohne den siebenmonatigen Auslandsaufenthalt im englischen Cheltenham während meiner Schulzeit, den meine Mutter gefördert hatte, wäre es mir nicht möglich gewesen, die Dissertation auf Englisch zu verfassen. Meinem Vater danke ich sehr, dass er mich ermutigt hat, die Herausforderung einer Dissertation anzunehmen. Auch danke ich meinem Neffen Max für das Vortesten des Lernprogramms.

Für die finanzielle Unterstützung des Projekts danke ich dem Deutschen Steuerzahler und der Deutschen Forschungsgemeinschaft, die das Graduiertenkolleg 1195 Passungsverhältnisse schulischen Lernens finanzierten. Das Stipendium und die Projektgelder haben es mir ermöglicht, meine Studie in diesem Umfang und in einem äußerst konstruktiven Forschungsumfeld durchzuführen. Durch den Auslandsaufenthalt und die Tagungsreisen hat sich die Perspektive auf mein Projekt und empirische Unterrichtsforschung allgemein sehr erweitert.

Und last, but not least danke ich der Leiterin der Jugendherberge, die nachts noch Stunden wartete, bis mein im Schnee steckengebliebener Zug endlich in dem Ort eintraf, wo die Erhebung am nächsten Morgen stattfand. 


\section{Abstract}

Environmental problems, the exploitation of natural resources and social injustice in a globalized world require the political actions and responsible behavior of all citizens. Therefore, students must be able to make thoughtful decisions about socioscientific issues pertaining to sustainable development. This demands analyses of complex scientific evidence as well as considerations of societal norms and personal values. To enable students to deal systematically with a multitude of possible courses of action, this dissertation aims to foster decisionmaking competence through the reflective application of decision-making strategies. Non-sustainable options that do not meet ecological, economic or social standards should be excluded using a non-compensatory strategy. Consequently, the advantages cannot compensate for the deficits. Equally legitimate options should be compared in a full trade-off by applying compensatory strategies. In addition, the effect of elements of self-regulated learning on the acquisition of decision-making competence was investigated. Two computer-based intervention studies were conducted in upper high school biology courses. The effects of the intervention were investigated in a pre-postfollow-up control-group design using a decision-making questionnaire with openended items and through analyses of process-related data collected during the intervention. The summative assessment of the first study showed that training in decision-making strategies enhanced the quality of the students' own decisions. The process-related analyses demonstrated reflective metadecision explanations of the students regarding the selection of an appropriate strategy. The second study revealed that reflection upon the strengths and deficits of other people's decision-making processes enhanced the students' own decision-making competence and their reflection skills. The elements of self-regulated learning led to a higher degree of perceived autonomy and ensured long-term effects of the decision-making training. 


\section{Zusammenfassung}

Umweltprobleme, die Übernutzung natürlicher Ressourcen und soziale Ungerechtigkeit in einer globalisierten Welt erfordern politische Maßnahmen und ein verantwortungsbewusstes Verhalten von Bürgerinnen und Bürgern. Reflektierte Entscheidungen zur Gestaltung von Nachhaltiger Entwicklung bedürfen der Analyse komplexer naturwissenschaftlicher Evidenz unter Einbezug gesellschaftlicher Normen und persönlicher Werthaltungen. Das Ziel der Dissertation ist es, Schülerinnen und Schüler zu befähigen, durch die reflektierte Anwendung von Entscheidungsstrategien systematische Entscheidungen zu treffen und somit Bewertungskompetenz zu fördern. Optionen, die entsprechend gesellschaftlicher Normen als nicht nachhaltig einzustufen sind, da sie ökologische, ökonomische oder soziale Standards nicht erfüllen, sollten durch die Anwendung einer non-kompensatorischen Strategie ausgeschlossen werden. Defizite werden somit nicht durch Vorteile kompensiert. Gleich legitime Optionen hingegen sollten mit einer kompensatorischen Strategie abgewogen werden. Zusätzlich wurde der Effekt von Elementen selbstregulierten Lernens auf den Erwerb von Bewertungskompetenz untersucht. Hierfür wurden zwei computergestützte Interventionsstudien in Biologiekursen der Sekundarstufe II durchgeführt. Die Effekte der Intervention wurden in einem Prä-Post-Follow-Up Kontrollgruppen-Design mit Hilfe eines Bewertungskompetenzfragebogens mit offenen Antworten sowie prozessnahen Analysen untersucht. In der ersten Studie wurde gezeigt, dass durch ein Entscheidungsstrategietraining Bewertungskompetenz gefördert werden kann. Die prozessnahen Analysen belegen elaborierte Erläuterungen zur Strategiewahl. In der zweiten Studie ließ sich nachweisen, dass die Reflexion bzgl. der Stärken und Schwächen anderer Entscheidungen Bewertungskompetenz in Hinblick auf die eigene Entscheidung sowie die Reflexionsfähigkeit fördert. Die Elemente selbstregulierten Lernens führten zu einer stärkeren wahrgenommenen Autonomie und bewirkten langfristige Effekte des Entscheidungsstrategietrainings. 


\section{Outline}

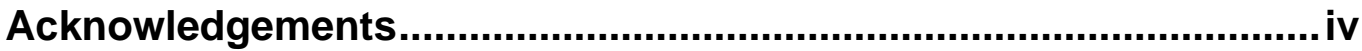

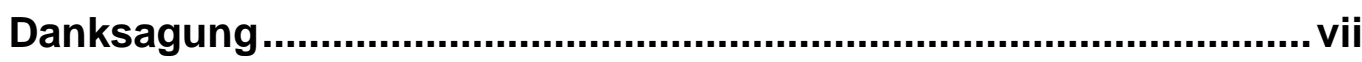

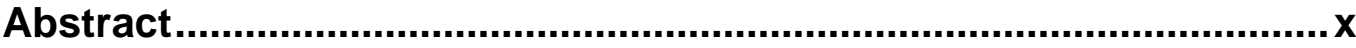

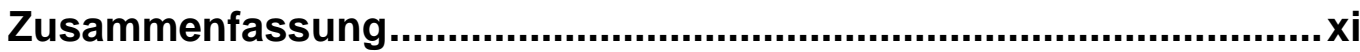

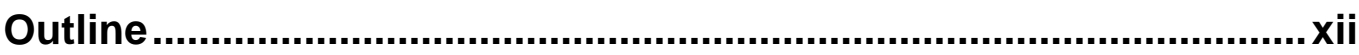

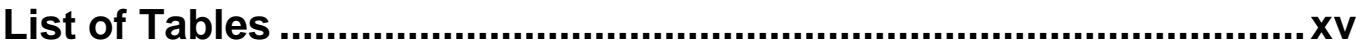

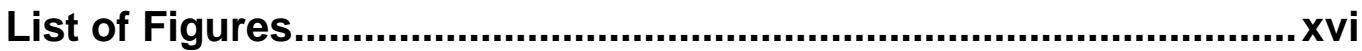

List of Boxes....................................................................................

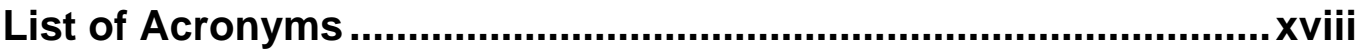

1 Introduction

2 Theoretical Framework: Socioscientific Decision-making in the Context of Sustainable Development.........................................

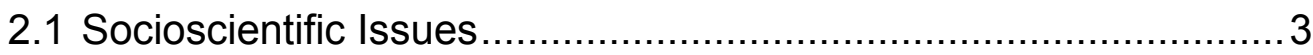

2.2 Education for Sustainable Development....................................

2.3 Decision-making Competence in Education for Sustainable

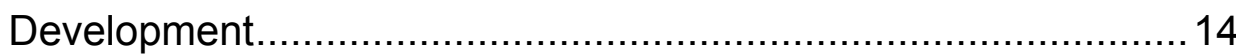

3 Theoretical Framework: Metadecision and Self-regulated

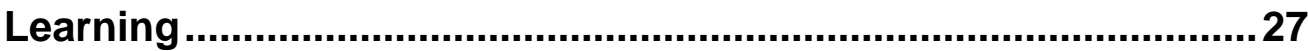

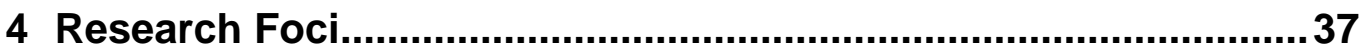

5 Training in Decision-making Strategies: An Approach to Enhance Students' Competence to Deal with Socio-scientific

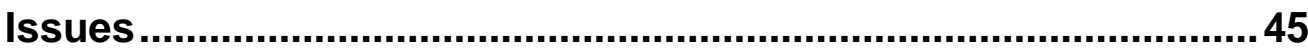

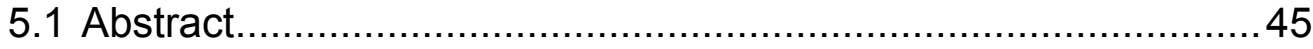

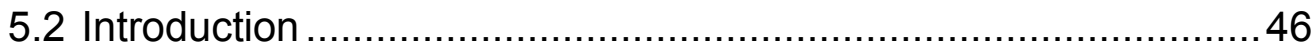

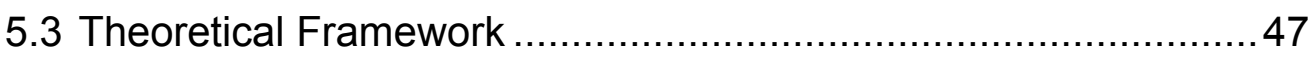

5.3.1 Socio-scientific Issues and Education for Sustainable

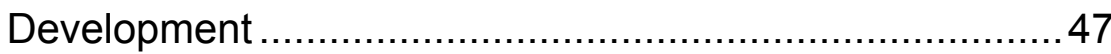

5.3.2 Decision-making Strategies............................................ 48

5.3.3 Decision-making Competence ........................................ 50 
5.3.4 Metadecision and Self-regulated Learning .....................5 53

5.3 .5 Self-determination Theory .................................... 54

5.4 Research Questions ....................................................... 55

5.5 Methods ........................................................................... 56

5.5.1 Description of the Training Programme......................... 56

5.5 .2 Research Design.................................................... 58

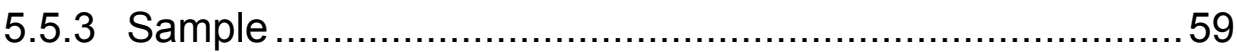

5.5.4 Assessment of Decision-making Competence .................59

5.5.5 Assessment of Intrinsic Motivation ................................6 63

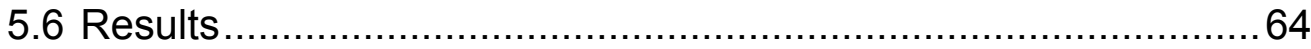

5.6.1 Decision-making............................................... 64

5.6 .2 Reflection ........................................................... 65

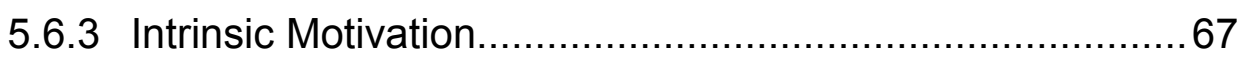

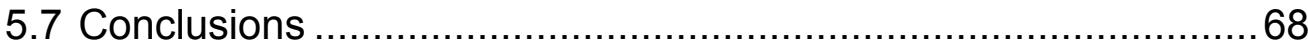

6 Identifying Non-sustainable Courses of Action - A Prerequisite for Decision-making in Education for Sustainable Development 73

6.1 Abstract............................................................................... 73

6.2 Theoretical Framework ..................................................... 74

6.2.1 Education for Sustainable Development ...................... 74

6.2.2 Decision-making Competence ................................... 75

6.2.3 Decision-making Strategies ..................................... 77

6.2.4 Metadecision and Self-regulated Learning .....................78

6.2.5 Review of the Summative Evaluation of the Presented Intervention Study ................................................... 79

6.3 Research Questions ................................................... 80

6.4 Intervention Study on Decision-making Strategies .................. 82

6.5 Methods .......................................................................... 86

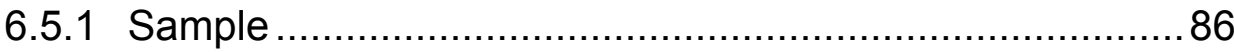

6.5.2 Recollection of Data and Data Analysis ........................ 87

6.5.3 Assessment of Cognitive Load ................................... 88

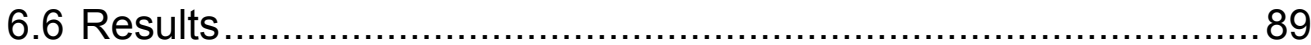

6.7 Summary and Conclusions ............................................. 103

6.8 Implications for Science and Environmental Education ............ 107

7 Reflecting on the Use of Decision-making Strategies through Self-regulated Learning ........................................................111 


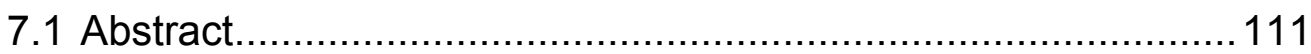

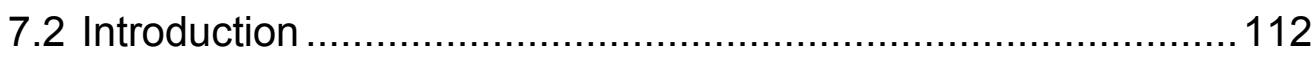

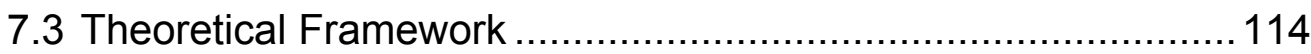

7.3.1 Decision-making and Argumentation in STSE Education 114

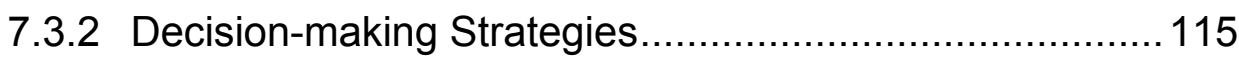

7.3.3 Self-regulated Learning ...............................................118

7.4 Research Questions .............................................................

7.5 Description of the Decision-making Training ............................120

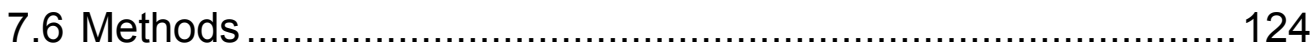

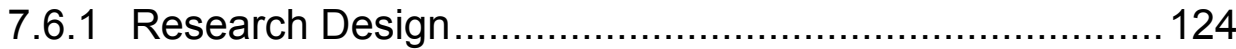

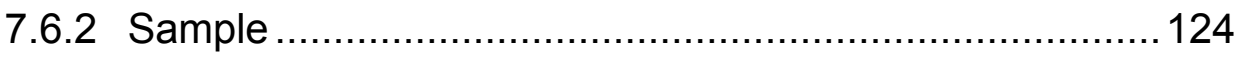

7.6.3 Measurement of Decision-making Competence.............. 125

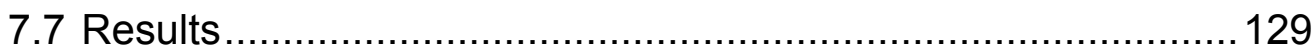

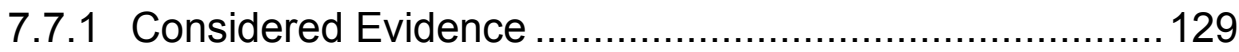

7.7.2 Metadecision Aspects ............................................... 130

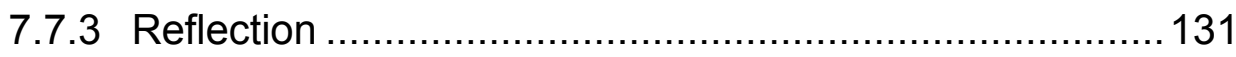

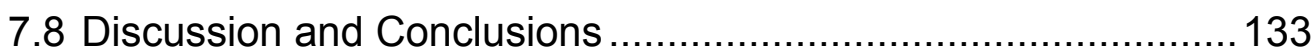

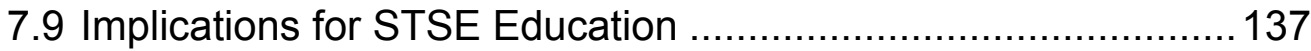

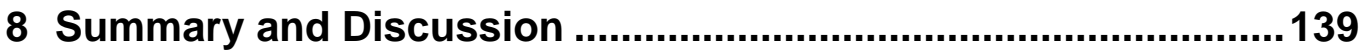

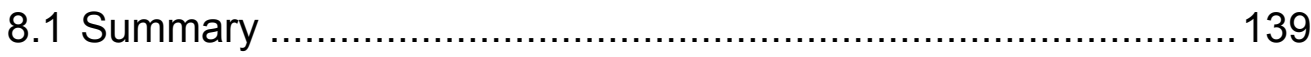

8.2 Training in Decision-making Strategies................................... 144

8.3 Dealing with Societal Norms and Personal Values in Socioscientific Issues Pertaining to Sustainable Development.. 149

8.4 Fostering Decision-making through Self-regulated Learning ..... 153

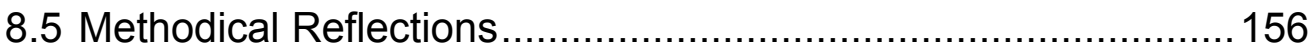

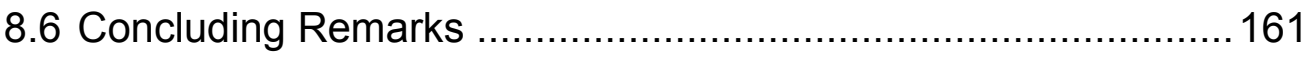

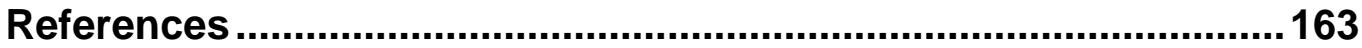

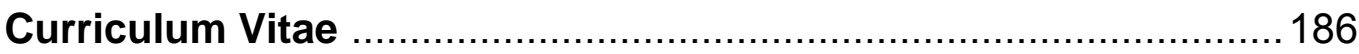




\section{List of Tables}

Table 5.1 Scoring guide for the assessment of decisionmaking competence

Table 5.2 Reflection: Changes in the score from the pre-test to the post-test

Table 5.3 Means and standard deviations of intrinsic motivation scales during the training program

Table 6.1 Structure of the training program: Contexts chosen to demonstrate the decision-making strategies

Table 6.2 Scoring rubric with anchor examples: Explanations for the selection of a decision-making strategy

Table 6.3 Relative frequencies of the categories and subcategories of explanations for the selection of a decision-making strategy

Table 6.4 Expected and observed patterns for the quality of metadecision explanations according to different selected decision-making strategies

Table 6.5 Self-reported cognitive load after applying the decision-making strategy

Table 7.1 Structure of training program

Table 7.2 Scoring guide of the decision-making questionnaire 


\section{List of Figures}

Figure 2.1 Model of decision-making competence 16

Figure 3.1 Zimmerman's model of self-regulated learning adapted to decision-making processes

Figure 5.1 Structure of the training program 56

Figure 5.2 Research design 58

Figure 5.3 Mean values of decision-making competence 64

Figure 6.1 Decision-making strategies selected in the learning program by the students in both training groups

Figure 6.2 Decision-making strategies selected in the learning program by the students in both training groups

Figure 7.1 Metadecision in decision-making task: Percentage of students who increased their scores

Figure 7.2 Reflection: Mean values 


\section{List of Boxes}

Box 4.1 Overview of decision-making strategies that were trained during the intervention 


\section{List of Acronyms}
AAAS
American Association for the Advancement of Science
BLK
Bund-Länder-Kommission für Bildungsplanung und Forschungsförderung (Commission of the Federal Republic of Germany and its states for educational strategies and research)
BMBF Bundesministerium für Bildung und Forschung (Ministry of education and research of the Federal Republic of Germany)
BMZ Bundesministerium für wirtschaftliche Zusammenarbeit und Entwicklung (Ministry of the Federal Republic of Germany for economic cooperation and development)
CG Control Group
ESNaS Evaluation der Standards in den naturwissenschaftichen Fächern der Sekundarstufe I (Evaluation of the (German) national science education standards for secondary education)
KMK Kultusministerkonferenz (Conference of the ministers of education)
LASSI Learning and Study Strategies Inventory
MSLQ Motivated Strategies for Learning Questionnaire
NRC National Research Council
OECD Organisation for Economic Co-Operation and Development
PISA Program for International Student Assessment
QCA Qualifications and Curriculum Authority
SEPUP Science Education for Public Understanding Project
SINUS Programm zur Steigerung der Effizienz des mathematisch- naturwissenschaftlichen Unterrichts (Program for the 
enhancement of the efficiency of mathematics and science education)

STSE Science, Technology, Society, Environment

TG Training Group

TIMSS Third International Mathematics and Science Study

UN United Nations

UNCED United Nations Conference on Environment and Development

UNESCO United Nations Educational, Scientific and Cultural Organization

WCED World Commission on Environment and Development 


\section{Introduction}

The students of the $21^{\text {st }}$ century grow up in a society that is faced with a multitude of challenges. Scientific and technological advances have changed the lives of the world population and provided the citizens with many possibilities to determine their way of living. However, these advances also require each citizen to act responsibly. The increase in consumption has led to an exploitation of resources and damage to fragile ecosystems. The global transportation of goods and people has mobilized the world, but is today considered one factor that causes climatic change. Moreover, not all people of the globalized world's society have profited equally from scientific and technological advances. Countries in the Northern Hemisphere have benefited, whereas poverty and famine dominate in many southern countries. In 1992, the world's politicians agreed on a global action plan to face these challenges and ensure sustainable world development with the purpose of meeting the needs of the present generations as well as future generations (United Nations Conference on Environment and Development (UNCED), 1992; World Commission on Environment and Development (WCED), 1987). Besides political actions, one focal point is on the individual citizen as the key player to change the world's society. All citizens should reflect upon their actions critically. What impact does a decision have with regard to its ecological, economic and societal consequences? Citizens are frequently faced with a multitude of complex decisions. The consumption of products and political debates demand them to critically evaluate possible courses of action with regard to sustainable development.

A central aim of science education is, hence, that students as citizens should be prepared to deal effectively with science-related situations that they will encounter in their lives (Roberts, 2007). Since the 1970s, the science, technology, society and environment (STSE) movement has promoted the integration of socioscientific issues, i.e., scientific topics that have an impact on society, into science classrooms (McConnell, 1982). 
Because of the controversial character of socioscientific issues, the enhancement of thoughtful decisions is a central claim of STSE education (Aikenhead, 1985; McConnell, 1982; Pedretti \& Nazir, 2011; Solomon \& Aikenhead, 1994). Consequently, science education should enable students to engage in individual and collective decision-making as well as discourse to educate responsible citizens (Aikenhead, 1985; Berkowitz \& Simmons, 2003; Driver, Newton, \& Osborne, 2000; Kolstø, 2001; Solomon \& Aikenhead, 1994; Zeidler, Sadler, Simmons, \& Howes, 2005). In conclusion, decisionmaking concerning socioscientific issues has become part of scientific literacy (American Association for the Advancement of Science (AAAS), 1989, 1993; National Research Council (NRC), 1996; Organisation for Economic Co-operation and Development (OECD), 1999).

How can these educational demands be met? Which methods are suitable to foster elaborate decision-making regarding controversial socioscientific issues pertaining to sustainable development? To answer these research questions, two promising approaches will be investigated and elaborated: the reflected use of decision-making strategies and the integration of elements of self-regulated learning into learning environments to support the decision-making process. This dissertation aims to examine the effects of these approaches on decision-making competence in processrelated and summative evaluations. 


\section{Theoretical Framework: Socioscientific Decision-making in the Context of Sustainable Development}

\subsection{Socioscientific Issues}

As opposed to purely scientific topics, socioscientific issues involve both considerations of scientific content and societal implications. Sadler refers to socioscientific issues as "complex, open-ended, and often contentious problems, with no definitive answers" (Sadler, 2004, p. 514). Their resolution requires interdisciplinary approaches because socioscientific issues involve evidence from many areas of research (Fensham, 1988; Kolstø, 2001; McConnell, 1982; Solomon \& Aikenhead, 1994). Furthermore, most issues are not only complex with regard to scientific evidence, but also complex in terms of the inherent values and societal norms that must be considered (Bögeholz \& Barkmann, 2003, 2005; Hogan, 2002; Jiménez-Aleixandre \& Pereiro-Muñoz, 2002; Kolstø, 2001; Ratcliffe \& Grace, 2003; Zeidler \& Sadler, 2007; Zeidler et al., 2005). In addition, for many issues, anomalous data are available because no consensus has been reached within the scientific community in areas of science-in-the-making (Bingle \& Gaskell, 1994; Kolstø, 2001). The knowledge base may be uncertain or involve risks (Kolstø, 2006). Due to this complexity, uncertain consequences and the contrary perspectives of a multitude of stakeholders, many alternative solutions to resolve socioscientific issues exist. Consequently, each socioscientific issue is by definition controversial and open for debate and discourse (Zeidler et al., 2005). Science and environmental education should enable students to form a reflected view on such issues and support them to participate in discussions. Within the STSE framework, much research has been conducted to unravel how students actually deal with socioscientific issues and which methods are suitable to foster the abilities of students to cope with these complex tasks most effectively. Generally, the implementation of socioscientific issues into science education requires 
meaningful real-world contexts that allow for an analysis of these complex relationships to promote the acquisition of competencies (Aikenhead, 2006; Bayrhuber, Bögeholz, Elster et al., 2007; Pedretti, 2003; Sadler, 2009, 2011).

\section{Argumentation about socio-scientific issues}

How students deal with socioscientific issues has been investigated based on different theoretical frameworks, such as socioscientific reasoning (Sadler, Barab, \& Scott, 2007) or the reflective judgment model (Zeidler, Sadler, Applebaum, \& Callahan, 2009; cf. King \& Kitchener, 1994). However, one of the most dominant approaches is the analysis of argumentation, which is mostly based on Toulmin's argumentation pattern (Erduran, Simon, \& Osborne, 2004; Jiménez-Aleixandre, Bugallo Rodríguez, \& Duschl, 2000; Toulmin, 1958; Venville \& Dawson, 2010; Zohar \& Nemet, 2002). Claims must be connected to evidence (data) to construct a sound argument. Warrants and backings support this justification. In addition to this presentation of one's own viewpoint, Kuhn $(1991,1993)$ and Means and Voss (1996) consider it vital to include alternative positions and counterarguments as part of good argumentation. Moreover, many research projects focus not only on the formal structure of arguments suggested by Toulmin but also on the correctness of the presented evidence and whether presented reasons support the claim (Jiménez-Aleixandre \& Pereiro-Muñoz, 2002; Means \& Voss, 1996; Zohar \& Nemet, 2002). With regard to the use of inappropriate evidence, confirmation biases and rejections of anomalous data, Zeidler (1997) has identified fallacies in the process of argumentation. Furthermore, metastatements are considered to be part of high-quality reasoning because the principle of structuring an argument may clarify complex reasoning situations (Kuhn, 1999; Means \& Voss, 1996).

Grounded on these considerations, programs to enhance the quality of argumentation in small group and whole class discussions have been introduced and evaluated. Zohar and Nemet (2002) explicitly trained students 
in argumentation skills when dealing with moral dilemmas in the context of genetics. The characteristics of high- and low-quality arguments were developed with the students regarding the justifications of claims and supporting evidence for alternative positions. As a result of the intervention, the quality of the students' arguments increased, and the students were able to transfer these skills to an everyday context. Moreover, it is compelling that argumentation training not only increased argumentation skills but also promoted gains in content knowledge. On the level of in-service teacher training, Erduran, et al. (2004) effectively trained teachers in a long-term intervention to apply the Toulmin argumentation pattern in their classrooms. The teachers effectively stimulated the students to support their claims with evidence in the course of the two-year program. Moreover, explicit argumentation trainings are not only valuable to increase the level of complexity based on Toulmin's argumentation pattern but also changed the students' type of informal reasoning from emotive to rational (Venville and Dawson, 2010; cf. Dawson \& Venville, 2010).

In conclusion, many studies have successfully trained argumentation skills. However, the necessary duration of such trainings is still debated. Kuhn (1991) suggests that students possess premature argumentation skills, but may lack the complete development of these skills to demonstrate them effectively. Consequently, she proposes that education can strengthen these preexisting abilities in a short amount of time. This is in line with the results of Zohar and Nemet (2002) and Venville and Dawson (2010) who showed that their short-term argumentation trainings (twelve and three periods, respectively) successfully improved the quality of the students' arguments. In contrast, Osborne, Erduran and Simon (2004) reported that a year-long training did not yield measurable effects. 


\section{Norms and values inherent in socioscientific issues}

In addition to the research on reasoning skills and argumentation, many studies have focused on the values inherent in socioscientific issues. Although it is generally agreed on that socioscientific issues require explicit value considerations, different domains, e.g., bioethical and sustainability issues, involve different sets of values and, hence, different approaches to incorporate them in argumentation and decision-making. For moral dilemmas, such as genetic engineering and preimplantation diagnostics, models of moral development have been adapted to the field of socioscientific issues, mostly based on Kohlberg's theoretical frameworks or philosophical approaches, e.g., the distinction between deontological and consequentialist reasoning (Bayrhuber, 1992; Dulitz \& Kattmann, 1990; Mittelsten Scheid \& Hößle, 2008; Reiss, 2008; Reitschert \& Hößle, 2007; Sadler \& Zeidler, 2004; Zeidler \& Keefer, 2003). While values in the aforementioned contexts often refer to the beginning and end of human life or human health, a different set of values must be considered in environmental and sustainable development issues. Biocentric and anthropocentric perspectives must be contrasted (Grace \& Ratcliffe, 2002; Große \& Bögeholz, 2005; Pedretti, 1999; Reiss, 2008), and the domain of sustainable development also requires the integration of global justice as a crucial value (de Haan, Kamp, Lerch, Martignon, Müller-Christ, \& Nutzinger, 2008; Fien \& Tilbury, 2002; Huckle \& Sterling, 1996). Moreover, societal norms and personal values must be contrasted. For environmental management decisions, Hogan (2002) found that students based their reasoning on personal values rather than values regarding other stakeholders who are impacted by the decision. However, education should encourage students not only to reflect on their own values, but also on the values of other individuals because differing sets of values in a pluralistic society demand the ability of perspective taking (Bögeholz, Hößle, Langlet, Sander, \& Schlüter, 2004; Eggert \& Hößle, 2006; Kolstø, 2001; Reiss, 2008; Sauvé, 2005). 
Generally, an explicit consideration of values in the decision-making process and argumentation as well as a distinction from facts is essential because this explicitness makes the decision more transparent and intersubjectively comprehensible (Bögeholz, 2006; Bögeholz \& Barkmann, 2003; Eggert \& Hößle, 2006).

In addition to the consideration of diverse sets of values, decisionmaking tasks of different domains are also structured differently. Bioethical and moral dilemmas often involve decisions for or against one specific action: Should a genetic test be conducted? Should active euthanasia be allowed for those who wish to die? Should genetically modified food be grown? In contrast, issues pertaining to sustainable development involve more gradual decisions or decisions with many options: Which position and size should a wind farm have? Which variety of apples should I buy out of a countless amount on offer? Which measures to protect an ecosystem can be combined to be most successful? It is often not a question of whether to pursue one option, but rather in which way the situation can be improved most effectively (Bögeholz \& Barkmann, 2005). Hence, socioscientific issues that are related to sustainable development require specific approaches to deal with them in an adequate way.

\subsection{Education for Sustainable Development}

One special field of STSE education is education for sustainable development (Pedretti, 2003). Moreover, issues related to sustainable development represent one essential domain of socioscientific issues. It will be argued that they are complex with regard to a multitude of stakeholders' interests and scientific evidence, are controversial and require interdisciplinary and values-based decisions. The relatively new domain of education for sustainable development is primarily a result of international political negotiations because education is considered one of the focal points 
to ensure sustainability (UNCED, 1992). Therefore, the historical roots and the social norms derived from this political consensus will be elaborated.

\section{Education for sustainable development as a global political consensus}

The rapid technological and scientific advances that have occurred since the industrial revolution have led to economic growth and wealth in industrialized countries. However, the production of goods for an increasing world population will inevitably reduce the quantity of available resources. This scarcity of resources and the limits of growth were identified in the 1970s by the Club of Rome (Meadows, Meadows, Randers, \& Behrens III, 1972). A related issue of concern in those decades is environmental degradation through deforestation, acid rain and many other causes. However, rather than viewing environmental problems in isolation, Brundtland and the members of the World Commission on Environment and Development (WCED) related these issues to developmental policy to unravel the complex causes and identify possible measures against environmental degradation (Redclift, 1987). In the final statement of the Brundtland report Our common future, the term sustainable development was coined. This term not only involves sustainable management of resources, economic growth and environmental protection but also social justice within and between generations (WCED, 1987).

Based on these concerns and a multitude of global challenges, such as threats to the earth's biodiversity, climate change and water scarcity (Hesse, 2006), the UNCED agreed on a global action plan at the world summit in Rio de Janeiro in 1992 to face the problems of a globalized world (Agenda 21; UNCED, 1992). Since this international political consensus, a general agreement exists that solutions can only be found through interdisciplinary approaches that involve ecological aspects such as the protection of the environment and biodiversity, social concerns, especially with regard to the less developed countries, and the economic prosperity of 
the world's population (Scott \& Gough, 2003; UNCED, 1992; Whitehead, 2007). To ensure sustainable development, the education of the world's citizens is a crucial prerequisite. This proposal of the conference in Rio de Janeiro was put into action at the subsequent United Nations (UN) conference in Johannesburg in 2002, where all the countries agreed on implementing education for sustainable development in their educational systems. Subsequently, the realization of Agenda 21 as a global action plan has been supported through the decade of education for sustainable development $^{1}$ of the United Nations Educational, Scientific and Cultural Organization (UNESCO) and an adaptation of international political agreements to national and local requirements.

In Germany, the importance of education for sustainable development has been widely recognized. The German parliament developed guiding principles for sustainable development (Deutscher Bundestag, 1998), which not only focus on environmental issues, as in previous decades, but also on societal and economic concerns. Moreover, to implement education for sustainable development in the educational system, the government introduced two programs, 21 and the successive program Transfer-21, which embrace many facets of education for sustainable development: research to gain further insights into the theoretical structure and necessary competencies, practical guidelines for teachers, professional development, support on institutional levels and research-based evaluation of the educational program (Bund-Länder-Kommission für Bildungsplanung und Forschungsförderung (BLK), 1998, 2005; Bundesministerium für Bildung und Forschung (BMBF), 2009; de Haan, 2006). Within this program, theoretical and practical contributions have been made with regard to fostering decision-

\footnotetext{
${ }^{1}$ The UN decade of education for sustainable development started in 2005 and will continue until 2014.
} 
making concerning issues pertaining to sustainable development (AhlfChristiani et al., 2003). Although education for sustainable development has not yet been established across the entire nation, significant progress has been made.

Another vital way to implement the political consensus on education for sustainable development is its inclusion in national and local curricula and standards. German and English standards have integrated sustainable development as core components of science education and other school subjects, including the interrelationship of this framework with regard to ecological, social and economic facets (Kultusministerkonferenz (KMK), 2005a, $c^{2}$; Qualifications and Curriculum Authority (QCA), 2005; cf. Niedersächsisches Kultusministerium (ministry of education of Lower Saxony), 2007, 2009, for state curricula of Lower Saxony, where this study was conducted). In contrast, the US National Educational Standards and Science for All instead focus on environmental problems and resource management (AAAS, 1989, 1993; NRC, 1996).

\section{Competencies in the field of education for sustainable development}

Following the political initiative to implement education for sustainable development, research must focus on the question of which competencies today's students should acquire to face the emerging problems of a globalized world. Within the German program 21, de Haan and Harenberg (1999) developed a normative model of the competencies that students should gain as part of education for sustainable development (cf. de Haan, 2006, 2008, 2010; de Haan et al., 2008 for English descriptions and modified

\footnotetext{
2 The German science education standards differentiate between biology (KMK, 2005a), chemistry (KMK, 2005b) and physics (KMK, 2005, c). However, the chemistry standards do not explicitly include sustainable development.
} 
versions of the model). The concept of Gestaltungskompetenz (shaping competence) focuses on the participation of citizens to actively shape and develop the society of the future rather than merely reacting to existing problems. In a revised version of the theoretical framework, de Haan et al. (2008) describe twelve subcompetencies, such as perspective taking, cooperative and individual planning and action and the ability to deal with complex decision-making situations that involve conflicting values. Consequently, decision-making competence is one vital component of Gestaltungskompetenz and education for sustainable development.

As required by Agenda 21, many research projects and classroom activities have focused on the integration of ecological, social and economic aspects of education for sustainable development (Bourn, 2005; Eilam \& Trop, 2011; Gausmann, Eggert, Hasselhorn, Watermann, \& Bögeholz, 2010; Herremans \& Reid, 2002; Marcinkowski, 2010; Menzel \& Bögeholz, 2006, 2009; Sauvé, 1996, 2005). Consequently, education for sustainable development aims to implement more interdisciplinary approaches to bring different pedagogical traditions together, e.g., environmental education and development education. Moreover, the interdependence of different components and the dynamic functioning of a system have to be understood by considering causes and consequences on a global level (BLK, 1998; Rieß \& Mischo, 2010; Rost, 2002; Rost, Lauströer, \& Raack, 2003). In addition to the necessity to integrate multiple disciplines, other factors account for a large complexity of sustainability issues. The effects of particular courses of action are difficult to predict because decisions regarding future developments mostly involve lagged consequences and uncertainty (ColucciGray, Camino, Barbiero, \& Gray, 2006; de Haan et al., 2008). Moreover, the relationship between causes and consequences is often hard to identify because of spatial and temporal disparities, and many processes are not linear, but exponential, and thus difficult to predict (Bögeholz \& Barkmann, 2005; de Haan \& Harenberg, 1999; Ernst, 2008). Consequently, education 
should aim to enable students to analyze the complex relationships between local actions and global consequences (Bourn, 2005) as a prerequisite for adequate decision-making.

\section{Norms and values in education for sustainable development}

Besides factual complexity, issues pertaining to sustainable development involve complex ethical implications (Bögeholz \& Barkmann, 2005). The interrelatedness of the ecological, social and economic domain is not only relevant for the analysis of background information but also for the analysis of inherent values. Different stakeholders base their decisions on different sets of values. Therefore, students should be able to take different perspectives to understand the underlying value conflicts. Moreover, if scientific evidence for a specific topic is scarce or involves a high degree of uncertainty, Colucci-Gray et al. (2006) suggest that the value considerations play an even more important role in the decision-making process.

One point of criticism toward education for sustainable development is that students are persuaded to advocate a particular point of view or pursue a particular action (de Haan et al., 2008; Jickling, 1992; Sauvé, 1996). However, in science and environmental education, a broad consensus exists that teachers should not educate one perspective or teach certain values; rather, they should enable students to think critically to make autonomous and elaborate decisions (de Haan et al., 2008; Hodson, 2003; Hungerford, 2010; Ratcliffe \& Grace, 2003). Nevertheless, this type of independence and autonomy of students should not be misinterpreted in a relativistic way as is apparent in the values clarifications method (Oser \& Althof, 1992; Simon, Howe, \& Kirschenbaum, 1972). This approach does not distinguish between universal values such as social justice and personal values (Bögeholz, Bittner, \& Knolle, 2006; Rost et al., 2003) and consequently, does not involve considerations concerning the role of societal norms (Eggert \& Hößle, 2006). On the contrary, it is legitimate and necessary to reflect upon the 
development and qualities of societal norms and contrast these with personal values to encourage self-reflection in the students (de Haan et al., 2008). With regard to education for sustainable development, students should be able to detect non-sustainable options, i.e., options that contradict societal norms, because they do not reach ecological or social standards and are unacceptable with regard to economic development (de Haan \& Gerhold, 2008). However, whether they actually pursue more sustainable courses of action instead cannot be part of school education (Rost et al., 2003).

Empirical studies in education for sustainable development have focused on values-based decisions from different viewpoints. While Lauströer (2005; Lauströer \& Rost, 2008) investigated the effect of an intervention study on the consistency between personal values and intended actions, which did not increase as a result of the training, Grace and Ratcliffe (2002) found that the students based their decisions on scientific concepts to some extent, but mostly referred to inherent values, thus presenting a variety of biocentric and anthropocentric values. Bögeholz and Barkmann (2005) integrated value considerations into a rational decision model and suggested weighting the criteria based on the importance to the decision-maker. Moreover, weighting of criteria is a component of decision-making strategies, e.g., a value hierarchy used to exclude options or a multiplication of attributes of different options with a weighting factor, which would ensure that important criteria contribute more to the decision than less important ones (Bögeholz and Barkmann, 2005; de Haan et al., 2008; Eggert \& Bögeholz, 2006, 2010; Jungermann, Pfister, \& Fischer, 2005; Payne, Bettmann, \& Luce, 1998). In conclusion, students should be able to cope with factual and ethical complexity and distinguish facts, societal norms and personal values to make elaborate decisions (Bögeholz \& Barkmann, 2005). 


\subsection{Decision-making Competence in Education for Sustainable Development}

Scholars in the field of education for sustainable development emphasize the need to foster decision-making competence. While much research in the field of socioscientific issues has been performed to examine and enhance argumentation, little is known about the actual decision-making process. It is important to state that despite many similarities, these two concepts have quite diverging characteristics. The role of argumentation is generally to present and defend one's point of view. Contrastingly, decision-making focuses on the preceding processes of evaluating possible options and finally choosing one alternative. Consequently, every individual makes a decision first, before presenting the outcome to others to convince them from his/her viewpoint by presenting arguments. Nevertheless, argumentation and decision-making have many characteristics in common. Both concepts require a thorough integration of evidence both for and against a possible viewpoint. The benefits and drawbacks of all possible options should be considered to make a high-quality decision and to provide valuable arguments and counterarguments. Furthermore, decision-making and argumentation are interlinked because discourse involving opposing viewpoints stimulates the reflection upon one's own position and may modify the standpoint as a result of social interactions (Zeidler, Osborne, Erduran, Simon, \& Monk, 2003).

The present study focuses on the reflected decision-making process when choosing one course of action in the field of education for sustainable development. For this purpose, decision-making competence ${ }^{3}$ is defined as

\footnotetext{
${ }^{3}$ The original German term in this definition is Bewertungskompetenz. As opposed to the English term decision-making competence, which specifically refers to the decision-making process, Bewertungskompetenz is used more broadly by German scholars with regard to other facets of dealing with socioscientific issues, including argumentation.
} 
"the ability to decide among different courses of action of complex problems in a reasoned and systematic way to participate in societal discourse about the promotion of sustainable development." (Bögeholz, 2007, p. 2094; cf. Bayrhuber, Bögeholz, Elster et al., 2007; Bögeholz et al., 2004; Eggert \& Bögeholz, 2006). This definition is based on the concept of competence. Weinert (2001a) refers to competence as the cognitive ability to solve domain-specific problems (cf. Weinert, 1999, 2001b). Moreover, competencies can best be acquired and assessed based on contextualized problems (Hartig \& Klieme, 2006; Klieme \& Leutner, 2006; Klieme et al., 2003; Koeppen, Hartig, Klieme, \& Leutner, 2008). At an international level, the theoretical construct of competencies has also been chosen for largescale assessments such as the Third International Mathematics and Science Study (TIMSS) and the Program for International Student Assessment (PISA). In Germany, the concept of competence is the most dominant approach to describe educational learning outcomes and it is the basis of the German educational standards (Klieme et al., 2003; KMK, 2005a,b,c), the development of competence models for various domains (priority program 12935; Klieme \& Leutner, 2006; Klieme, Leutner, \& Kenk, 2010) and the evaluation of the German national science education standards ${ }^{6}$ (Kauertz, Fischer, Mayer, Sumfleth, \& Walpuski, 2010; cf. Schecker \& Parchmann, 2006). Moreover, regarding the national PISA test 2003 and the evaluation of the German science education standards, the construct of competence is used as a basis to assess decision-making (Kauertz et al., 2010; Senkbeil,

4 translated into English

5 Schwerpunktprogramm 1293: Kompetenzmodelle zur Erfassung individueller Lernergebnisse und zur Bilanzierung von Bildungsprozessen (priority program 1293: models of competencies for the assessment of individual learning outcomes and the evaluation of educational processes)

6 Evaluation der Standards in den naturwissenschaftlichen Fächern der Sekundarstufe I (ESNaS) 
Rost, Carstensen, \& Walter, 2005). Although motivational, volitional and social dispositions are vital to act in a competent way (Weinert, 2001a) and, moreover, to pursue actions ensuring a sustainable development (de Haan et al., 2008; Rost et al., 2003), the construct of decision-making competence is restricted to the cognitive component of competence to resolve specific types of contextualized situations (Bögeholz, 2007; cf. Klieme \& Leutner, 2006). Consequently, this emphasis on cognitive processes is an essential basis of the definition of decision-making competence, particularly with regard to the "reasoned and systematic" (Bögeholz, 2007, p. 209) way of dealing with different courses of action.

\section{Theoretical model of decision-making competence}

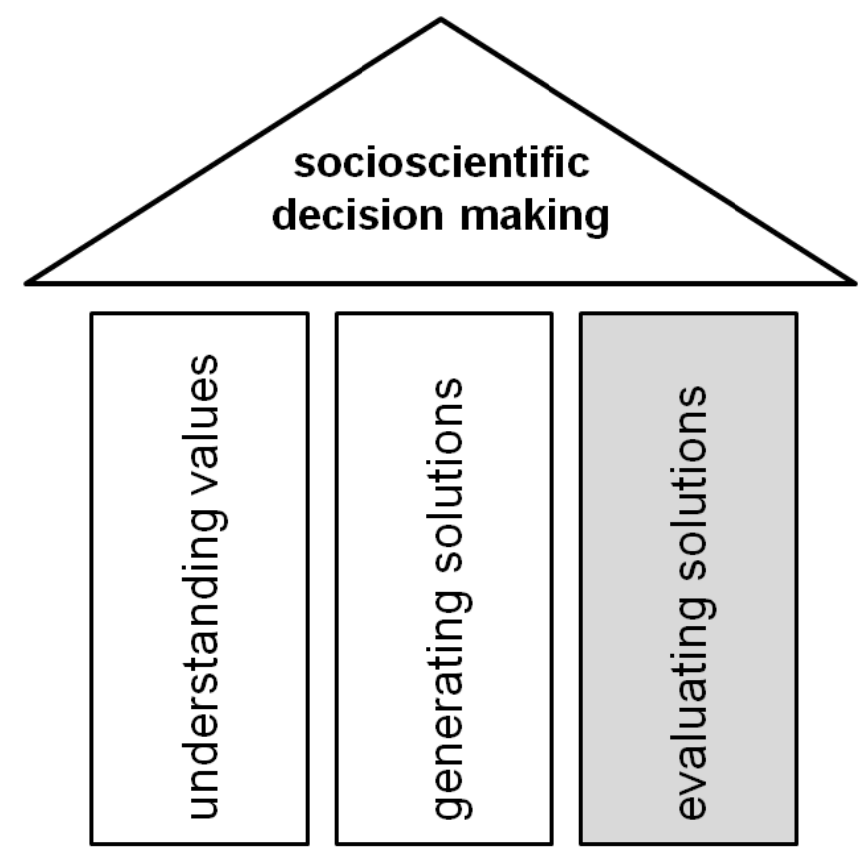

Figure 2.1. Model of decision-making competence (Bögeholz, 2011; Eggert \& Bögeholz, 2006; cf. Bernholt, Eggert, \& Kulgemeyer, in press); grey shading: focus of dissertation. 
To structure the construct of decision-making competence, Eggert and Bögeholz (2006, cf. Bögeholz, 2007, 2011) developed a competence model that represents both a structure to assess distinct dimensions of decisionmaking competence and a theoretical framework to develop specific trainings. The model postulates three dimensions (see Figure 2.1), of which the first describes the ability to understand and reflect upon inherent values and norms of decision-making situations related to sustainable development. This can be considered a prerequisite for the decision-making process. The decision for one course of action is differentiated into two consecutive steps based on the metadecision model of Betsch and Haberstroh (2005). In the first instance, the decision-maker identifies the decision-making situation and generates solutions in a pre-selective phase. Evidence is gathered to describe possible courses of action with regard to relevant criteria. Eggert and Bögeholz (2006) refer to this dimension as "generation of solutions" (cf. Gausmann et al., 2010). Once a set of solutions is available, the decisionmaker compares and contrasts all options by considering relevant evidence to make a decision in the selective phase (Betsch \& Haberstroh, 2005). Eggert and Bögeholz (2006) describe this dimension as the "evaluation of solutions", which also involves the reflection on one's own decision and the decisions made by others. Aikenhead (1985), Kortland (1996) and Ratcliffe (1997) also introduced decision-making models with subsequent phases, in which alternatives are generated and evaluated in consecutive steps, based on the frameworks of Baron and Brown (1991), Carroll and Johnson (1990) and other scholars. Although actual decision-making may also proceed by conducting these steps simultaneously or in an iterative way rather than in a neat order (Eggert \& Bögeholz, 2006; Hong \& Chang, 2004; Kortland, 1996), this normative model provides a valuable structure to assess different facets of decision-making competence and to develop specific interventions. In addition to Kortland's or Ratcliffe's framework, the model of Eggert and Bögeholz (2006; cf. Bögeholz, 2011; Gausmann et al., 2010) provides more specific information concerning the demands of a generation of solutions and 
the inherent search for information with regard to sustainable development and detailed insights into the processes of the evaluation of different options based on behavioral decision research. Consequently, it provides a normative framework for the resolution of socioscientific issues pertaining to sustainable development. This dissertation focuses on the third dimension, the evaluation of solutions. For this subcompetence, it is claimed that a high level of decision-making competence involves a systematic decision, e.g., through a decision-making strategy suitable to solve the complex decisionmaking task adequately.

\section{Decision-making strategies}

The strategies that people actually employ to resolve decision-making situations have been investigated in the field of behavioral decision research. Many decisions are made by implicitly or explicitly using a choice rule (Abelson \& Levi, 1985). These strategies vary according to their complexity depending on the characteristics of the decision-making situation and the effort that the decision-maker makes to resolve the issue (Beach, 1990; Jungermann et al., 2005). Routine decisions may have little significance for the decision-maker and are often highly automated. Thus, they require less attention, whereas other decisions of greater relevance demand further considerations and thoughts. Decisions with few options and a low number of attributes can be solved without much effort, whereas decision-making situations that involve a multitude of options are much more demanding. Moreover, in such complex decisions, the decision-maker may pursue different - often conflicting - goals. In summary, the methods of dealing with a decision-making task differ with regard to complexity and effort.

In situations that involve many options, the complexity can be reduced by eliminating options as part of a non-compensatory strategy. The name of the strategy refers to the fact that other benefits of one option do not compensate for the dominant deficits that lead to an exclusion of that option. 
Furthermore, situations with few options may also be solved by applying a non-compensatory strategy if attributes of one or several options are unacceptable for the decision-maker. Simon (1955) claims that decisionmakers often pursue a satisficing rule as one example of a noncompensatory strategy. Unsatisfying options are eliminated, and the search for an option is continued until a sufficing option is found. Although other more satisfying options may exist, the first suitable option is chosen without maximizing utility. Another example of a non-compensatory strategy is the lexicographic rule (Jungermann et al., 2005; Payne et al., 1998; Plous, 1993). If one option does not reach the minimum threshold (cut-off level) of the attribute that is considered most important based on the personal values of the decision-maker or societal norms, this option is eliminated. Subsequently, other options are excluded if the threshold of the second-most important criterion is not reached and so forth until only one option is left. A variation of this lexicographic rule to describe actual decision-making behavior more realistically is the elimination-of-aspects rule (Tversky, 1972). This rule takes probabilistic considerations into account because the decision-maker may weight the attributes slightly differently if faced with the same decision again, whereas the deterministic lexicographic rule implies static decision-makers.

Contrary to non-compensatory decision-making strategies, in which the disadvantages are not compensated for by other advantages, compensatory strategies allow for a complete trade-off of all evidence. How good does the attribute of one option have to be to compensate for a less favorable attribute of the same option? One example is the weightedadditive-value rule (Payne et al., 1998). Here, the partial value of one attribute is determined, e.g., through a positive or negative score that describes the quality of the option with regard to the considered criterion. Depending on the importance of this criterion, this score is multiplied with a weighting factor. The total value of the option can then be determined by adding all these weighted values. A simplification of this strategy is the equal 
weight strategy, in which the decision-maker does not distinguish between more and less important criteria. The weighted-additive-value model to determine the chosen option has not only been used in descriptive research but also in prescriptive decision-making theories to claim which decisionmaking strategy is most suitable from a normative viewpoint because all evidence is taken into account simultaneously to maximize the outcome (Jungermann et al., 2005).

Beach (1990) described decision-making processes as a combination of different strategies in two subsequent phases. In the screening phase, a compatibility test is conducted to determine whether the options reach the cut-off level of relevant criteria. If the characteristics contradict the values or goals of the decision-maker, one or several options are eliminated in a noncompensatory approach. The remaining options are then evaluated in detail in the profitability test after the selection of a decision-making strategy. In this phase, different types of strategies are used (Beach \& Mitchell, 1978; Beach, 1990). They may be aided-analytic and highly formalized like the weightedadditive-value strategy, in which tools are used to support the decision, e.g., a calculator is used to compute a final value for each option or balancing pros and cons with a list of all attributes. Other types of strategies do not require tools and allow for a resolution in one's head. In this group of unaidedanalytic strategies, the decision-maker still attempts to make a systematic decision by evaluating all options in detail. Contrary to these analytic procedures, the decision-maker may also choose one of the remaining options with a non-analytic strategy, such as tossing a coin or deciding intuitively. Consequently, Beach (1990) integrates different decision-making models to describe actual decision-making in two consecutive steps. This dissertation focuses on aided-analytic strategies and uses Beach's framework to introduce a mixed strategy as a combination of noncompensatory and compensatory strategies. 


\section{Decision-making and intuitive judgments - Results from behavioral decision research and normative educational considerations}

Most of the presented theories about decision-making assume a rational decision-maker. However, scholars such as Haidt, Gigerenzer and Simon criticize this underlying assumption. In his social intuitionist model, Haidt (2001) suggests that moral decisions are based on intuition and the social environment. Moreover, a person's reasoning is considered a post-hoc justification for the intuitive judgment. Although Haidt acknowledges that rational considerations influence a person's judgment to some extent, he claims that prior research overestimated the effect of rational thoughts. Based on Simon's notion of "bounded rationality," Gigerenzer and Todd (2001) argue that rational decision-making models such as the weightedadditive-value model cannot effectively explain how people actually decide on one option because such approaches do not account for the uncertainty that is inherent in real-world scenarios. Moreover, only a finite amount of time and knowledge is available for a decision-maker to invest in a decision; this has not been included in most rationalistic decision-making models. Consequently, Gigerenzer and Selten (2001) suggest that heuristics are more suitable to explain actual decision-making.

In contrast to descriptive research about decision-making, the appropriateness of different methods of decision-making is a crucial issue of concern. Whether intuition or analytic strategies lead to more suitable outcomes of decisions has long been debated. Gigerenzer and Todd (2001) argue that heuristics are not only often executed but also produce adequate solutions, whereas Haidt (2001) and Baron (1998) acknowledge that the outcome of intuitive judgments may not be best from a normative viewpoint. The empirical results of Hammond, Hamm, Grassia and Pearson (1987) and McMackin and Slovic (2000; cf. Hogarth, 2005) suggest that whether intuitive judgments outperform analytical approaches depends on the characteristics of the tasks. Intuition-inducing characteristics require intuitive approaches, 
whereas tasks with analytic-inducing characteristics are best solved with analytic strategies. In the field of science and environmental education, normative considerations have to be taken into account to determine which approach to resolve an issue is most appropriate. Routine decisions that students make, such as recycling, allow for fast decisions without much discussion (Hogan, 2002). However, complex decisions about the environment, especially those that involve a variety of stakeholders, require a thorough evaluation of information and underlying values. Regarding issues pertaining to sustainable development, Bögeholz and Barkmann (2003, p. $45^{7}$ ) comment on this claim as follows: "Those who content themselves with a decision for one agreeable-sounding option in a more or less incidental way after a general discussion of the problem act irresponsibly in the light of hunger, ecological degradation, injustice and threats to freedom." Moreover, rational decisions should not be confounded with egoistic decisions that maximize personal utility or economic benefits (Bögeholz \& Barkmann, 2005; Baron, 1994). For the field of socioscientific issues, Sadler and Zeidler (2005) suggest that science classes should account for different patterns of informal reasoning and encourage students with more intuitive or emotive, i.e., empathetic or care-based, rather than rationalistic reasoning patterns to participate in discourse by valuing these approaches. Nevertheless, the basis of such reasoning should be challenged and reflected upon, e.g., by considering anomalous data and contrasting viewpoints (Sadler \& Zeidler, 2005).

Eggert and Bögeholz (2006) integrated these results from descriptive research into their model of decision-making competence and related the decision-making strategies to socioscientific issues regarding sustainable development. It is claimed that students should be able to solve different

\footnotetext{
7 translated into English
} 
types of tasks with different decision-making strategies. Situations with nonsustainable options, i.e., with courses of actions that do not meet the standards set by societal norms such as the global action plan Agenda 21, should be resolved by applying a non-compensatory strategy to exclude unacceptable options. The three pillars of sustainable development (ecology, society, economy) and their related standards must be considered to determine whether one option is sustainable or not. Other types of tasks require a complete trade-off of all evidence if no knockout criteria exist based on societal norms, such as the framework for sustainable development. According to Eggert and Bögeholz (2006), intuitive judgments represent a lower level of decision-making competence because the complexity of socioscientific issues related to sustainable development is high and should induce analytic strategies to resolve the issue adequately, rather than intuition and heuristics.

To investigate the decision-making competence of students, Eggert and Bögeholz (2010) developed a test instrument with open-ended items that focuses on the use of decision-making strategies. For the tasks that all involved legitimate, i.e., sustainable options only, the normative assumption was made that a hierarchy of appropriate decision-making strategies can be stated. The lowest competence level represents intuitive decision-making, whereas the application of a non-compensatory strategy characterizes a basic level, the use of mixed strategies an intermediate level and the compensatory strategy the highest level of decision-making competence (Eggert \& Bögeholz, 2006). It could be demonstrated empirically that these levels represent the actual hierarchy of the students' competencies ${ }^{8}$ (Eggert,

\footnotetext{
${ }^{8}$ After modeling the data according to the Rasch partial credit model, the Thurstonian thresholds revealed that the a priori assumed hierarchy of competence levels represents the students' actual levels of decision-making competence.
} 
2008; Eggert \& Bögeholz, 2010). Consequently, it was easier for students to use cut-offs than to integrate several attributes of all options at the same time. In the field of science education, Hong and Chang (2004) have also investigated the use of decision-making strategies of students in an everyday life decision based on the scoring rubric of Abelson and Levi (1985). The analyses of the thinking aloud protocols revealed that most students used non-compensatory strategies or mixed strategies, but avoided a complete trade-off in a compensatory strategy.

\section{Teaching decision-making}

Teaching decision-making explicitly has been investigated in other areas such as business, medicine or the military (Baron, 1994). For environmental education, Arvai, Campbell, Baird and Rivers (2004) have developed guidelines for decision-making training. They recommend focusing on the deficits of heuristics to improve the decision-making process itself. To foster decision-making in science classes, Ratcliffe (1997) has provided her students with a six-step guideline. In the first step, students were asked to generate possible options and describe them according to relevant criteria after a thorough search for information. Based on this set of information, they had to evaluate these options to come to a conclusion. In addition, the students reflected upon their decision-making processes after the decision. Although the participating students perceived this guideline to be useful, Ratcliffe found that the evaluation of evidence was not systematic. Grace (2009) used this decision-making framework to successfully enhance the quality of the students' arguments based on the scoring rubric of Kuhn, Shaw and Felton (1997), i.e., the students considered alternatives more often and referred to the function of biological conservation rather than making unjustified claims. However, many students did not manage to finally decide on one option in the pre-test, the post-test and the group discussions. Roberts, Wilson and Draney (1997), Seethaler and Linn (2004) and Siegel (2006) focused on the evaluation of evidence and counterevidence as part of 
the decision-making process. Despite these successful interventions to improve the consideration of evidence or the presentation of the students' viewpoints, very few studies have focused on fostering the decision-making process itself by making it more systematic. Eggert, Bögeholz, Watermann and Hasselhorn (2010) investigated the effect of a cooperative evaluation of the quality of limnological ecosystems by focusing on compensatory decision-making combined with metastrategic training that triggered the reflection and strategic considerations regarding the evaluation process. In both training groups, the level of decision-making competence increased from the pre-test to the post-test. However, metastrategic structuring elements did not increase the competence level at a higher rate.

In spite of these attempts to improve decision-making in science classes, Pedretti (2003) claims that science teachers lack appropriate instructional methods to teach decision-making. Most of the decision-making trainings described above focused on complete trade-offs between all pieces of evidence (Eggert et al., 2010; Roberts et al., 1997; Seethaler \& Linn, 2004; cf. Bögeholz, 2006; Eggert, Barfod-Werner \& Bögeholz, 2008, 2010, for classroom materials). However, little empirical evidence exists about the issue of whether training students to employ a set of different decisionmaking strategies in different types of decision-making tasks enhances the competence level of students to resolve socioscientific issues adequately. Because explicit decision-making training is considered valuable for science and environmental education (Arvai et al., 2004; Bayrhuber, Bögeholz, Eggert et al., 2007; Eggert \& Bögeholz, 2006), the effect of decision-making strategies was investigated to address the research gap regarding instructional methods to teach decision-making in science education. 


\section{Theoretical Framework: Metadecision and Self- regulated Learning}

The contemporary field of socioscientific issues already involves a multitude of different contexts that students have to deal with. Future scientific and technological advances will challenge students even more to judge new controversial issues critically and to make an elaborate decision. Consequently, a primary goal of STSE education is to enable students to transfer these strategies to new, unfamiliar contexts. Students should be capable of adapting to new challenges that they will face in the course of their lives, which inevitably requires life-long learning. Therefore, this dissertation aims at integrating elements of self-regulated learning into the research on socioscientific decision-making to improve the transfer of decision-making strategies to new contexts.

\section{Models of self-regulated learning}

Self-regulated learning is a construct from educational psychology that embraces cognitive, metacognitive and motivational facets (Artelt, Demmrich, \& Baumert, 2001; Boekaerts, 1999; Hasselhorn \& Labuhn, 2008; Schmitz, Schmidt, Landmann, \& Spiel, 2007; Zimmerman, 2000). New tasks require cognitive strategies to deal with the particular demands associated with the task. Moreover, selecting the most suitable strategy out of a repertoire of strategies is necessary for optimal performance and, hence, involves metacognitive skills (for a classification of subcategories of metacognition, cf. Hasselhorn, 1992). Whether available cognitive and metacognitive skills are actually applied to a task depends on the motivation of the student. Consequently, this requires students to take over responsibility for their own learning progress by planning learning activities and setting goals (Hasselhorn \& Labuhn, 2008). As a result, self-regulation from a social cognitive perspective involves adapting to changing learning environments and reflections on person characteristics as well as on behavior (Bandura, 
1986; Zimmerman, 2000). Therefore, the ability to learn in a self-regulated way is neither a genetic predisposition nor a personality trait, but a contextdependent competence (Hasselhorn \& Labuhn, 2008; Labuhn, 2008). Nevertheless, many facets of self-regulated learning can be transferred to other domains, making it a cross-curricular competence (Klieme, Artelt, \& Stanat, 2001).

One influential model of self-regulated learning has been described by Zimmerman (2000). Within this framework, self-regulation is defined as the "self-generated thoughts, feelings, and actions that are planned and cyclically adapted to the attainment of personal goals" (Zimmerman, 2000, p. 14). The cyclical character of self-regulated learning has been emphasized through the division of the learning process into three consecutive phases. In a forethought phase, self-regulated individuals analyze the task to set goals and conduct strategic planning. Based on the characteristics of the task, learning strategies are selected that are considered appropriate to maximize the task performance. Moreover, the forethought phase also involves motivational aspects. Self-efficacy, outcome expectations, interest in the task and goal orientations have a strong impact on goal setting and the selection of a strategy. During the performance phase, the learner observes and controls the individual steps of the learning process and uses volitional measures to focus on the task. The self-reflection phase involves selfevaluation regarding the learning process and outcomes. Which steps have been conducted during the performance? Were the strategies appropriate? Which goals have been reached? Causal attributions for the results are made with regard to ability, effort and the strategies used in the performance phase. Based on these reflections, self-regulated learners draw conclusions for future tasks. For example, goals may be generated or modified based on previous experiences to improve performance on future tasks.

Other models of self-regulated learning emphasize different facets. In her three-layered model of self-regulated learning, Boekaerts (1999) stresses 
the person characteristics, whereas Schmitz (2001; cf. Schmitz, et al., 2007) investigates how the learning task, the environment and the personal situation influence self-regulation. Leutner and Leopold (2006) focus on process-oriented approaches, particularly on a micro-level, i.e., the observation and regulation of concrete steps of a learning strategy. For the goals of this study, however, Zimmerman's model of self-regulation is most appropriate because the division of learning processes into distinct phases when dealing with learning tasks is more valuable for the design of an intervention that involves the resolution of socioscientific decision-making tasks than models that focus on characteristics of the learner. Hence, Zimmerman's process-oriented phase model allows for a focus on specific sub-processes in interventions (cf. Labuhn, 2008).

The acquisition of self-regulation skills involves different developmental levels (Zimmerman, 2000). A certain behavior is observed from a model and is then imitated. At a later stage, the learner is capable of displaying the skills in structured conditions. The highest level of selfregulation is reached when the learner takes changes in personal and environmental conditions into account to adapt to new situations.

The ability to use cognitive strategies to process information and inherent metacognitive processes to select a strategy are considered core components of self-regulated learning (Artelt et al., 2001; Hasselhorn \& Gold, 2006; Leopold, den Elzen-Rump, \& Leutner, 2006; Schunk \& Zimmerman, 1998). A good strategy user is, hence, characterized as a person with a repertoire of different strategies who knows when and where a strategy is useful and how much cognitive effort it requires (Pressley, Borkowski, \& Schneider, 1987, 1989). Therefore, one research focus on self-regulation has been the relationship between cognitive learning strategies and learning outcomes. However, many studies showed that this relationship remains unclear (Baumert \& Köller, 1996; Pintrich, Smith, Garcia, \& McKeachie, 1993). Artelt $(1999,2000)$ and Labuhn (2008) claim that the correlation 
between learning strategies and performance is low because of the measurement of the use of learning strategies. In many studies, questionnaires were employed in which students self-reported on their use of strategies (Artelt, 2000), such as the motivated strategies for learning questionnaire (MSLQ; Pintrich et al., 1993) or the learning and study strategies inventory (LASSI; Weinstein, 1988). However, the validity of questionnaires about self-reported strategy use is limited because reporting on the use of strategies requires metacognitive reflections about the students' own learning process. Therefore, it cannot be determined whether declarative knowledge about the application of strategies or the actual use of these strategies is reported (Souvignier \& Rös, 2005). Moreover, most questionnaires are based on decontextualized items. However, the application of learning strategies is highly context-dependent because students may be able to apply sophisticated strategies in one domain and merely simple strategies in another. Consequently, Artelt (1999, 2000), Leutner and Leopold (2006) and Labuhn, Bögeholz and Hasselhorn (2008a) propose to conduct process-related studies, in which the use of strategies is examined in situations in which students deal with contextualized problems rather than using abstract questionnaires based on self-reports (cf. Wirth \& Leutner, 2008, for assessment methods).

\section{Intervention studies in the field of self-regulated learning}

A number of studies have focused on training self-regulated learning in order to improve the performance in specific domains. To ensure an effective understanding of texts, interventions combined the use of highlighting strategies and concept-maps as cognitive learning strategies with the observation of a correct application and subsequent reactions based on this self-evaluation. The tools to stimulate metacognitive reflections led to a deeper understanding of the content of the presented texts (den Elzen-Rump \& Leutner, 2007; Leutner, Leopold, \& den Elzen-Rump, 2007; Leutner \& 
Leopold, 2006). Perels, Gürtler and Schmitz. (2005) combined elements of self-regulated learning with mathematical problem-solving. Strategies to deal with mathematical problems were introduced alongside with explicit goal setting, motivational and volitional techniques as well as self-monitoring and instructions on the general use of learning strategies. All these measures were derived from an adapted version of Zimmerman's model of selfregulated learning (Schmitz, 2001; Zimmerman, 2000). Regarding the results of the self-regulation questionnaire (self-reported goal-setting, motivation, strategy use, self-reflection and self-efficacy) small effects could be found for the combined training (problem solving and self-regulation). The outcome in terms of problem-solving skills was better in all three experimental groups (combined training; pure self-regulation training; pure problem-solving training) compared with the control group. In conclusion, training selfregulated learning has shown to be effective in a contextualized intervention.

In the field of science education few research studies have explicitly integrated the concept of self-regulated learning. Schraw, Crippen and Hartley (2006) describe how different facets of self-regulated learning link with current practices and research in science education, e.g. metacognitive skills that are necessary to monitor the processes during inquiry based activities. Regarding experimentation in physics classes, Thillmann (2007) integrated metacognitive prompts into a computer-based environment that stimulates students to apply the cognitive strategy of isolating single variables in the experimentation process and integrating results of the experiments into preexisting concepts. This contextualized self-regulated strategy use led to an increase in conceptual knowledge. Another area of science education that is conceptually linked to self-regulated learning is critical thinking (Schraw et al., 2006) because it requires metacognitive skills to scrutinize the credibility of information and arguments and to self-reflect upon one's own thinking (ibid.; Kuhn, 1999). This self-reflection as part of 
critical thinking is vital for decision-making to stimulate a reflective evaluation of possible options.

In biology education, Labuhn et al. (2008a) integrated various elements of self-regulated learning into a classroom unit on nutrition. The intervention was based on all three phases of self-regulated learning according to Zimmerman's model (Zimmerman, 2000) and included goal setting (forethought phase), self-monitoring, volitional strategies and methods to improve the learning environment (performance phase) as well as selfreflection processes in relation to previously set goals (self-reflection phase). The effect was measured with a questionnaire about self-regulated learning by Perels et al. (2005) and a test on content knowledge. The intervention had an effect on self-regulation on the whole, although the effect sizes were smaller than expected. However, a compelling result is that the class with self-regulated learning units reached the same levels of content knowledge as the group with pure biology periods although the self-regulation units reduced the time for content-based instructions by a third. Moreover, after a subsequent unit about decision-making, which was identical for all students, the knowledge about systematic decisions was tendentially higher in the experimental group compared to the control group. In a follow up (Labuhn et al., 2008b) the gains in self-regulation of the training group were still significant at the $10 \%$ level, and the training in self-regulated learning promoted a long-run increase in content knowledge.

To enhance the quality of mathematics and science education, the German government introduced a program with practical orientations named SINUS (Programm zur Steigerung der Effizienz des mathematischnaturwissenschaftlichen Unterrichts; program for the enhancement of the efficiency of mathematics and science education; BLK, 1997; Herzig, 2005). One focus was the implementation of self-regulated learning into mathematics and science classes. Therefore, teachers engaged in professional development courses and developed teaching units and 
materials in cooperation with researchers. Using the 2003 PISA assessment, Prenzel, Carstensen, Senkbeil, Ostermeier and Seidel (2005) reported a positive impact of the program on the students' performance. Consequently, the value of integrating self-regulated learning into science education has been acknowledged by researchers and practitioners.

In conclusion, self-regulated learning is a promising approach to foster the learning processes of students. However, so far, most studies have focused on gains in content knowledge or simple processes, such as extracting information from a given text. Perels et al. (2005) have demonstrated that self-regulation can be effectively combined with the more complex competence of mathematical problem-solving. For research in science education, Schraw et al. (2006) described the conceptual links between different areas of science education and self-regulated learning. However, the relationships between the theoretical constructs of selfregulation and decision-making have not yet been described.

\section{Integrating self-regulated learning into socioscientific decision-making}

One aim of this dissertation is to develop a learning environment that integrates self-regulated learning into socioscientific decision-making because until now, no study has been conducted that specifically contextualizes elements of self-regulated learning for decision-making training. For this purpose, research traditions, self-regulated learning and socioscientific decision-making as well as the inherent theoretical models were examined to interlink them for the development of effective, contextualized instructional methods (see Figure 3.1). The first connecting factor is the task analysis of the forethought phase (Zimmerman, 2000), in which strategies are selected for the present task based on the student's repertoire of different strategies and the characteristics of the task. The task analysis is considered suitable to promote decision-making with regard to fostering metadecision skills (Beach, 1990; Beach \& Mitchell, 1978). After 
analyzing the decision-making task, the student reflects upon the appropriateness of the decision-making strategies and selects the most suitable one. Consequently, decision-making strategies are considered to be cognitive strategies, whereas the selection of a suitable strategy is regarded as a metacognitive strategy. In addition to the characteristics of the decisionmaking task, this metadecision process also depends on the characteristics of the decision-maker as well as the environment of the decision (Beach, 1990; Beach \& Mitchell, 1978). Accordingly, the ability to use a specific strategy and motivational factors, e.g., the willingness to invest time and resources into the decision-making process, have an impact on the selection and application of a decision-making strategy.

For interventions regarding education for sustainable development, this should also involve considerations about the sustainability of options. As described in a previous chapter, students should be able to resolve decisionmaking tasks with non-sustainable options by employing a noncompensatory decision-making strategy, whereas decisions with equally legitimate options based on the societal norms of the framework for sustainable development require the use of compensatory strategies. Consequently, metacognitive skills are required for the selection of an appropriate decision-making strategy. In conclusion, from a theoretical point of view, the task analysis of the forethought phase of Zimmerman's model of self-regulated learning can be connected to Beach's concept of metadecision and normative considerations regarding sustainable development (Beach, 1990; Zimmerman, 2000). 


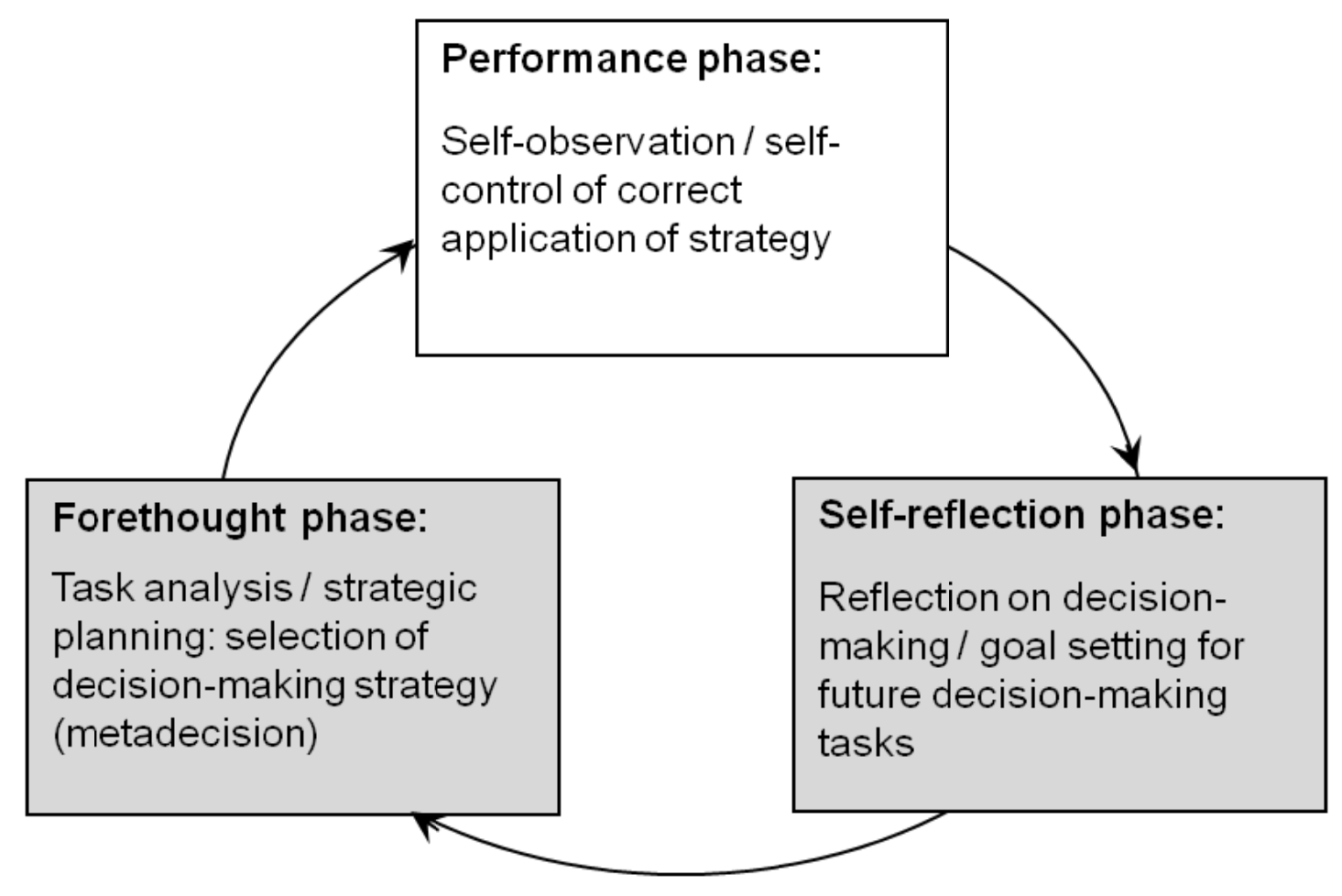

Figure 3.1. Zimmerman's model of self-regulated learning adapted to decision-making processes (Zimmerman, 2000); grey shading: focus of dissertation.

The second point of interlinkage is between the self-reflection phase of Zimmerman's model and reflections about the decision-making processes of other people, e.g., classmates or experts in the field of the considered socioscientific issue. Ratcliffe and Grace (2003; cf. Eggert \& Bögeholz, 2010) consider such a reflection on strengths and weaknesses of decisions useful to enhance one's own reasoning. Consequently, after the analysis of decision-making processes, students can make conclusions for the improvement of future tasks by setting new goals regarding efficient decisionmaking. This procedure also emphasizes the cyclical character of Zimmerman's model of self-regulated learning, which assumes various feedback loops that originate from previous tasks and impact future tasks. This corresponds to the claims of Betsch and Haberstroh (2005) and Betsch, 
Haberstroh and Höhle (2002), who stress the importance of feedback from a behavioral decision research perspective.

To summarize, despite intensive research and promising empirical evidence on the positive impact of self-regulated learning on performance, two main desiderata for future research remain. First, research is needed to gain deeper insights about contextualized trainings in self-regulated learning that truly integrate self-regulation and specific domains. Second, it should be examined whether training in self-regulated learning is not only successful in enhancing content knowledge and conceptual understanding, but also with regard to the acquisition of complex competencies. For this purpose, the evaluation of interventions should involve the assessment of elaborate competencies. 


\section{$4 \quad$ Research Foci}

Science education should provide students with the resources to make thoughtful decisions concerning socioscientific issues related to sustainable development. This requires students to reflect upon how the society in which they live should develop and how their actions affect other people and the biosphere. Moreover, students should be educated as autonomous decisionmakers, i.e., students who do not simply adopt the viewpoints of others, but reflect upon the underlying values and societal norms. Although several studies have examined the quality of argumentation as a way of presenting one's standpoint (Driver et al., 2000; Kuhn, 1991; Osborne et al., 2004; Toulmin, 1958; Venville \& Dawson, 2010; Zohar \& Nemet, 2002), few studies have investigated the actual decision-making process (Eggert \& Bögeholz, 2010; Eggert et al., 2010). However, the process of evaluating possible courses of actions to come to a conclusion in a systematic way is an essential prerequisite for collective decision-making and, hence, argumentation. Consequently, students should acquire decision-making competence to resolve socioscientific issues related to sustainable development. One promising approach to make the decision-making process more systematic and transparent is the application of decision-making strategies (Eggert \& Bögeholz, 2006; Eggert et al., 2010). According to Eggert and Bögeholz (2006), different types of decision-making tasks require different strategies to solve the conflict adequately. Tasks with options that have a severe impact on the biosphere and/or society should be solved by excluding these non-sustainable options with a non-compensatory strategy. On the other hand, tasks with equally legitimate options should be solved in a complete trade-off between all benefits and drawbacks, i.e., with a compensatory strategy. Thus, this dissertation aims at fostering decisionmaking competence through a reflective application of decision-making strategies with regard to the evaluation of solutions (see Figure 2.1). 
One way to support the process of dealing with tasks in general and decision-making tasks in particular is self-regulated learning. For other areas of science education, it has been demonstrated that conceptual links between self-regulation and research in science education exist (Schraw et al., 2006). In biology education, Labuhn et al. (2008a, 2008b) have successfully used elements of self-regulated learning to enhance the performance of the students. An assessment of knowledge about decisionmaking processes after a decision-making unit showed that the selfregulation could be transferred to another area. However, until now, elements of self-regulated learning have not been integrated into the resolution of socioscientific issues in a contextualized way. Yet, the concept of selfregulated learning is suitable to be integrated into decision-making from a theoretical point-of-view because it consists of both cognitive and metacognitive activities (Boekaerts, 1999; Zimmerman, 2000; cf. Kuhn, 1991). The application of decision-making strategies is a cognitive process that must be reflected upon on a metacognitive level to regulate the decisionmaking process.

Therefore, the integration of training in decision-making strategies and self-regulated learning is promising to foster decision-making competence. Consequently, two studies are presented to investigate how decision-making strategies and self-regulated learning can best be incorporated in a learning environment (see Figure 3.1). 


\section{Non-compensatory strategy:}

Knockout criteria based on societal norms (ecological, economic or social standards) require the exclusion of non-sustainable options. Advantages cannot compensate for these deficits.

\section{Compensatory strategy:}

All options are equally legitimate with regard to societal norms and should be compared in a full trade-off. Advantages and disadvantages can compensate for one another.

\section{Mixed strategy:}

One or several non-sustainable options are excluded based on knockout criteria. The remaining options are compared in a trade-off.

Box 4.1. Overview of decision-making strategies that were trained during the intervention.

\section{Research focus 1: Application of decision-making strategies}

In the first study, the effects of training in decision-making strategies on decision-making competence are investigated by focusing on the evaluation of solutions (see Figure 2.1). The students should acquire the knowledge to apply different strategies, and moreover, they should transfer these skills to new decision-making tasks by selecting a strategy that fits best according to the decision-making task. Do knockout criteria exist that suggest the application of a non-compensatory strategy or should all evidence be weighed in a full trade-off?

Two approaches to analyze the effect of the training in decisionmaking strategies are chosen. In a first step, the gains in decision-making 
competence are investigated using a pre-post-follow-up control-group design (summative evaluation). In addition, process-related data collected during the intervention are examined to gain further insights into the mechanisms of the training (process-related evaluation).

\section{Summative evaluation}

The assessment of decision-making competence before and after the training in decision-making strategies should reveal whether the training groups yield gains in competence compared to the control group because of the intervention. To investigate the long-term effects of the training, decisionmaking competence is assessed during a follow up three months after the training. Consequently, the first hypothesis regarding data from the pre-postfollow-up analyses is as follows:

\subsection{Training in decision-making strategies enhances decision-making competence.}

Furthermore, it should be investigated how the transfer of these decisionmaking strategies to unfamiliar socioscientific issues can be enhanced. For this purpose, the model of self-regulated learning (Zimmerman, 2000) is a suitable framework from a theoretical point of view. Before the application of a decision-making strategy the decision-making situation should be analyzed. To conduct this task analysis, metadecision skills (Beach, 1990; Beach \& Mitchell, 1978; cf. Eggert \& Bögeholz, 2006) are used to determine which strategy fits best to solve the issue. Hence, the second hypothesis is as follows:

1.2 The combination of training in decision-making strategies and an explicit task analysis enhances decision-making competence at a higher rate.

Decision-making strategies allow one to choose freely among different courses of action without external constraints. The independent selection of a 
suitable strategy should induce perceived autonomy. Furthermore, this systematic structure may evoke the perception of competence when resolving socioscientific issues. According to the works of Deci and Ryan (1985, 2002), perceived autonomy and perceived competence would enhance motivation and are, therefore, beneficial for the students' performance. Consequently, we expect the following outcome:

1.3 The self-determined use of decision-making strategies when resolving a socioscientific issue enhances perceived competence and perceived autonomy.

\section{Process-related evaluation}

Regarding the process-related data, it should be determined which metadecision considerations the students generate. Why do they consider a particular strategy to fit best according to the characteristics of the task? How elaborate are their explanations? The quality levels should be evaluated in terms of their validity by investigating the relatedness to decision-making competence:

2.1.1 How do students explain their use of different decision-making strategies?

2.1.2 Are the quality levels of the explanations valid? In which way are they related to decision-making competence?

To transfer the decision-making strategies to new socioscientific issues, the tasks of the intervention are selected and adjusted in a way that one decision-making strategy fits best to the type of the task based on considerations of societal norms regarding the framework of sustainable development. To investigate the performance in the transfer phase of the intervention, the following research question will be investigated:

2.2.1 To what extent do the students select the decision-making strategies that best fit the decision-making tasks according to societal norms? 
In a subsequent step, inferences should be made about the students' performance and the quality of the intervention based on the metadecision statements for selecting a particular decision-making strategy. Is the quality of the explanations for selecting a strategy associated with the strategy the students applied? Because all the decision-making tasks that are included in the training are selected carefully to ensure the fit of the task characteristics with one particular decision-making strategy, it would be plausible that those who select the strategy that is assumed to be best by the research group according to societal norms have conducted a more thorough task analysis and, hence, provided higher level explanations than students who chose a different strategy:

2.2.2 Do those students who select the strategy that fits best according to societal norms elaborate more on explanations than those who select a different strategy?

From a theoretical point of view, the application of a non-compensatory strategy may be less demanding because less evidence is considered compared to a compensatory strategy, where all benefits and drawbacks must be taken into account at the same time (Hong \& Chang, 2004). To ensure that the students dealt with the tasks of the intervention adequately and did not select one strategy to avoid more challenging strategies, the following is examined:

\subsubsection{Is the use of the non-compensatory decision-making strategy associated with a lower cognitive load?}

\section{Research focus 2: Reflecting on decision-making processes}

Reflecting on the decision-making process after the decision has been made has been shown to be a useful activity in other studies to draw conclusions for future decisions (Hogan, 2002). Moreover, Ratcliffe and Grace (2003; cf. 
Eggert \& Bögeholz, 2006) claim that reflecting upon the strengths and weaknesses of other decisions enhances the quality of one's own decisions. An elaborate reflection, however, requires strategic background knowledge to evaluate the decisions of others (Eggert \& Bögeholz, 2006). Consequently, the students apply three decision-making strategies as in the first study to become familiar with these strategic considerations. However, rather than exerting metadecision skills to select a decision-making strategy, the second study stimulates students to reflect on the quality of the decision-making processes of other people. For this purpose, the participating students are asked to compare and contrast presented decision-making processes of fictitious persons. Is the applied strategy appropriate? Are options hastily excluded, although a complete trade-off would have been more beneficial to base the decision on all available evidence? The central aim of this study is to investigate whether the application of decision-making strategies combined with such a reflection process fosters decision-making competence. Hence, the first hypothesis is as follows:

3.1 Training students in the application of decision-making strategies and reflection on the quality of the decision-making processes of others enhances decision-making competence.

Moreover, how this reflection process can be made more effective should be investigated. Two elements of the model of self-regulated learning seem promising: students should self-reflect on their own performance regarding the judgment of other people's decision-making processes, and they should set goals for future tasks. On which aspects should they focus when reflecting on the quality of the decision-making processes of other people? We expect that these elements of self-regulated learning further enhance decision-making competence:

3.2 A combination of reflections on the decisions of others with selfreflection on a student's own performance and the setting of goals for future tasks enhance decision-making competence at a higher rate. 
These research foci are examined in the three subsequent chapters. In chapter 5, the empirical results of the summative assessment of the first intervention study (application of decision-making strategies) will be presented. Chapter 6 focuses on the analyses of process-related data from this study. The results of the second intervention (reflection on decisionmaking processes) will be described in chapter 7. General conclusions regarding all research foci will be discussed in chapter 8 . 


\section{$5 \quad$ Training in Decision-making Strategies: An Approach to Enhance Students' Competence to Deal with Socio-scientific Issues ${ }^{9}$}

\subsection{Abstract}

Dealing with socio-scientific issues in science classes enables students to participate productively in controversial discussions concerning ethical topics, such as sustainable development. In this respect, well-structured decisionmaking processes are essential for elaborate reasoning. To foster decisionmaking competence, a computer-based programme was developed that trains secondary school students (grades 11-13) in decision-making strategies. The main research question is: does training students to use these strategies foster decision-making competence? In addition, the influence of metadecision aids was examined. Students conducted a task analysis to select an appropriate strategy prior to the decision-making process. Hence, the second research question is: does combining decisionmaking training with a task analysis enhance decision-making competence at a higher rate? To answer these questions, 386 students were tested in a prepost-follow-up control-group design that included two training groups (decision-making strategies/decision-making strategies combined with a task analysis) and a control group (decision-making with additional ecological information instead of strategic training). An open-ended questionnaire was used to assess decision-making competence in situations related to sustainable development. The decision-making training led to a significant improvement in the post-test and the follow-up, which was administered three months after the training. Long-term effects on the quality of the students'

9 Source: Gresch, H., Hasselhorn, M., \& Bögeholz, S. (2011, online first). Training in decision-making strategies: An approach to enhance students' competence to deal with socioscientific issues. International Journal of Science Education.

doi:10.1080/09500693.2011.617789. 
decisions were evident for both training groups. Gains in competence when reflecting upon the decision-making processes of others were found, to a lesser extent, in the training group that received the additional metadecision training. In conclusion, training in decision-making strategies is a promising approach to deal with socio-scientific issues related to sustainable development.

Keywords: decision-making, socio-scientific issues, STSE education, education for sustainable development, environmental education

\subsection{Introduction}

Controversial discussions about socio-scientific issues require students to understand complex scientific and ethical issues (Zeidler et al., 2005). A central aim of science education is to teach students to be critical thinkers and participatory citizens who are capable of making well-informed and systematic decisions. Moreover, dealing with socio-scientific issues has become an essential part of scientific literacy and has therefore been included in various standards and curricula (AAAS, 1989; KMK, 2005a; NRC, 1996; Zeidler et al., 2005). One crucial topic in the field of socio-scientific issues is the sustainable development of our environment (Bögeholz et al., 2004; Pedretti, 2003; Ratcliffe \& Grace, 2003). Sustainable development provides natural resources and welfare for today's society as well as for future generations. Decisions about sustainability issues are complex and include a wide range of possible courses of action. As a result, decisionmaking competence is a core component of education for sustainable development and environmental education (Arvai et al., 2004; de Haan, 2010; Eggert \& Bögeholz, 2006).

Because socio-scientific issues concerning sustainable development are not fully integrated into science education, new methods of approaching these topics must be developed. Which classroom activities are useful for fostering informed decision-making? The central purpose of this study is to 
investigate whether training in the use of decision-making strategies contributes to systematic and elaborate reasoning in the field of sustainability issues. A second goal is to determine whether metadecision aids, which are based on the framework of self-regulated learning, enhance the decisionmaking process at a higher rate.

\subsection{Theoretical Framework}

\subsubsection{Socio-scientific Issues and Education for Sustainable Development}

Socio-scientific issues are controversial scientific topics that involve social and ethical considerations (Sadler, 2004; Zeidler \& Sadler, 2007; Zeidler et al., 2005). They are complex and ill-structured real-world problems for which a definite solution does not exist (Sadler, 2004). In addition to complex scientific evidence, normative considerations and personal values must be taken into account when constructing moral judgments (Bögeholz \& Barkmann, 2005; Jiménez-Aleixandre \& Pereiro-Muñoz, 2002; Kolstø, 2001; Ratcliffe \& Grace, 2003; Zeidler \& Sadler, 2007).

Much research has been done on the structure of argumentation, characteristics of a good argument and fallacies in reasoning (Driver et al., 2000; Kuhn, 1991; Sadler \& Zeidler, 2005; Zeidler, 1997; Zohar \& Nemet, 2002). However, before a student can justify his/her position, the student must decide which position is best. Therefore, the individual decision-making process is a necessary prerequisite for argumentation and discourse.

One vital domain of socio-scientific issues is sustainable development. Since the publication of the Agenda 21 (UNCED, 1992), social and economic aspects of development policies are supposed to be considered along with environmental concerns. These three domains of sustainable development (social, economic and ecological) and their interdependencies have become the fundamental bases of action plans and education for sustainable 
development (de Haan, 2010; Huckle \& Sterling, 1996; Sauvé, 1996; Scott \& Gough, 2003).

The concept of sustainable development has been incorporated into standards and curricula to different extents. The AAAS (1989) and the US National Science Education Standards (NRC, 1996) include resource management and the protection of the environment. In addition, German and English national standards (KMK, 2005a; KMK \& BMZ, 2007; QCA, 2004) emphasise the need for education for sustainable development.

\subsubsection{Decision-making Strategies}

Behavioural decision research aims to describe and explain the judgment and decision-making processes in order to improve decision-making behaviour (Payne et al., 1998). Before relating this descriptive approach to the normative aspects of decision-making in education for sustainable development, three models that describe actual decision-making behaviour will be presented (Jungermann et al., 2005; Payne et al., 1998).

Decision-making situations often consist of a set of possible options that can be described with regard to different criteria relevant for the decision-making process. A full trade-off of all the given information can best be described by the weighted-additive-value model (Jungermann et al., 2005; Payne et al., 1998). In this model, all of the available information is used to evaluate the overall quality of each option. Furthermore, important criteria will affect the decision more than less important criteria. This model assumes that there are equally legitimate options and that a decision-maker takes all information into account. Although this model dominated the behavioural decision research, various other models have been developed.

In contrast with a compensatory strategy, in which benefits and drawbacks compensate one another (Jungermann et al., 2005), noncompensatory strategies describe a decision-making behaviour, where unacceptable options are eliminated. Therefore, the disadvantages are not 
compensated for by other advantages. According to the elimination-byaspects model (Jungermann et al., 2005; Payne et al., 1998), options are excluded if they do not meet a minimum cut-off threshold with respect to the most important criterion. Subsequently, the second most important criterion is used to exclude further options. This process is repeated until only one option remains.

Frequently, decision-making strategies are combined to reach a conclusion. In his image theory, Beach (1990) describes a screening phase in which unacceptable options are excluded before an in-depth analysis of the remaining options, including full trade-offs, is performed.

Payne et al. (1998) claim that decisions that are entirely or partly based on non-compensatory procedures are grounded in rational considerations to some extent, but are also based upon heuristics that were used to simplify the decision. In the context of moral judgment, Haidt (2001) goes one step further by stating that most ethical decisions are primarily based on intuitions rather than rational considerations. According to his social-intuitionist model, reasoning is usually a post-hoc construction used to justify the initial judgment. Although actual decision-making processes may be intuitive and may lead to satisfying results in routine decisions, Haidt (2001), Arvai et al. (2004) and Eggert and Bögeholz (2006) acknowledge that intuitional decisions are not considered the best from a normative viewpoint for all types of decisions. Baron (1998) states that intuitive decisions may even have disastrous consequences. This is especially true in complex decision-making situations, such as those concerning sustainable development, in which a systematic decision is considered more appropriate than one based on heuristics (Arvai et al., 2004; Eggert \& Bögeholz, 2006). However, models that describe actual decision-making behaviour may help educators to design learning environments that help students improve their decision-making processes (Haidt, 2001; Payne et al., 1998). 
Considering socio-scientific issues, decision-making tasks with equally legitimate options should only be solved using processes that trade off the positive and negative aspects (Eggert \& Bögeholz, 2006; Seethaler \& Linn, 2004; Siegel, 2006). However, not all decision-making tasks have equally legitimate options. If possible solutions concerning sustainable development do not reach a minimum threshold in terms of ecological, social or economic attributes a non-compensatory or mixed strategy should be used. In conclusion, different types of decision-making tasks demand different decision-making strategies to solve the conflict adequately.

It should be stated that, in this context, the elimination of inadequate options is not seen as a simplification of the decision-making task, but meets the requirements of the framework of sustainable development.

During the decision-making process, personal values are taken into account in an explicit or implicit way (Bell \& Lederman, 2003; Grace \& Ratcliffe, 2002; Kolstø, 2006; Sadler \& Zeidler, 2004). Seethaler and Linn (2004) found that students listed benefits and drawbacks, but did not state why advantages could outweigh disadvantages. Hence, Seethaler and Linn (2004) conclude that this weighing of evidence should be made explicit in the students' decisions. In contrast, Jiménez-Aleixandre and Pereiro-Muñoz (2002) found that 11th-grade students considered a value hierarchy of environmental and economic aspects in their discussions. The consideration of values is included in both classical and more recently developed decisionmaking models (e.g., through a weighting factor in compensatory strategies or as a hierarchy of values used to eliminate options).

\subsubsection{Decision-making Competence}

One crucial competence in the field of education for sustainable development is participation in decision-making processes (de Haan, 2010; Eggert \& Bögeholz, 2006). Students should be able to cope with multi-criteria decisionmaking situations that include competing objectives of sustainable 
development. Because it is not appropriate for teachers to judge their students' opinions, the focus should be on the students' reasoning in reaching their conclusions (Ratcliffe \& Grace, 2003).

The main theoretical model upon which this study is based is the model of decision-making competence in situations related to sustainable development by Eggert and Bögeholz (2006; Bögeholz, 2011). Central aspects of the selection process were derived from a metamodel of decisionmaking by Betsch and Haberstroh (2005). In the first instance, the decisionmaker gathers information regarding the three domains of sustainable development (ecological, social and economic domain) to describe the decision-making situation and generate possible options. The characteristics and consequences of each option are explicitly described according to relevant criteria. Once the possible options are generated, the decisionmaker considers evidence for and against each option to reach a conclusion. This process may involve the implicit or explicit use of a choice rule. However, complex decision-making situations are cognitively demanding because large amounts of information and personal values have to be considered at the same time to make a trade-off. This study focuses on the judgment of different options and the way to reach a final decision. With respect to the goal of this study, this model is the most suitable as it provides a detailed framework that focuses on the decision-making process and education for sustainable development.

Previously, intervention studies have concentrated on the improvement of trade-off-processes (Eggert et al., 2010; Seethaler \& Linn, 2004; Siegel, 2006; Roberts et al., 1997 (Science Education for Public Understanding Project, SEPUP)). Seethaler and Linn (2004) showed that students significantly improved in their consideration of supporting evidence and counter-evidence after working with a web-based curriculum on genetically modified food, which scaffolds students in gathering evidence in favour of and against their own position. However, in the final conclusion 
students encountered difficulties explaining why the evidence in favour outweighed the evidence against their position. Therefore, future research should focus on the inclusion of evidence for and against all available options, as well as how to weigh this evidence.

Ratcliffe (1997) found that structuring the decision-making process enabled students to identify relevant criteria of the decision-making task and discuss benefits and drawbacks in detail. Students followed a six step guideline of decision-making processes. First, students were asked to list options, list the relevant criteria and gather information. Then, students evaluated the advantages and disadvantages and arrived at a conclusion. The conclusion was finally reviewed with reflection on the decision-making process. Although students did not employ all aspects of the decision-making framework and did not discuss opposing positions systematically, they considered this structure to be helpful during the decision-making process.

Eggert et al. (2010) investigated the influence of training in compensatory decision-making and a combination of the compensatory approach with metacognitive structuring. All students (seventh grade) dealt with decision-making tasks concerning sustainability issues in a co-operative learning environment. In both treatment groups (compensatory decisionmaking and a combination of compensatory decision-making and metacognitive structuring), students' competence levels increased significantly from the pre-test to the post-test, although the metacognitive structuring did not have an additional effect.

In other disciplines such as business, medicine and the military, the teaching of decision-making has been investigated to a greater extent. Baron (1994) claims that the study of decision-making strategies may help avoid flaws in decision-making, such as the failure to consider all future consequences, alternative options and evidence.

In conclusion, there already exists a degree of successful training in decision-making. However, one central research gap remains: how students 
can be trained to make more systematic decisions with regard to sustainable development. The impact of decision-making strategies, which are considered valuable in other disciplines, on decision-making competence when resolving socio-scientific issues has only been investigated with regard to compensatory decision-making (Eggert et al., 2010). The use of different strategies has not yet been addressed in intervention studies.

\subsubsection{Metadecision and Self-regulated Learning}

How can students resolve socio-scientific issues autonomously and thus become reflective and participatory citizens? Generally, they should be prepared to analyse the conflict in a socio-scientific issue and reflect on an appropriate method to resolve it. One approach is the application of a decision-making strategy. To determine the most appropriate strategy the decision problem, the environment of the decision and the characteristics of the decision-maker have to be taken into account (Beach, 1990; Beach \& Mitchell, 1978). The complexity of these factors, which influence the selection of a decision-making strategy, require metadecision skills to resolve the conflict adequately (Beach, 1990). Therefore, decision-making involves not only the application of a decision-making strategy as a cognitive process but also the selection of an appropriate decision-making strategy as a metacognitive process.

The way in which students could approach such decision-making tasks in science classes can be embedded in the concept of self-regulated learning. The resolution of a socio-scientific issue can be considered a learning task in which the metacognitive reflection of the underlying processes may enhance the quality of the decision, and experiences with previous decision-making tasks can affect the success of future tasks. Selfregulated learning is considered a dynamic process that integrates cognitive, metacognitive and motivational aspects of learning (Boekaerts, 1999; Zimmerman, 2000). Therefore, it provides a useful framework for the demands of the selection and application of decision-making strategies. 
According to Zimmerman (2000), the process of performing a specific task has three phases: forethought, performance and self-reflection. Before beginning a task, self-regulated learners analyse the underlying task and select strategies to deal with it. During the task performance, learners observe and control the process. Afterwards, they reflect on their performance.

This sequence can be applied to the task of resolving socio-scientific issues. First, a thorough task analysis is conducted prior to selecting an appropriate decision-making strategy. The decision-making situation should be analysed with the sustainability framework in mind. Do the advantages and disadvantages compensate for one another? Or, do the knockout criteria exist, which imply the exclusion of options? Second, the selected strategy is applied to resolve the issue. Finally, the performance and adequacy of the applied strategy are reflected upon.

\subsubsection{Self-determination Theory}

According to the self-determination theory (Deci \& Ryan, 1985, 2002), motivation and performance are best supported when learning environments satisfy three basic psychological needs: perceived competence, perceived autonomy and relatedness. Therefore, a setting that offers choices as well as possibilities to self-regulate the learning process, and that lets the learner experience competence in fulfilling a task, should increase motivation and thereby optimise performance. Moreover, in the field of socio-scientific issues, a high degree of self-determination would not only be supportive in terms of motivation but would also represent a requirement of education for citizenship and environmental education, as students should be enabled to make decisions autonomously (Darner, 2009). Whether decision-making strategies help students acquire a higher level of perceived competence and perceived autonomy when dealing with socio-scientific issues has not yet been investigated. 


\subsection{Research Questions}

Although the decision of a course of action is a core component of resolving socio-scientific issues, little research has been done with regard to the enhancement of the decision-making process itself. Thus, the present study is an attempt to uncover results from behavioural decision research that will be useful for science education. It was investigated, whether the application of decision-making strategies aids students in structuring their decisionmaking process and thereby increases their level of decision-making competence. The main hypothesis is as follows:

1. Training in decision-making strategies enhances decision-making competence.

In addition, it was investigated how metadecision aids help students in their selection of adequate decision-making strategies. In accordance with the model of self-regulated learning by Zimmerman (2000), a task analysis was included in the intervention to aid the selection of an appropriate decisionmaking strategy. The task analysis should induce metacognitive reflection. The second hypothesis is as follows:

2. The combination of training in decision-making strategies and an explicit task analysis enhances decision-making competence at a higher rate.

Moreover, the effect of using decision-making strategies on motivational aspects such as perceived choice and perceived competence was examined. A positive effect would support the approach of training in decision-making strategies as compared with unstructured decisions. Especially for the training unit that involves elements of self-regulated learning a higher level of perceived autonomy is expected.

3. The self-determined use of decision-making strategies when resolving a socio-scientific issue enhances perceived competence and perceived autonomy. 
In order to investigate these hypotheses, a computer-based training programme that focused on three decision-making strategies was designed.

\section{$5.5 \quad$ Methods}

\subsubsection{Description of the Training Programme}

\begin{tabular}{|l|l|l|}
\hline Training group 1 & Training group 2 & Control group \\
\hline Session 1: training decision-making strategies & \\
- Non-compensatory strategy & Decision-making with \\
- Compensatory strategy & additional ecological \\
- Mixed strategy & information \\
\hline \begin{tabular}{l|l} 
Session 2: application of decision-making strategies \\
- Selection of strategy \\
without task analysis
\end{tabular} & after task analysis & \\
\hline
\end{tabular}

Figure 5.1. Structure of the training programme.

All participating students dealt with complex decision-making tasks related to sustainable development. These tasks were embedded in a webbased training programme (Figure 5.1). Generally, competencies are acquired best when applied to a specific context. Therefore, contexts that are suitable for the application of each decision-making strategy were selected. These contexts include political measures about the preservation of ecosystems (coral reefs and limnological ecosystems), the land-use planning after the mining of brown coal in Germany and consumer decisions. Therefore, local actions related to the students' lives as well as global consequences were incorporated, as these are essential aspects of education for sustainable development. Competing objectives were inherent in all contexts. Groups that would be affected by the result of the decision had to be considered. These groups included proprietors of diving schools 
close to the endangered coral reefs, the workers in a production chain who depend on fair working conditions and the local population. In addition, the conservation of biodiversity and economic constraints had to be contrasted with these social considerations and integrated into students' decisions.

All tasks required thorough information processing. The given information had to be evaluated to finally decide upon one of the possible options. To scaffold the decision-making process, tools for the application of three different decision-making strategies were included in the training programme.

In the first session (45 $\mathrm{min}$ ) students from both training groups learned how to apply a compensatory strategy (complete trade-off), a noncompensatory strategy (identification of knockout criteria and elimination of options) and a mixture of both (exclusion of unacceptable options followed by a trade-off of the remaining options). The use of these decision-making strategies was scaffolded in different ways. For the compensatory strategy, students applied the weighted-additive-value strategy (Jungermann et al., 2005; Payne et al., 1998) by converting advantages and disadvantages into positive and negative scores. Furthermore, all criteria had to be weighted to prioritise the underlying values. The non-compensatory strategy was applied with buttons that allowed the students to systematically eliminate options that had unacceptable traits, starting with the most important criterion, followed by the second most important one, and so forth to induce the hierarchisation of personal values. Under this strategy, the programme followed the steps of an elimination-by-aspects rule (Jungermann et al., 2005; Payne et al., 1998). Special attention was paid to the three domains of sustainable development to help students to decide which options were unacceptable with regard to these criteria. The third strategy was based on Beach's image theory (Beach, 1990; Beach \& Mitchell, 1978) and was implemented using a combination of the other two strategies. All tasks offered an opportunity to reflect on the use of these strategies. 
In the second session (45 min) students applied these strategies to three new contexts in which they were required to select the strategy that best fits the type of the task.

The first session was identical for both training groups (Figure 5.1). In session 2, however, an element of self-regulated learning was integrated into the version for the second training group. Students in the second training group were asked to conduct an explicit task analysis in which they reflected upon the fit of the type of the decision-making task and the decision-making strategy. This required the use of metadecision skills.

The control group (CG) dealt with the same issues, but received additional ecological information instead of training in decision-making strategies.

\subsubsection{Research Design}

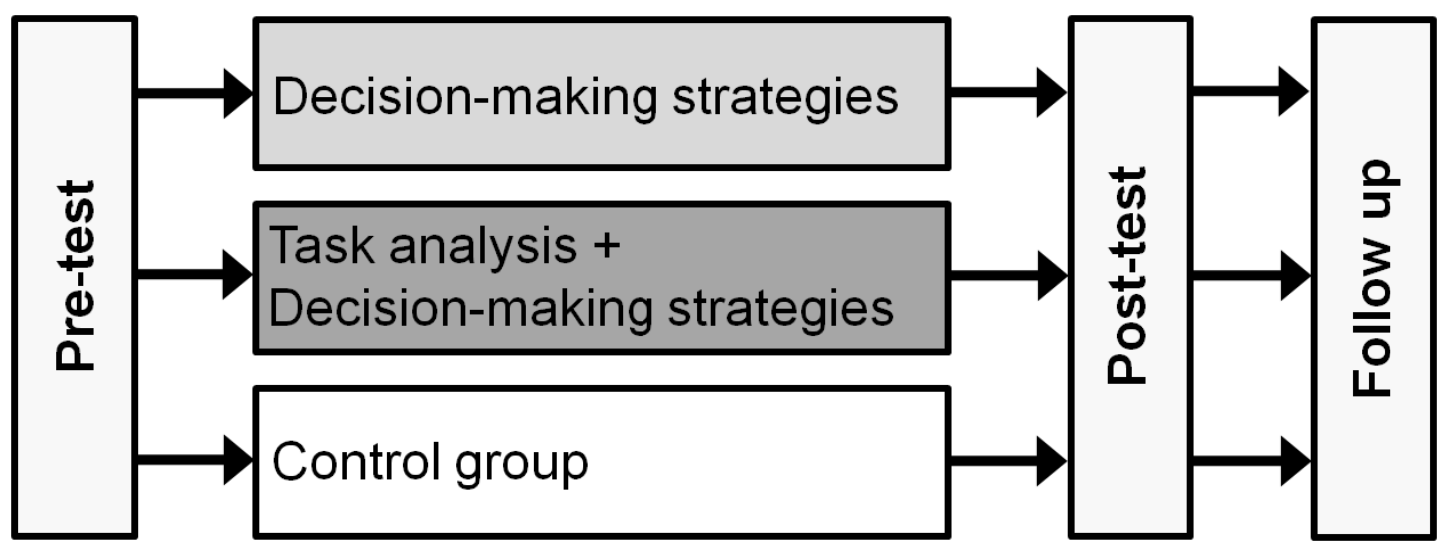

Figure 5.2. Research design.

The effects of the computer-based training programme were examined in a pre-post-follow-up control-group design (Figure 5.2) using the questionnaire of Eggert and Bögeholz (2010) at all measurement times. The pre-test and the first part of the training programme took place in a $90 \mathrm{~min}$ block. During a second 90 min block, which was carried out within a week of 
the first block, students completed the second part of the training programme and the post-test. The follow-up test was conducted three months after the intervention. At the beginning of the training programme, all participating students were randomly assigned to two different training groups and a control group by the computer programme. All of the groups were present in each classroom at the same time and each student was provided with a computer.

\subsubsection{Sample}

The study was conducted in 25 biology courses at five different German high schools. A total of 386 students from grades 11-13 took part in the training programme as well as pre-test and post-test (training group 1: 126, training group 2: 137, control group: 123). A total of 279 students took part in all three tests. Out of the 386 students, 154 were male and 226 were female (there were 6 missing values). The average age was 17.3 years. The two training groups and the control group did not differ significantly in terms of age, sex, previous biology grades, level of biology course or number of biology classes per week.

\subsubsection{Assessment of Decision-making Competence}

The effects of this training programme were measured with a 45 min paperand-pencil test on decision-making competence (Eggert \& Bögeholz, 2010; Eggert et al., 2010). The test consisted of two different types of tasks. In the first section of the questionnaire, students were asked to compare different options in two real-world situations concerning sustainable development. Students had to decide upon the most suitable option according to their individual preferences and explain in detail how they reached their decision. In the second section of the questionnaire, students were asked to reflect upon the decision-making processes of others in a third context. In this section, the decisions of three people were presented and students had to 
describe their way of reasoning and give advice on how these decisionmaking processes could be optimised.

All of the chosen contexts in this test instrument belonged to a group of situations in which all options were considered equally legitimate according to the sustainability framework. Thus, a compensatory strategy is assumed to fit best, which requires a complete trade-off process.

The open answers were scored on 15 items (Table 5.1; Eggert et al., 2010; Eggert \& Bögeholz, 2010). Regarding the students' own decisionmaking process, two items indicate response behaviour for the chosen options and six items for the rejected options. In addition, the weighting of criteria according to individual preferences is included. The scale consists of dichotomous and polytomous items and therefore items have different maximum scores. The items indicating the response behaviour for the chosen and rejected options were weighted $2 / 3$, and the items indicating the weighting of criteria were weighted $1 / 3$. This takes into account that the number of items for the description of options was far larger than the number of items indicating the weighting of criteria. Furthermore, this ratio was chosen to maintain comparability with the study of Eggert and Bögeholz (2010).

Regarding the reflection on the decision-making processes of others, three items address the description of the presented decision-making strategies and two items address the suggestions for improvement (Table 5.1). The items indicated whether students described the decisions and offered suggestions on a content level or provided strategic aspects (i.e. focused on the underlying decision-making strategies). 
Table 5.1

Scoring guide for the assessment of decision-making competence

\begin{tabular}{|c|c|c|c|c|c|c|}
\hline No. & $\begin{array}{l}\text { Item } \\
\text { description }\end{array}$ & Score 0 & Score 1 & Score 2 & Score 3 & Score 4 \\
\hline \multicolumn{7}{|c|}{ Decision-making } \\
\hline $1+6$ & Chosen option & $\begin{array}{l}\text { Does not } \\
\text { state } \\
\text { anything }\end{array}$ & $\begin{array}{l}\text { States } \\
\text { only } \\
\text { positive } \\
\text { aspects }\end{array}$ & $\begin{array}{l}\text { States } \\
\text { positive } \\
\text { and } \\
\text { negative } \\
\text { aspects }\end{array}$ & & \\
\hline $\begin{array}{l}2,3,4 \\
7,8,9\end{array}$ & $\begin{array}{l}\text { Rejected } \\
\text { options }\end{array}$ & $\begin{array}{l}\text { Does not } \\
\text { state } \\
\text { anything }\end{array}$ & $\begin{array}{l}\text { States } \\
\text { only } \\
\text { negative } \\
\text { aspects }\end{array}$ & $\begin{array}{l}\text { States } \\
\text { positive } \\
\text { and } \\
\text { negative } \\
\text { aspects }\end{array}$ & & \\
\hline $5+10$ & $\begin{array}{l}\text { Weighting } \\
\text { criteria }\end{array}$ & $\begin{array}{l}\text { Does not } \\
\text { explicitly } \\
\text { weight } \\
\text { criteria }\end{array}$ & $\begin{array}{l}\text { Weights } \\
\text { criteria } \\
\text { explicitly }\end{array}$ & & & \\
\hline \multicolumn{7}{|c|}{ Reflection } \\
\hline 11 & $\begin{array}{l}\text { Description of } \\
\text { non- } \\
\text { compensatory } \\
\text { decision- } \\
\text { making }\end{array}$ & $\begin{array}{l}\text { Does not } \\
\text { respond to } \\
\text { the task }\end{array}$ & $\begin{array}{l}\text { Reference } \\
\text { only to } \\
\text { content }\end{array}$ & $\begin{array}{l}\text { Reference } \\
\text { to some } \\
\text { aspects of } \\
\text { strategy }\end{array}$ & $\begin{array}{l}\text { Reference } \\
\text { to all } \\
\text { aspects of } \\
\text { strategy }\end{array}$ & $\begin{array}{l}\text { Score } 3 \\
\text { and } \\
\text { explains } \\
\text { underlying } \\
\text { conflict }\end{array}$ \\
\hline 12 & $\begin{array}{l}\text { Description of } \\
\text { compensatory } \\
\text { decision- } \\
\text { making }\end{array}$ & $\begin{array}{l}\text { Does not } \\
\text { respond to } \\
\text { the task }\end{array}$ & $\begin{array}{l}\text { Reference } \\
\text { only to } \\
\text { content }\end{array}$ & $\begin{array}{l}\text { Reference } \\
\text { to some } \\
\text { aspects of } \\
\text { strategy }\end{array}$ & $\begin{array}{l}\text { Reference } \\
\text { to main } \\
\text { aspects of } \\
\text { strategy }\end{array}$ & $\begin{array}{l}\text { Reference } \\
\text { to all } \\
\text { aspects of } \\
\text { strategy }\end{array}$ \\
\hline 13 & $\begin{array}{l}\text { Description of } \\
\text { intuitive } \\
\text { decision- } \\
\text { making }\end{array}$ & $\begin{array}{l}\text { Does not } \\
\text { respond to } \\
\text { the task }\end{array}$ & $\begin{array}{l}\text { Reference } \\
\text { only to } \\
\text { content }\end{array}$ & $\begin{array}{l}\text { Reference } \\
\text { to some } \\
\text { aspects of } \\
\text { strategy }\end{array}$ & $\begin{array}{l}\text { Reference } \\
\text { to all } \\
\text { aspects of } \\
\text { strategy }\end{array}$ & \\
\hline 14 & $\begin{array}{l}\text { Suggestions for } \\
\text { improvement of } \\
\text { intuitive } \\
\text { decision- } \\
\text { making }\end{array}$ & $\begin{array}{l}\text { No } \\
\text { suggestions }\end{array}$ & $\begin{array}{l}\text { Sugges- } \\
\text { tions on } \\
\text { content } \\
\text { level }\end{array}$ & $\begin{array}{l}\text { Sugges- } \\
\text { tions on } \\
\text { strategic } \\
\text { level }\end{array}$ & & \\
\hline 15 & $\begin{array}{l}\text { Suggestions for } \\
\text { improvement of } \\
\text { compensatory } \\
\text { decision- } \\
\text { making }\end{array}$ & $\begin{array}{l}\text { No } \\
\text { suggestions }\end{array}$ & $\begin{array}{l}\text { Sugges- } \\
\text { tions on } \\
\text { content } \\
\text { level }\end{array}$ & $\begin{array}{l}\text { Sugges- } \\
\text { tions on } \\
\text { strategic } \\
\text { level }\end{array}$ & & \\
\hline
\end{tabular}


Eggert and Bögeholz (2010) analysed the quality of the questionnaire with data from students in grades $6-12(N=436)$ and showed that the Rasch partial credit model best describes the decisionmaking competence of the investigated sample. According to their analyses, the instrument provides an adequate way to analyse decisionmaking competence in terms of item separation reliability, person separation reliability and construct validity. The education level of the student had a significant influence on decision-making. In addition, there was a significant correlation between decision-making competence and grades in the students' first language (German). In the standards and curricula of German as a subject argumentation plays an important role, which supports the validity of the questionnaire. Furthermore, decisionmaking can be distinguished from general cognitive abilities (ibid.). Eggert et al. (2010) used this questionnaire with a slightly modified scoring system in an intervention study with seventh graders. They demonstrated that this questionnaire was suitable for studies with repeated measurements.

In this study, analyses of covariance of the post-test/follow-up results as the dependent variables were conducted with the pre-test scores as a covariate. Reliability was calculated using Cronbach's alpha. For the dependent variables of the decision-making scale (post-test and follow-up test scores), Cronbach's alpha was .63 and .65, respectively. For the reflection scale, the internal consistency was lower (.62 and .52 for the post-test and follow-up test, respectively). Therefore, the students' responses were analysed on the item level with non-parametric tests. In this study, $50 \%$ of all questionnaires were coded by a second person. The interrater reliability (Cohen's kappa) was good (.81). After determining this value all items with different scores were discussed by the two raters so that they could agree upon a final score. 
For motivational reasons, different contexts were used in the questionnaire before and after the treatment. The questionnaires were structured and scored in the same way but they contained different topics. The post-test and follow-up test comprised the tasks used in Eggert and Bögeholz (2010) and Eggert et al. (2010). Due to the different contexts of the questionnaire, which may lead to varying levels of difficulty, the data from the control group were $z$-standardised for each measurement time to provide a baseline that was identical for all tests. The raw data of the training groups were then transformed according to the means and standard deviations of the control group.

For the analyses on the item level, it was determined whether students improved (gained a higher score) in the post-test/follow-up test compared with the pre-test results (score 1) or whether the score remained constant or decreased (score 0 ). The training groups and the control group were compared pairwise using $2 \times 2$ (group $\times$ change of score) chi square analyses.

\subsubsection{Assessment of Intrinsic Motivation}

At the end of the training programme, students were asked to complete a 12-item intrinsic motivation questionnaire. This was a short version of the intrinsic motivation inventory (University of Rochester, 1996) that had been translated into German and pre-tested by Krombass and Harms (2006) and Wilde, Bätz, Kovaleva and Urhahne (2009). The questionnaire consisted of four subscales with three items each. Students self-reported their subjective interest/enjoyment, perceived competence, perceived choice and pressure/tension on a five-level Likert scale. Reliability (Cronbach's alpha) was good for all subscales: .83, .83, .84 and .73. Perceived competence and perceived choice (autonomy) are positive predictors of intrinsic motivation and pressure/tension is a negative 
predictor (University of Rochester, 1996). Differences between the groups were calculated using ANOVA and $t$-tests.

\subsection{Results}

\subsubsection{Decision-making}

Figure 5.3 shows the mean z-standardised values for the pre-test, posttest and follow-up test for the two training groups (TG1 and TG2) and the control group (CG). Missing data were excluded listwise. In the pre-test, the training groups and the control group did not differ significantly.

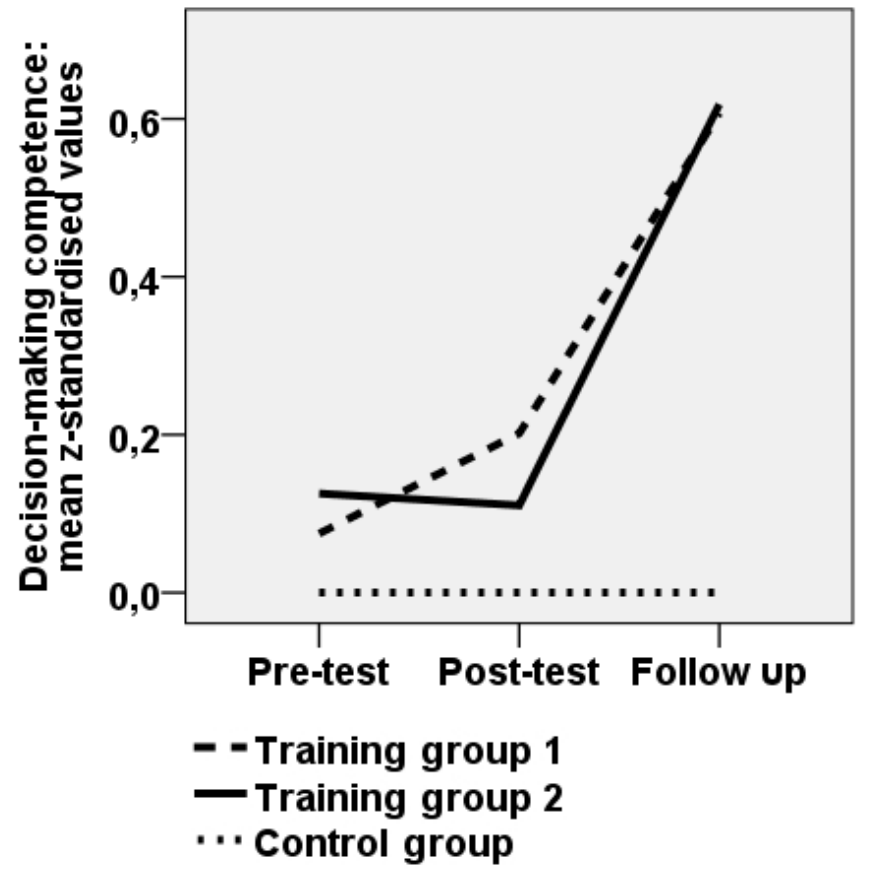

Figure 5.3. Mean values of decision-making competence (z-standardised using mean and standard deviation of control group).

The analysis of covariance of the post-test results with pre-test scores as a covariate did not show significant differences between the training groups and the control group. However, in the long run, the treatment did have a significant effect. Comparing the follow-up results of 
TG1 and the CG in a pairwise ANCOVA, the effect of the group after controlling for the effect of the pre-test result was found to be $F_{(1,162)}=12.8, p<.001$, partial $\eta^{2}=.074$. Comparing TG2 and the CG, the effect of the group was $F_{(1,177)}=13.2, p<.001$, partial $\eta^{2}=.070$. TG1 and TG2 did not differ significantly.

To gain further insight into the effects of the training programme, the weighting of criteria according to personal values and the way students dealt with advantages and disadvantages will be presented on the item level. Looking at the development from the pre-test to the post-test, students from TG1 and TG2 improved significantly more frequently in weighting criteria than students from the CG (TG1-CG: $\chi^{2}=8.0, d f=1$, $p<.01$; TG2-CG: $\chi^{2}=7.7, d f=1, p<.01$ ). This effect was even stronger in the long run (pre-test to follow-up: TG1-CG: $\chi^{2}=17.0, d f=1, p<.001$; TG2-CG: $\left.\chi^{2}=20.2, d f=1, p<.001\right)$. The training groups did not differ significantly.

However, the way students supported their claims by stating benefits and drawbacks of each option did not improve after the training and decreased slightly from the pre-test to the post-test. Furthermore, students in the training groups tended to identify fewer advantages and disadvantages than the control group.

\subsubsection{Reflection}

In Table 5.2, the observed and expected absolute frequencies of an increase versus a constancy or decrease of the scores from the pre-test to the post-test are presented. An increase of the score indicates a shift from content-based descriptions and suggestions to responses involving strategic aspects of the decision-making process. 
Table 5.2

Reflection: Changes in the score from the pre-test to the post-test (observed and expected absolute frequencies)

\begin{tabular}{cccc}
\hline Training & Training & Control & Total \\
group 1 & group 2 & group & \\
obs. & obs. & obs. & \\
(exp.) & (exp.) & (exp.) & \\
\hline
\end{tabular}

Description of non-compensatory decision-making

\begin{tabular}{lcccc} 
Increase & 74 & 81 & 25 & 180 \\
& $(59.5)$ & $(66.2)$ & $(54.4)$ & \\
Constancy / decrease & 42 & 48 & 81 & 171 \\
& $(56.5)$ & $(62.8)$ & $(51.6)$ & \\
Total & 116 & 129 & 106 & 351 \\
\hline \multirow{4}{*}{ Increase } & Description of compensatory decision-making & \\
& 70 & 73 & 32 & 175 \\
Constancy / decrease & $(58.0)$ & $(64.5)$ & $(52.5)$ & \\
& 46 & 56 & 73 & 175 \\
Total & $(58.0)$ & $(64.5)$ & $(52.5)$ & \\
& 116 & 129 & 105 & 350
\end{tabular}

Suggestions for the improvement of intuitive decision-making

\begin{tabular}{lcccc} 
Increase & 17 & 37 & 17 & 71 \\
& $(21.7)$ & $(26.5)$ & $(22.8)$ & \\
Constancy / decrease & 61 & 58 & 65 & 184 \\
& $(56.3)$ & $(68.5)$ & $(59.2)$ & \\
Total & 78 & 95 & 82 & 255 \\
\hline
\end{tabular}


Regarding the description of the presented non-compensatory decision, the gains of the training groups were highly significant when compared with the control group: TG1-CG: $\chi^{2}=36.2, d f=1, p<.001$; TG2CG: $\chi^{2}=36.1, d f=1, p<.001$. The quality of the description of the compensatory decision-making process also improved as a result of the training: TG1-CG: $\chi^{2}=19.8, d f=1, p<.001$; TG2-CG: $\chi^{2}=16.0, d f=1$, $p<.001$. Furthermore, the scores regarding the suggestions that students made to improve the presented intuitive decision-making process increased significantly more often in TG2 as compared with TG1 and the CG: TG2-TG1: $\chi^{2}=5.9, d f=1, p<.05$; TG2-CG: $\chi^{2}=6.9, d f=1, p<.01$. However, no significant changes were found for the remaining two items, the description of the intuitive decision-making process and suggestions to improve the compensatory decision (not documented in Table 5.2).

Regarding the changes from the pre-test to the follow-up test, an improvement in the scores could only be seen for one item, the suggestions for the improvement of the intuitive decision (not documented in Table 5.2): TG2-TG1: $\chi^{2}=5.6, d f=1, p<.05$; TG2-CG: $\chi^{2}=4.2, d f=1$, $p<.05$. TG1 and the CG did not differ significantly. In conclusion, only the training group that was stimulated to conduct an initial task analysis as an aspect of self-regulated learning experienced a long-run increase in the test scores regarding the reflection of the decision-making processes of others.

\subsubsection{Intrinsic Motivation}

Table 5.3 presents the means and standard deviations of the four scales related to intrinsic motivation during the training programme. With regard to interest/enjoyment, perceived competence and pressure/tension, the groups did not differ significantly. However, the perceived choice during the training programme was significantly higher for TG2 compared with the 
CG $\left(t_{(242)}=2.63, p<.01, r=.17\right)$. Comparing TG1 to the CG and TG1 to TG2, no significant differences were found.

\section{Table 5.3}

Means and standard deviations of intrinsic motivation scales during the training programme (five-level Likert scale; 1-5)

Training group 1 Training group 2 Control group

\begin{tabular}{lcccccc}
\hline & $M$ & $(S D)$ & $M$ & $(S D)$ & $M$ & $(S D)$ \\
Interest / enjoyment & 2.91 & $(0.80)$ & 2.91 & $(0.81)$ & 2.95 & $(0.79)$ \\
Perceived competence & 3.36 & $(0.78)$ & 3.22 & $(0.82)$ & 3.26 & $(0.64)$ \\
Perceived choice & 3.62 & $(0.87)$ & 3.74 & $(0.86)$ & 3.45 & $(0.88)$ \\
Pressure / tension & 2.07 & $(0.86)$ & 2.26 & $(0.90)$ & 2.16 & $(0.81)$ \\
\hline
\end{tabular}

\subsection{Conclusions}

In this intervention study, it was investigated whether training in decisionmaking strategies fosters decision-making competence when resolving socio-scientific issues related to sustainable development. The results of the post-test and the follow-up test suggest that the strategic training enhanced the competence level. Considering the impact of the training programme on the students' own decision-making process, the significant difference in the follow-up test between each training group and the control group shows a satisfying result. The intervention triggered a development that could be identified three months later. However, in the short run, no increase in competence level could be found. While students from both training groups improved more frequently in weighting criteria than the control group, they stated fewer advantages and disadvantages. Thus, positive and negative effects of the training were cancelled out in the short 
term analysis. One possible explanation could be that the training programme unintentionally triggered the use of non-compensatory strategies, where fewer aspects must be considered compared with a full trade-off. Students applied three different strategies in the learning programme, but only the compensatory approach is considered to be appropriate in the questionnaire, as no knockout criteria exist in the presented contexts according to the framework of sustainable development. Because the use of non-compensatory strategies is cognitively less demanding, students may have used this strategy more frequently than a compensatory strategy, especially in the post-test, which was administered right after the possibly tiring training programme.

Looking at the reflection of the decision-making processes of others, a significant improvement from the pre-test to the post-test was shown for both training groups with regard to several items. However, turning to the follow-up test, the effects of the training could only be demonstrated with respect to the suggestions for the improvement of the presented intuitive decision. As the training programme did not specifically focus on such a reflection task, the observed short term enhancement is quite plausible.

For the second hypothesis, only some supporting evidence could be found, as the differences between the two training groups were not significant with regard to the decision-making scale and most of the items concerning the reflection of decision-making processes. However, the integration of a task analysis as a metadecision aid, which was based on the concept of self-regulated learning, had an additional effect on one aspect of the reflection: the quality of suggestions to improve intuitive decision-making processes. This effect could be identified three months after the intervention. The finding that the differences between the two training groups were not significant for most aspects of decision-making competence can be explained by a deficit in producing the newly acquired 
metacognitive strategy of conducting a task analysis or an inefficient use due to the very short duration of the intervention (Hasselhorn \& Gold, 2006).

Regarding the third hypothesis, supporting evidence was uncovered. The combination of the decision-making training and selfregulatory elements had a positive effect on the perceived level of choice, as compared with the control group. The analysis of the decision-making task and the deliberate and reflected selection of a strategy to tackle the task helped students perceive more control over their actions when resolving the issue. This aligns with the assumptions of the self-regulation framework by Zimmerman (2000) and the self-determination theory by Deci and Ryan $(1985,2002)$. Self-regulation of the learning process should lead to a perceived internal locus of causality of one's actions and thus a higher degree of perceived autonomy and self-determination. Consequently, experiencing autonomy is valuable because autonomy is a positive predictor of intrinsic motivation. Moreover, the perceived autonomy and self-determination when resolving socio-scientific issues are useful for citizenship education and environmental education from a normative viewpoint (Darner, 2009). In conclusion, the combined training that induces a higher level of self-determination is more beneficial.

One aspect worth further consideration is the reliability of the decision-making questionnaire. For the analysed decision-making scale, Cronbach's alpha has acceptable values as one type of decision-making task was presented: decisions in which all options are considered equally legitimate according to the framework of sustainable development. However, regarding the students' own decision, those who prioritised criteria according to their personal values did not necessarily state all of the advantages and disadvantages because their prioritisation already implied reasons for choosing or rejecting one specific option. Those students who did not prioritise the underlying criteria tended to explain 
their choice by offering more advantages and disadvantages. However, both aspects belong to the same construct from a theoretical perspective (Eggert \& Bögeholz, 2006). Regarding the reflection of the decisionmaking processes of other people, students needed to describe a wide range of different decision-making strategies. Furthermore, making suggestions for the improvement and the description of the presented decisions represents important aspects of the reflection regarding tasks with equally legitimate options. Owing to the heterogeneity of this second construct, which covers a wide range of facets, the internal consistency (Cronbach's alpha) of the reflection was moderate. Therefore, the data were analysed exclusively on the item level rather than on the scale level.

A limitation of the study is that it cannot determine whether the level of competence of any group increased from the pre-test to subsequent measurement times because different contexts were used in the questionnaire at different points in time. Only differences in competence level of the training groups relative to the control group could be described.

However, considering the conservative choice of a control group, which also dealt with the same decision-making tasks during the intervention, and the very short time of the learning programme, the overall effects are quite compelling. Furthermore, the self-regulatory decisionmaking training led to higher levels of perceived choice (autonomy) than a decision-making training without self-reflection. Altogether, it can be concluded that systematic training in decision-making strategies, combined with a task analysis as an element of self-regulated learning, may be a suitable approach to foster elaborate reasoning.

One implication for the use of decision-making strategies in science classes is that the inappropriate and hasty exclusion of options should be addressed by teachers. From a normative viewpoint, a non-compensatory 
strategy should only be applied if knockout criteria exist according to the sustainability framework. However, it would not be appropriate to use it in order to avoid the cognitively demanding compensatory strategies. One approach would be to reflect upon another person's decision, where options are precipitately excluded without explicitly reflecting on the framework of sustainable development. According to Ratcliffe and Grace (2003), evaluating the decisions of others enables students to identify the strengths and weaknesses of their own reasoning. In this way, knowledge about decision-making strategies can be combined with a reflection to enhance the decision-making competence level. This should be investigated in future studies.

In order to measure the effects of the use of decision-making strategies, students resolved the socio-scientific issues individually. The impact of integrating these strategies into group discussion processes should be examined in future research. To what extent do collective negotiations of knockout criteria or thresholds, which may lead to the elimination of options, affect the students' decision-making competence? Moreover, scholars should determine whether small group or whole class discussions about the fit of certain decision-making strategies and types of decision-making situations lead to a deeper understanding of the underlying decision-making processes and thus a long-term gain in decision-making competence. Collective decision-making and discourse in the field of socioscientific issues are crucial in today's world (Zeidler et al., 2005). A next step would be to examine how to integrate personal decision-making skills such as the reflected use of decision-making strategies with classroom discourse. 


\section{$6 \quad$ Identifying Non-sustainable Courses of Action - A Prerequisite for Decision-making in Education for Sustainable Development ${ }^{10}$}

\subsection{Abstract}

Students are faced with a multitude of decisions as consumers and in societal debates. Because of the scarcity of resources, the destruction of ecosystems and social injustice in a globalized world, it is vital that students identify non-sustainable courses of action when involved in decision-making. The application of decision-making strategies is one approach to enhancing the quality of decisions. Options that do not meet ecological, social or economic standards should be excluded using noncompensatory strategies, whereas other tasks may require a complete trade-off of all the evidence, following a compensatory approach. To enhance decision-making competence, a computer-based intervention study was conducted that focused on the use of decision-making strategies. While the results of the summative evaluation are reported by Gresch, Hasselhorn, \& Bögeholz (2011), in-depth analyses of processrelated data collected during the intervention are presented in this paper to reveal insights into the mechanisms of the intervention. The quality of upper high school students' $(N=120)$ metadecision skills when selecting a decision-making strategy was investigated using qualitative content analyses combined with inferential statistics. The results reveal that the students offered elaborate reflections on the sustainability of options.

10 Source: Gresch, H., \& Bögeholz, S. (2011). Detecting non-sustainable courses of action - A prerequisite for decision-making in education for sustainable development. Manuscript submitted for publication. 
However, the characteristics that were declared non-sustainable differed among the students because societal norms and personal values were intertwined. One implication for education for sustainable development is that students are capable of reflecting on decision-making tasks and on corresponding favorable decision-making strategies on a metadecision level. From these results, we offer suggestions for improving learning environments and constructing test instruments for decision-making competence.

Keywords: decision-making, education for sustainable development, socioscientific issues, societal norms, values

\subsection{Theoretical Framework}

\subsubsection{Education for Sustainable Development}

Within the last two decades, the global community has acknowledged the need to ensure sustainable development of the world to meet the "needs of the present without compromising the ability of future generations to meet their own needs" (WCED, 1987, p. 43). Environmental threats and increasing social injustice require thoughtful decisions and actions on both a political and an individual level. As a consequence, non-sustainable courses of action must be identified when deciding for a course of action. An international consensus on the characteristics of sustainable development was reached at the UN Conference on Environment and Development and in its final action plan, Agenda 21 (UNCED, 1992). However, these goals can only be reached through interdisciplinary approaches that integrate ecological, social and economic aspects (Bourn, 2005; Eilam \& Trop, 2011; Herremans \& Reid, 2002; Marcinkowski, 2010; Sauvé, 1996, 2005; Scott \& Gough, 2003; UNCED, 1992). One vital aspect of promoting sustainable development is education (UNCED, 
1992). Education should aim to foster societal development according to norms negotiated by the global community, i.e., the UN (de Haan et al., 2008). However, education in general, and science and environmental education in particular, should not promote a specific point of view or certain courses of action; instead, it should strengthen students' autonomy and empower them to make thoughtful decisions (Aikenhead, 1985; de Haan et al., 2008; Hodson, 2003; Hungerford, 2010; Jickling, 1992; McConnell, 1982; Pedretti, 2003; Ratcliffe \& Grace, 2003; Solomon \& Aikenhead, 1994).

Within the broader framework of STSE education, which embraces education for sustainable development (Pedretti, 2003), the quality of the students' decisions can be enhanced through dealing with socioscientific issues (Eggert \& Bögeholz, 2006; Eggert et al., 2010; Gresch et al., 2011; Pedretti, 2003; Ratcliffe \& Grace, 2003). Sadler (2004) defines these types of issues as complex, open-ended and contentious problems that lack simple and straightforward solutions. Moreover, scientific evidence, ethical implications and inherent values must be integrated to deal with socioscientific issues adequately (Aikenhead, 1985; Bögeholz \& Barkmann, 2003; Eggert \& Bögeholz, 2006; Kolstø, 2001; Ratcliffe \& Grace, 2003; Sadler, 2004; Sauvé, 2005; Zeidler et al., 2005). Consequently, decision-making regarding socioscientific issues has been incorporated into national standards worldwide (AAAS, 1993; KMK, 2005; NRC, 1996; QCA, 2004). Moreover, education for sustainable development as a field of socioscientific decision-making has been integrated into the national standards of many countries, including England and Germany (KMK, 2005; QCA, 2004).

\subsubsection{Decision-making Competence}

In the present study, decision-making competence refers to the ability to systematically evaluate possible courses of action in factually and ethically 
complex situations related to sustainable development and systematically decide on one final option. Moreover, students are expected to reflect on their own decision-making processes and those of others (Bögeholz, 2007; Bögeholz \& Barkmann, 2003; Eggert \& Bögeholz, 2006, 2010). This concept of decision-making competence is based on the general definition of competence as a domain-specific cognitive ability to solve specific problems (Hartig \& Klieme, 2006; cf. Weinert, 2001a, 2001b), which was proposed by the Organisation for Economic Co-operation and Development (OECD).

Several intervention studies in the field of science education have focused on improving the quality of students' decision-making processes (Eggert et al., 2010; Grace, 2009; Gresch et al., 2011; Jiménez-Aleixandre \& Pereiro-Muñoz, 2002; Ratcliffe, 1997; Roberts, Wilson \& Draney, 1997 (Science Education for Public Understanding Program (SEPUP)); Seethaler \& Linn, 2004; Siegel, 2006). In the science and sustainability curriculum that was part of SEPUP, Siegel (2006) successfully trained students to connect specific evidence to their arguments to make tradeoffs. Ratcliffe (1997) provided her students with a guideline to structure the decision-making process. Although the students considered this guideline helpful, they did not weigh the advantages and disadvantages of their options in a systematic way. Using this guideline in small-group discussions about biological conservation issues, Grace (2009) found that the students' level of personal reasoning could be improved within a short time. In the field of education for sustainable development, Eggert et al. (2010) trained students in cooperative learning settings to trade off several courses of action. A general increase in decision-making competence was found, although additional metadecision training in a second training group did not further improve the students' decision-making processes. 
Although several interventions have been conducted to enhance students' decision-making processes, no study has examined whether reflectively applying several decision-making strategies fosters decisionmaking competence. Because such strategies seem promising for structuring the decision-making process, they were chosen for the present study.

\subsubsection{Decision-making Strategies}

Different decision-making tasks related to sustainable development require different decision-making strategies to evaluate possible courses of action because some decisions involve non-sustainable and, thus, unacceptable options with regard to ecological, social or economic standards while others may demand a full trade-off of all evidence.

Behavioral decision research aims to describe the strategies people use to make a decision. In certain decision-making situations, decisionmakers exclude options if one or several characteristics do not reach the required standards. Some criteria may be considered knockout criteria, for which unacceptable characteristics cannot be outweighed by other attributes. Jungermann et al. (2005) and Payne et al. (1998) describe this choice rule as a non-compensatory strategy. One example is the elimination-by-aspects rule (Tversky, 1972). If the characteristics of the most important criteria do not reach the threshold level to fulfill the required standards, the options are eliminated. For other decisions, the decision-maker may weigh all available information before reaching a conclusion. Hence, in this compensatory strategy, all advantages and disadvantages are evaluated in a full trade-off (Jungermann et al., 2005; Payne et al., 1998).

Beach (1990) and Beach and Mitchell (1978) state that decisionmaking frequently involves both compensatory and non-compensatory approaches. During a screening phase, unacceptable options are 
eliminated in the first step, and the remaining options are compared in a full trade-off (mixed strategy).

\subsubsection{Metadecision and Self-regulated Learning}

The application of a decision-making strategy is a cognitive process, whereas the selection of a decision-making strategy requires metacognitive skills to determine which strategy fits best. Beach (1990) refers to this concept as metadecision, which involves considering the features of a decision-making problem, the environment of the decision and the characteristics of the decision-maker. From a normative, educational perspective, students should be enabled to detect nonsustainable options based on societal norms regarding the framework of sustainable development and apply a non-compensatory strategy to such tasks. On the other hand, students should also be capable of identifying decision-making situations with equally legitimate options (i.e., options without knockout criteria based on societal norms) and employing a compensatory strategy (Eggert \& Bögeholz, 2006; Gresch et al., 2011). Consequently, science and environmental education should foster the ability to distinguish between different types of decision-making situations to apply an appropriate decision-making strategy.

Zimmerman's model of self-regulated learning provides a suitable framework to foster these metadecision skills because it integrates cognitive, metacognitive and motivational aspects to describe how selfregulated learners deal with new tasks (Zimmerman, 2000). Before beginning a task, learners should analyze the task in the forethought phase to select an appropriate strategy; they should observe and control the procedure during the performance phase; and finally, they should selfreflect on their own performance and draw conclusions for future tasks in the reflection phase. 
To resolve socioscientific issues related to sustainable development, these concepts of metadecision and self-regulated learning can be combined to construct a training program that focuses on the reflective application of decision-making strategies (Gresch et al., 2011). In the forethought phase, the learner analyzes the decision-making task in terms of the sustainability of the options. Can the benefits and drawbacks of different options be compensated for, or should a non-compensatory strategy be applied to exclude non-sustainable options if knockout criteria exist based on societal norms? Do the task's characteristics require a combination of both strategies? In this metadecision activity, a decisionmaking strategy should be selected. During the performance phase, the learner observes the correct application of the strategy and, finally, reflects on the outcome and whether the decision-making strategy was appropriate for the presented task.

\subsubsection{Review of the Summative Evaluation of the Presented Intervention Study}

To investigate the effects of a reflected use of decision-making strategies on decision-making competence, a computer-based intervention study was conducted. Two distinct perspectives were selected to describe the outcomes and mechanisms of the intervention: a summative evaluation to demonstrate the effects using a pre-post-follow-up control-group design and an in-depth analysis of qualitative data collected during the intervention. This paper focuses on the analyses of process-related data, and therefore, the results of the summative evaluation reported by Gresch et al. (2011) will only be reviewed briefly.

The participating students were randomly assigned to one of two training groups (training in decision-making strategies with/without task analyses as elements of self-regulated learning) and a control group (see below for details). To determine the effects of the intervention, decision-making 
competence was assessed at three measurement times using an openended questionnaire developed by Eggert and Bögeholz (2010). The analyses revealed that the quality of the students' decisions on the followup test administered three months after the intervention were significantly more elaborate in the training groups compared to the control group. However, the students who received a strategic training tended to overuse non-compensatory strategies in the post-test. Further analyses showed that their ability to reflect on the decision-making processes of others improved between the pre- and post-tests. The long-term effects on reflection were less evident.

\subsection{Research Questions}

Although the summative evaluation of the intervention has shown promising results with regard to gains in decision-making competence, it is still unclear in which way students who are familiar with different decisionmaking strategies use metadecision skills to transfer these strategies to new tasks by selecting a strategy suitable for the given task. Moreover, the mechanisms of the intervention study should be investigated by looking at the processes that take place in the course of the training. The qualitative data collected during the intervention are considered valuable for this purpose.

First, it is essential to investigate the explanations for selecting a decision-making strategy as one central aspect of metadecision and to determine the quality of these explanations. Hence, the first research question is as follows:

1.1. How do students explain their use of different decision-making strategies?

Categories of explanations are generated, and levels of quality are described. These quality levels of the explanations should be validated. 
From a theoretical point of view, the level of explanations for selecting a decision-making strategy should be related to decision-making competence. Hence, we expect that students with higher levels of explanations also yield higher scores in the decision-making questionnaire administered before the training (Gresch et al., 2011; cf. Eggert \& Bögeholz, 2010). Consequently, the next research question is as follows:

1.2. Are the quality levels of the explanations valid? In which ways are they related to decision-making competence?

From these levels of metadecision explanations, inferences should be made about the students' performance in the transfer phase of the decision-making training and the quality of the learning tasks used to train the students to deal systematically with socioscientific issues.

The construction of the learning environment was based on one premise: The characteristics of the task should induce the selection of one specific decision-making strategy (Eggert \& Bögeholz, 2006; Gresch et al., 2011). Options that were unacceptable in terms of the societal norms stated in the sustainable development framework should be detected and excluded using a non-compensatory or mixed strategy, whereas equally legitimate options should be compared in a full trade-off. Hence, the next research question is as follows:

2.1 To what extent did the students select the decision-making strategies that best fit the decision-making tasks according to societal norms?

The next step was to unravel whether selecting the best-fitting strategy depends on the student's metadecision performance. Regarding the fit of a decision-making task with one specific strategy, we supposed that those students who selected the expected strategy had conducted a thorough task analysis, whereas those who chose a different strategy conducted superficial task analyses: 
2.2 Did those students who selected the strategy that fits best according to societal norms elaborate more on explanations than those who selected a different strategy?

The results of the summative assessment showed that the students who were familiar with the application of decision-making strategies tended to overuse the non-compensatory strategy during the post-test administration of the decision-making questionnaire $\left(F_{(373,2)}=2.51, p<.10, \eta^{2}=.013\right)^{11}$. In another study in science education, Hong and Chang (2004) found that students most frequently applied the non-compensatory strategy. They suggested that the non-compensatory strategy was chosen because it is less cognitively demanding; i.e., it allows the user to consider less evidence compared with a complete trade-off. Therefore, the next research focus is as follows:

2.3 Is the use of the non-compensatory decision-making strategy associated with a lower cognitive load?

\subsection{Intervention Study on Decision-making Strategies}

In the computer-based intervention, which consists of two 45-minute sessions, students resolved different socioscientific issues pertaining to sustainable development (Gresch et al., 2011). All students were assigned to one of two training groups or the control group when they began the program.

In the first session, all students were introduced to one crucial principle of sustainable development: the interrelatedness of ecological,

\footnotetext{
${ }^{11}$ ANCOVA of post-test scores (number of considered advantages and disadvantages for chosen and rejected options; see Gresch et al. (2011) for detailed scoring rubric; pretest scores as covariate), including both training groups and the control group.
} 
social and economic facets. Subsequently, the students were confronted with three decision-making tasks, which the students in the training groups solved by applying a non-compensatory, a compensatory and a mixed strategy. Each context was selected and modified to match one of the three strategies (see Table 6.1). The central features of the strategy and the way to apply it were introduced. The control group received additional ecological information instead of strategic training.

In the second session, which took place within a week of the first session, the students in the training groups were asked to select the strategy they considered to fit best by taking the framework of sustainable development into account. The first training group selected the strategy directly, whereas the second training group had to conduct a prior task analysis and explain why they considered this strategy to fit best. They were encouraged to reflect on whether knockout criteria based on societal norms were inherent in the given task. The control group again was given additional information instead of strategic training, as in the first session. 
Table 6.1

Structure of the training program: Contexts chosen to demonstrate the decision-making strategies

Context Features: Do knockout criteria exist according to societal norms?

Decision-making strategy that fits best according to societal norms

\section{Session 1}

Task 1 Choice of different measures for the protection of coral reefs

Several knockout criteria (effect on ecosystem, impact on local society, financial constraints)

Non-compensatory strategy

Task 2 Land-use decision after brown coal No knockout criteria (equally legitimate options) mining

Task 3 Choice of an aquaculture site ${ }^{a}$

One knockout criterion (poor conditions for fish in Mixed strategy aquaculture)

Session 2

Task 1 Selection of apples for the school cafeteria $^{\mathrm{b}}$

Task 2 Choice of a production site for a shipyard $^{\mathrm{c}}$

No knockout criteria (equally legitimate options)

One knockout criterion (state of the limnological ecosystem)

Several knockout criteria (wood from primeval forests, working conditions, length of transportation route)

\section{Compensatory strategy}

\section{Compensatory strategy}

Mixed strategy

Non-compensatory strategy

Task 3 Consumer decision to purchase a bed

Note. Based on Gresch et al. (2011). The indicated decision-making strategies represent the strategies that fit best according to societal norms.

${ }^{\mathrm{a}} \mathrm{cf}$. Bayer et al., 2008. ${ }^{\mathrm{b}} \mathrm{cf}$. Barfod-Werner et al., 2008. ${ }^{\mathrm{c}} \mathrm{cf}$. Mühlenhoff, 2009. 
All contexts were chosen and designed so that one strategy fit best in terms of the societal norms of the framework of sustainable development (see Table 6.1). The features of all courses of action were discussed with the research group and optimized in several consecutive steps to improve the strategy's fit with the decision-making task. The presentation of the contexts included short descriptions of the decisionmaking situation and each option, followed a table containing an overview of all the options' characteristics. In each task, three or four options were presented with regard to four or five criteria.

1. Example for the compensatory decision-making strategy: Apples for the school cafeteria: The first context of the second session was a consumer decision. The students were asked to select one variety of apples that should be sold in the school's cafeteria (cf. Barfod-Werner et al., 2008). Characteristics such as the price (1.80 to 2.49 Euro/kg), the taste (sweet, slightly sour, juicy), the length of the transportation route (short to intermediate; all within Europe) and whether the apples were organically grown were presented.

Because all these features were considered acceptable according to the normative framework of sustainable development, the compensatory strategy was expected to provide the best fit by allowing a complete tradeoff between all advantages and disadvantages.

2. Example for the mixed decision-making strategy: Shipyard production site: In the second decision-making task, possible production sites of a shipyard had to be examined from a political point of view (cf. Mühlenhoff, 2009). One option would have a strong negative impact on the quality of the adjacent river; hence, these effects on the limnological ecosystem are considered unacceptable in terms of ecological standards. To pursue this course of action, the river would have to be dammed to launch the container ships safely. Consequently, the water temperature 
would increase in the summer and the oxygen concentration would fall below a level that could support animal life, e.g., endangered fish species. Furthermore, the implications for the workforce in a region with high unemployment rates and the productivity of the enterprise had to be taken into account.

Thus, one option had unacceptable characteristics based on societal norms (ecological standards), whereas the features of the remaining options should be compared in a full trade-off. Hence, the mixed strategy was expected to fit best.

3. Example for the non-compensatory decision-making strategy: Purchase of a bed: In this task, four beds for the student's new apartment after he or she left school were presented as options. Upon closer examination, most of the beds either consisted of wood from primeval forests, in which endangered animal species such as the Siberian tiger live, or were built in regions with extremely low wages, where social standards are nearly non-existent. Moreover, disproportionately long transportation routes were necessary to deliver one bed from Indonesia across the globe to Europe.

Hence, several knockout criteria based on societal norms were apparent (wood from primeval forests, working conditions, long transportation), which would suggest the use of the elimination-by-aspects rule as one example of a non-compensatory strategy.

\section{$6.5 \quad$ Methods}

\subsubsection{Sample}

A total of 386 students from 25 biology classes (Grades 11 to 13) in Northern Germany participated in the entire intervention and were randomly assigned to one of two training groups or a control group (training group 1: $n=126$; training group $2: n=137$; control group: $n=$ 
123). For 120 students in the second training group, who conducted an initial task analysis before selecting a decision-making strategy, complete process-related data sets with explanations for their decision-making strategy selection are available. The mean age of this subsample was 17.3 years, and $58 \%$ were girls.

For research questions 1.1, 1.2 and 2.2 process-related data from training group 2 is used as only this group reported explanations regarding the selection of a decision-making strategy. For research questions 2.1 and 2.3 data from both training groups is analyzed.

\subsubsection{Recollection of Data and Data Analysis}

The metadecision statements for the task analysis were entered online by the students in the second training group during the second session of the computer-based intervention. After each of the three decision-making situations was presented, the students were asked to respond to the following:

Note in bullet points the task characteristics that provide information about which decision-making strategy best fits this situation. Explain briefly why these task characteristics make one decision-making strategy particularly appropriate. Finally, click on a button to select the strategy that you consider to fit best to this task.

The data were imported using software for qualitative content analyses (MAXQDA, 2007) and coded using a deductive-inductive approach (Mayring, 2008). In the first step, categories were derived from behavioral decision-making research (Eggert \& Bögeholz, 2006; Jungermann et al., 2004; Payne et al, 1998). Next, sub-categories and different quality levels were developed according to the data to further differentiate between different types of responses. For each sub-category, examples (anchors) and definitions were generated. 
A second rater coded all text passages to further refine the categories and sub-categories, the selection of examples and the definitions. All data were then independently coded by the two raters based on this final scoring rubric. The interrater reliability (Cohen's kappa; percentage of agreement) was good: $k=.72(94 \%)$. In a final step, all differing scores were discussed to reach a consensus before the statistical analyses were performed.

To determine the validity of the quality levels of the explanations (see research question 1.2), the pre-test scores of the decision-making questionnaire were used. This test was administered directly before the intervention.

Moreover, data regarding the frequencies of the selected decisionmaking strategies were collected in the course of the intervention.

\subsubsection{Assessment of Cognitive Load}

Cognitive load is a concept that consists of two aspects: mental load, which is induced by the task structure and other instructional parameters, and mental effort, i.e., the capacity that a person allocates to the task (Paas, 1992). The higher the mental load of a task, i.e., the more difficult it is, the more mental effort it requires. Consequently, an assessment of mental effort offers information about the difficulty of the instructions and the task. In other studies, mental effort has been assessed effectively in problem-solving tasks and computer-based trainings (Paas, 1992; Paas \& van Merriënboer, 1994) to provide insights about the quality of different instructions. Consequently, instructions should have a medium level of cognitive load to be efficient. In the present study, the cognitive load construct is used to determine which decision-making strategy requires more mental effort and, consequently, produces more cognitive load. After each task of the learning program, the students were asked to self-report 
the level of mental effort expended during the preceding task on a symmetrical seven-level Likert scale $(-3 /+3)$.

\subsection{Results}

Research question 1.1: How do the students explain their use of different decision-making strategies?

In the qualitative content analysis, all students' responses were assigned to two major categories: explanations for the use of parts of a compensatory and a non-compensatory strategy. Because the mixed strategy is a combination of both, explanations were scored separately for each component. Furthermore, we distinguished between three levels of explanations. At the lowest level (Score: 0), the students made no reference to the strategy they selected. At a basic level (Score: 1), the students explained their selection in terms of strategic considerations; however, this explanation was not linked to specific task characteristics. At the highest level (Score: 2), the students based their decision-making strategy selection on both strategic aspects and task characteristics. Both aspects were clearly linked.

At the lowest level (Score: 0), the students did not refer to strategic aspects. Instead, they merely described the presented options, chose one course of action without reference to the decision-making strategy or stated which criteria they considered important. Because the students had been asked to explain which decision-making strategy would be most appropriate to resolve the issue and, hence, to provide metadecision statements, these types of responses were coded with score of 0 :

"I decide for the 380 Euro bed from Finland because it seems best to me. Furthermore, it is made from birch wood and is hence from nature." (Task 3, purchase of a bed; UserID 429) 
"For such a topic, the compensatory strategy is best." (Task 2, shipyard production site; UserID 465)

"Mixed strategy: I'll take Granny Smith." (Task 1, apples for the school cafeteria; UserID 468)

"It's important to preserve jobs!" (Task 2, shipyard production site; UserID 531)

For the more elaborate responses (Scores 1 and 2), subcategories were developed and refined using an inductive approach, according to the investigated data (see Table 6.2): 
Table 6.2

Scoring rubric with anchor examples: Explanations for the selection of a decision-making strategy

Score 1:

Reference to strategic aspects.

\section{Score 2:}

Reference to the interrelation between strategic aspects and specific task characteristics.

\section{Compensatory strategy}

Subcategory 1:

Trade-off possible
"If you compare the different varieties of apples, you cannot identify a severe disadvantage for any variety, which would suggest the non-compensatory strategy. Therefore, I would choose the compensatory decision-making strategy in this case." (Task 1, apples for the school cafeteria; UserID 480)

"Compensatory decision-making strategy because you can weigh up advantages and disadvantages. There are no knockout criteria." (Task 3, purchase of a bed; UserID 093)

Subcategory 2: "Compensatory (strategy), because I consider no criterion to be so important that it could not Value hierarchy: be compensated for." (Task 3, purchase of a Equal weights for bed; UserID 549) all criteria
"I don't think that a non-compensatory decisionmaking strategy would be the right solution here, as there are no severe disadvantages (the prices are similar; all (apples) are sweet or juicy)." (Task 1 , apples for the school cafeteria; UserID 231)

"I decide to take the compensatory strategy here because I think that every disadvantage of a bed can potentially be compensated for. A high price, for example, with environmentally friendly production and good appearance; a moderate look with a low price; and so on." (Task 3, purchase of a bed; UserID 105)

"In this task, several factors can generally be compensated for, because taste as well as price and organic farming are important factors that all have to be taken into account." (Task 1, apples for the school cafeteria; UserID 255) 


\begin{tabular}{|c|c|c|}
\hline \multicolumn{3}{|c|}{ Non-compensatory strategy } \\
\hline $\begin{array}{l}\text { Subcategory 1: } \\
\text { Trade-off not } \\
\text { possible }\end{array}$ & $\begin{array}{l}\text { "Several knockout criteria exist." (Task } 2 \text {, } \\
\text { shipyard production site; UserID 042) } \\
\text { "Non-compensatory (strategy) because the } \\
\text { severe disadvantages cannot be compensated } \\
\text { for by the advantages." (Task 3, purchase of a } \\
\text { bed; UserID 216) }\end{array}$ & $\begin{array}{l}\text { "Because the school has a role model function and } \\
\text { should place value on offering local products, the } \\
\text { transportation route should be a knockout } \\
\text { criterion." (Task 1, apples for the school cafeteria; } \\
\text { UserID 390) } \\
\text { "In this decision-making task, I consider the non- } \\
\text { compensatory decision-making strategy to be most } \\
\text { suitable because knockout criteria exist. } \\
\text { Permanent damage to the river cannot be } \\
\text { compensated for through advantages but must be } \\
\text { prevented." (Task 2, shipyard production site; } \\
\text { UserlD 093) }\end{array}$ \\
\hline $\begin{array}{l}\text { Subcategory 2: } \\
\text { Value hierarchy: } \\
\text { Important criteria } \\
\text { as knockout } \\
\text { criteria }\end{array}$ & $\begin{array}{l}\text { "The non-compensatory decision-making } \\
\text { strategy would be appropriate, as the most } \\
\text { important criteria should be observed. A } \\
\text { compensation would not be reasonable." (Task } \\
1 \text {, apples for the school cafeteria; UserID 540) }\end{array}$ & $\begin{array}{l}\text { "The deterioration of the water quality is very } \\
\text { important and should have top priority. It would not } \\
\text { be reasonable to compensate for this." (Task } 2, \\
\text { shipyard production site; UserID 540) }\end{array}$ \\
\hline
\end{tabular}


The explanations for compensatory and non-compensatory decision-making showed two clear patterns in each category. In the first subcategory, which was the most frequently occurring one (see Table 6.3), the students' responses referred to whether a full trade-off was necessary and/or whether knockout criteria existed in the decision-making situation. At Level 1 (Score: 1), only a general statement was made about whether the task permitted a trade-off, whereas at level 2 (Score: 2 ) it was explicitly stated, between which criteria of the decision-making situation a trade-off was possible, or which criteria were considered knockout criteria. In the second subcategory, the students explained their decision-making strategy selection by stating that the relevance of the task criteria influenced their selection. Regarding non-compensatory decision-making, the students identified as knockout criteria those factors they considered important; hence, they referred to a hierarchy of values. On the other hand, those students who considered all criteria equally important tended to use compensatory strategies to weigh all available evidence. While this occurred at a general level for responses scored 1, responses that identified specific criteria that were important or equally important and linked these to the strategic considerations yielded scores of 2. On average across all three contexts, more than $10 \%$ (sum of responses scored 1 and 2) of the students explained their choice of a decisionmaking strategy by referring to a hierarchy of values (see Table 6.3). 
Table 6.3

Relative frequencies of the categories and subcategories of explanations for the selection of a decision-making strategy

\begin{tabular}{ll}
\hline Score 1: & Score 2: \\
Reference to & Reference to the \\
strategic aspects. & interrelation between \\
& strategic aspects and \\
& specific task \\
& characteristics. \\
\hline
\end{tabular}

Compensatory decision-making

Trade-off possible ${ }^{a}$

$48.7 \%$

$10.2 \%$

Value hierarchy: Equal

$8.4 \%$

$3.1 \%$

weights for all criteria. ${ }^{a}$

Non-compensatory decision-making

No trade-off possible ${ }^{\mathrm{b}}$

$25.9 \%$

$36.8 \%$

Value hierarchy. Important

$0.9 \%$

$9.8 \%$

criteria as knockout criteria. ${ }^{b}$

Note. All values are the mean percentages of the three contexts for Session 2.

${ }^{\text {a }}$ Percentage of those who selected the compensatory strategy.

${ }^{\mathrm{b}}$ Percentage of those who selected the non-compensatory strategy.

Other subcategories had lower frequencies. Some students explained their choice of a strategy by referring to the differences between single attributes inherent in the decision-making situation. Students justified selecting the compensatory strategy by stating that the differences between the characteristics of two options were rather small $(6.4 \%$ of those who selected the compensatory strategy responded this way): 
"I choose the compensatory decision-making strategy because the price difference is not too big, and the rest should be weighed up." (Task 1, apples for the school cafeteria; UserID 621)

On the other hand, students reported selecting the non-compensatory strategy because of perceived large differences between different options (1.8 \% of those who selected the non-compensatory strategy made statements to this effect):

"The differing prices are particularly conspicuous and could result in an exclusion principle." (Task 1, apples for the school cafeteria; UserID 261)

The students presented explicit thresholds justifying the use of a noncompensatory strategy only in regard to financial criteria. A few students stated that options that were unacceptable in financial terms should be excluded.

"First, the price is important, because only 400 Euros are at my disposal. Higher prices can be excluded." (Task 3, purchase of a bed)

For other criteria, no ecological or social standards were stated as a threshold.

Research question 1.2: Are the quality levels of the explanations valid? In which way are they related to decision-making competence?

To validate the quality levels of the explanations, a total score was calculated, indicating the overall performance in the explanations of the selected decision-making strategies. The scores of each task were added, and the median score was used to divide the students into one group with 
high-quality explanations and another with low-quality explanations. Furthermore, the median of the decision-making questionnaire scores (Eggert \& Bögeholz, 2010) was determined ${ }^{12}$, and the students were divided into those who showed a high level of decision-making competence and those with a lower level. Chi-square analyses revealed that the students who had higher-quality explanations also reached a higher level of decision-making competence, according to the questionnaire: $\chi^{2}=5.6, d f=1, p<.05$. Hence, the level of explanations and decision-making competence are connected. This connection supports the validity of the identified quality levels.

Research question 2.1: To what extent did the students select the decision-making strategies that best fit the decision-making tasks according to societal norms?

Figure 6.1 shows the relative frequencies of the selected strategies. Generally, the a priori expected decision-making strategy was the one most frequently chosen by the students in the training groups: $43 \%$ selected the compensatory strategy for Task 1 (apples for the school cafeteria). For Task 2 (shipyard production site), $39 \%$ selected the mixed strategy, which was only the second-most selected strategy. A total of 55 $\%$ selected the non-compensatory strategy for Task 3 (purchase of a bed). Although a large proportion of the students chose a strategy other than the one we expected, most students were able to detect options that were

\footnotetext{
${ }^{12}$ The decision-making questionnaire developed by Eggert and Bögeholz (2010) consists of two scales based on the student's own decision and his/her reflection on decisions of other people. A total score was calculated for this study by weighting each scale with 50 $\%$. For the analyses, the pre-test scores from the intervention study (Gresch et al., 2011) were chosen.
} 
non-sustainable based on societal norms. For the second and third tasks, approximately $80 \%$ selected the non-compensatory or mixed strategy and, hence, identified at least one knockout criterion presented in the decision-making task. However, for the first task, in which a full trade-off with a compensatory strategy was expected to fit best, many students excluded options based on personal values.
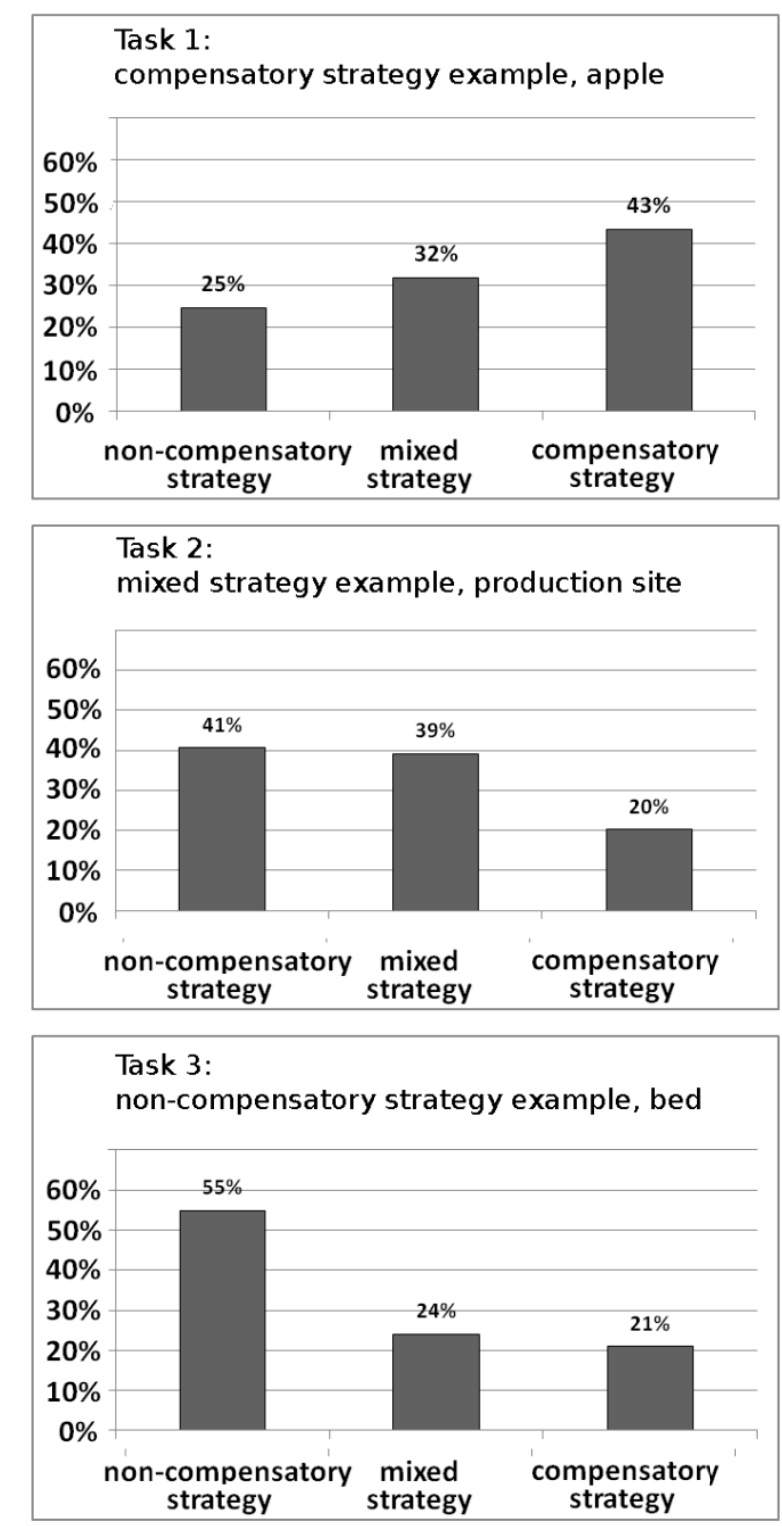

Figure 6.1. Decision-making strategies selected in the learning program by the students in both training groups $(n=263)$. 
Research question 2.2: Did those students who selected the strategy that fits best, according to societal norms, elaborate more on their explanations than those who selected a different strategy?

Table 6.4

Expected and observed patterns for the quality of metadecision explanations according to different selected decision-making strategies

\begin{tabular}{lll}
\hline Selected strategy & $\begin{array}{l}\text { Expected } \\
\text { pattern }\end{array}$ & $\begin{array}{l}\text { Observed } \\
\text { pattern }\end{array}$ \\
\hline & Score 1 Score 2 & Score 1 Score 2 \\
\cline { 2 - 3 } & &
\end{tabular}

Task 1: Compensatory strategy example:

Apple selection

Compensatory strategy

Non-compensatory strategy

Task 2: Mixed strategy example:

Shipyard production site

Compensatory strategy

Non-compensatory strategy

Task 3: Non-compensatory strategy example:

Purchase of a bed

Compensatory strategy

Non-compensatory strategy

$\begin{array}{llll}- & + & + & - \\ + & - & - & +\end{array}$

Note. +: significantly higher frequency than in random distribution; -: significantly lower frequency than in random distribution. o: random distribution (no significant differences); see Figure 6.2 for observed scores. 


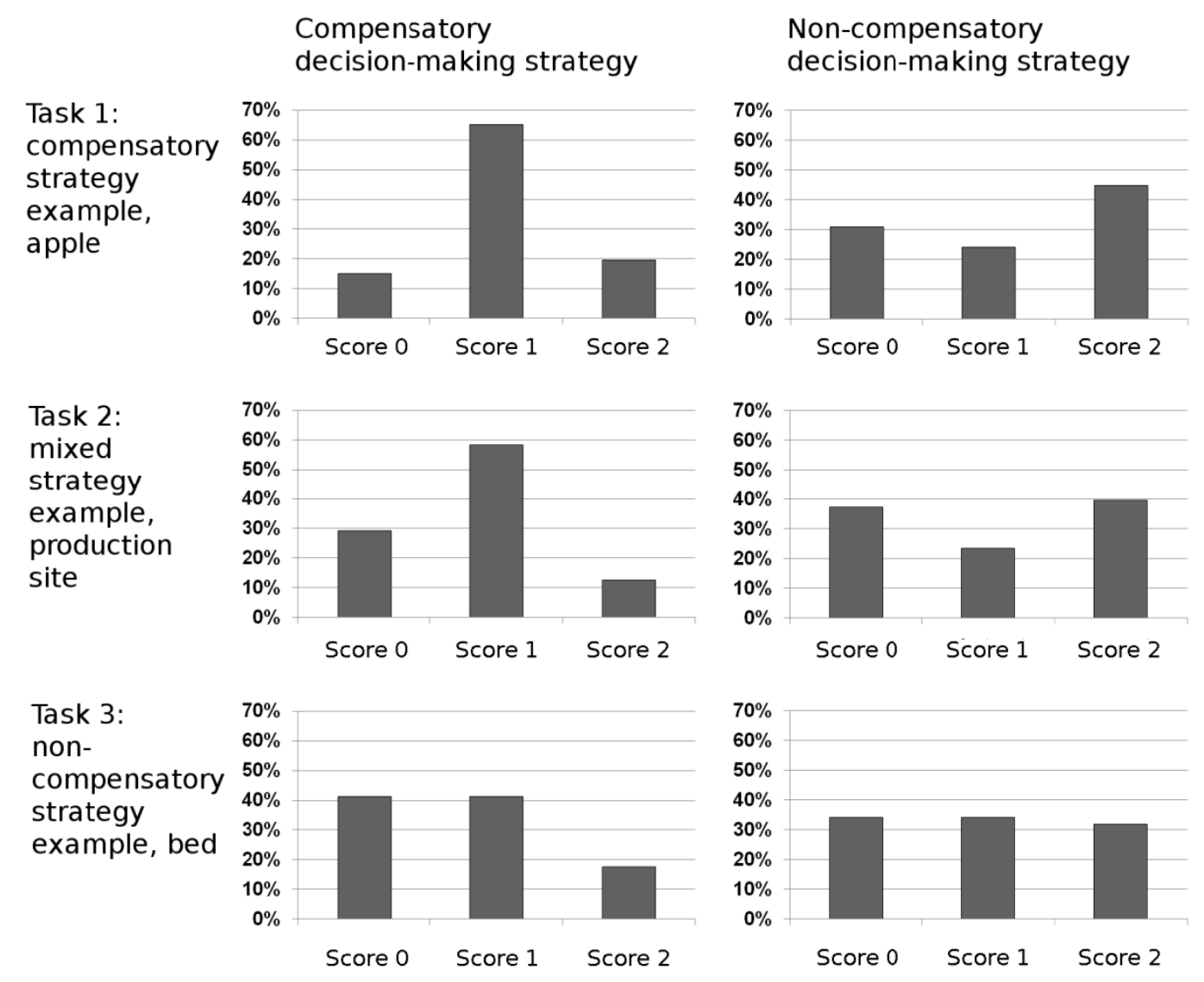

Figure 6.2. Decision-making strategies selected in the learning program by the students in both training groups $(n=263)$.

Figure 6.2 shows the relative frequencies of the different levels of explanations among those who chose a compensatory strategy and those who applied a non-compensatory strategy. Contrary to our expectations, the level of the explanation was not higher for those students who selected the strategy that fits best according to societal norms (see Table 6.4 for a schematic overview of the expected and observed results). Instead, these data demonstrate that the levels of the students' explanations show a similar pattern for each context, regardless of the decision-making strategy that the research group assumed would fit best according to the characteristics of the task. The students' explanations of why they would 
use a compensatory decision-making strategy were more frequently made on a purely strategic level (Score: 1), whereas the explanations regarding non-compensatory aspects were based on strategic considerations linked to specific task characteristics (Score: 2). 2x2 (Score 1 versus Score 2; selection of a compensatory versus a non-compensatory strategy) chisquare analyses were conducted to analyze whether this difference was statistically significant (see Table 6.4). For the first task (the compensatory decision-making strategy example, apples for the school cafeteria), it could be shown that the students who selected the compensatory strategy provided explanations at a basic level (Score: 1), whereas those who selected the non-compensatory strategy provided higher-level explanations (Score: 2): $\chi^{2}=9.9, d f=1, p<.01$. For Task 2 (the mixed strategy example, shipyard production site), the pattern was similar: $\chi^{2}=8.6, d f=1, p<.01$. For the third task (the non-compensatory strategy example, purchase of a bed), however, the students who chose the compensatory strategy offered fewer strategic explanations in general, whereas those who selected a non-compensatory strategy offered Level 1 explanations more often than in the preceding tasks. Thus, no differences in the level of explanation could be found between the students who applied a compensatory strategy in Task 3 and those who selected a noncompensatory strategy: $\chi^{2}=1.0, d f=1, p>.05$ ).

These analyses reveal that in the first two tasks, the pattern of responses was quite similar, even though different strategies were expected to fit best according to societal norms (the compensatory strategy in the first task and the mixed strategy in the second task). The third task presented a comparable pattern, although the level of the explanation was generally lower than in the preceding tasks: it included more statements that did not refer to the selection of a strategy, and more explanations were made on a basic level than the higher level, at which strategic considerations were linked to specific task characteristics. Hence, 
the hypothesis that those students who selected the a priori expected strategy would also offer higher-level explanations for their selection had to be rejected.

Research question 2.3: Is the use of the non-compensatory decisionmaking strategy associated with lower cognitive load?

To investigate this research question, three types of results were examined. First, verbal data from the students' explanations about their selection of a decision-making strategy were considered. Second, analyses of the levels of explanations were conducted to examine whether the proportion of students who did not provide an elaborate explanation for their strategy choice (Score: 0 ) was higher for those who used a noncompensatory strategy than for those who used a compensatory approach. Third, we tested whether the application of non-compensatory strategies caused less cognitive load than the application of compensatory strategies and, hence, is less complex.

Some students justified selecting the non-compensatory strategy by stating that this would be the easiest and fastest way to reach a decision because of the reduced number of options to consider:

"I have chosen the non-compensatory strategy because it works faster than the mixed strategy and, thus, comes faster to a conclusion." (Task 1, apples for the school cafeteria; User ID 594)

However, only $3 \%$ of the students per task explained their strategy selection by referring explicitly to reduced complexity.

Across all three tasks, the average percentage of the students who used a compensatory strategy but did not provide an explanation for doing so (Score: 0 ) was $28.5 \%$, whereas the average percentage of students with a 0 score was higher among those who applied a non-compensatory 
strategy (34.1\%; cf. Figure 6.2 for the relative frequencies separately for each task). However, this difference was not significant. Chi-square analyses were conducted separately for each task, contrasting inadequate explanations (Score: 0) with adequate explanations (Score: 1 or 2) differentiated according to whether the compensatory or the noncompensatory strategy was chosen. As a result, a score of 0 was not significantly more frequent for those who used the non-compensatory strategy than those who used the compensatory strategy for any of the tasks.

In addition, we investigated whether the use of non-compensatory strategies was related to low cognitive load. Therefore, the mean selfreported cognitive load values, which were measured after each task during the learning program, are reported in Table 6.5. The results of $t$ tests revealed that in the first two tasks, the perceived cognitive load did not differ according to the strategy applied. In the third task, however, the students who selected the non-compensatory strategy perceived significantly less cognitive load than the students who chose the compensatory strategy $\left(t_{(143)}=-2.30, p<.05, d=.42, r=.19\right)^{13}$.

\footnotetext{
${ }^{13}$ Both effect sizes Cohen's $d$ and $r$ are presented. Because the sample sizes differ $\left(n_{\text {comp }}=40 ; n_{\text {non-comp }}=105\right.$, see Table 5$), r$ is more adequate. The values can be converted:$$
r=\frac{d}{\sqrt{d^{2}+\frac{(n 1+n 2)^{2}}{n 1 n 2}}}
$$ 
Table 6.5

Self-reported cognitive load after applying the decision-making strategy (means and standard deviations; seven-level Likert scale; -3/+3)

\begin{tabular}{lccccccc}
\hline & \multicolumn{3}{c}{$\begin{array}{c}\text { Compensatory } \\
\text { strategy selected }\end{array}$} & \multicolumn{3}{c}{$\begin{array}{c}\text { Non-compensatory } \\
\text { strategy selected }\end{array}$} \\
\hline & $M$ & $(S D)$ & $n$ & & (SD) & $n$ \\
$\begin{array}{l}\text { Task 1 (Compensatory } \\
\text { strategy example: apples) }\end{array}$ & -0.16 & $(1.52)$ & 101 & -0.04 & $(1.75)$ & 57 \\
$\begin{array}{l}\text { Task 2 (Mixed strategy } \\
\text { example: production site) }\end{array}$ & 0.27 & $(1.39)$ & 45 & & -0.10 & $(1.64)$ & 90 \\
$\begin{array}{l}\text { Task 3 (Non-compensatory } \\
\text { strategy example: bed) }\end{array}$ & 0.00 & $(1.78)$ & 40 & & -0.74 & $(1.72)$ & 105 \\
\hline
\end{tabular}

\subsection{Summary and Conclusions}

In this study, we investigated how students made decisions on socioscientific issues pertaining to sustainable development in a computerbased training. The design of the intervention aimed to enable students to differentiate between sustainable and non-sustainable options through training that focused on the reflective application of three decision-making strategies. In a transfer phase, the students had to use metadecision skills to select an appropriate strategy for resolving the socioscientific issue based on the characteristics of the decision-making situation. Such analysis required considering the following questions: Does the issue involve options that are non-sustainable and thus, in terms of societal norms, unacceptable, and that should be excluded by using a noncompensatory strategy, or can benefits and drawbacks generally be compensated for in a full trade-off? The students' explanations for selecting a decision-making strategy were categorized. For both categories (compensatory and non-compensatory aspects of a decision- 
making strategy), two subcategories with three levels of sophistication were identified in a deductive-inductive approach. The high interrater reliability suggests clearly identifiable categories. Moreover, the levels of explanations could be validated by measures of decision-making competence, as assessed with the open-ended questionnaire developed by Eggert \& Bögeholz (2010; cf. Gresch et al., 2011).

The majority of the students scrutinized the task to analyze whether knockout criteria existed or whether a full trade-off was possible (Subcategory 1). In addition, several students based their explanation on a hierarchy of values, i.e., important criteria were considered knockout criteria to exclude options, whereas criteria perceived to be equally important implied compensatory approaches (Subcategory 2). The levels described to which extent strategic considerations regarding the selection of a decision-making strategy were linked with specific task characteristics. The highest score required the students to reflect on the application of the decision-making strategies in a more elaborate way and process the task information more deeply. This graduation of levels according to the degree of contextualization is in line with the more general definition of competence as a cognitive ability to master particular, contextualized problems effectively (Hartig \& Klieme, 2006; cf. Weinert, 2001a, 2001b). On the whole, it is compelling that approximately three-quarters of the students offered reflective explanations on a strategic level to explain their strategy choice. We suggest that these elaborate metadecision considerations are an important component of thoughtful decisions (Eggert \& Bögeholz, 2006; Gresch et al., 2011). Similarly, Kuhn (1999) and Means and Voss (1996) consider metastatements to be part of high-quality argumentation as a way to structure an argument. Moreover, the application of decision-making strategies combined with metadecision considerations allow for a free choice of a course of action, while still 
triggering deeper reflection upon the inherent task characteristics. Consequently, the intervention study addresses one central requirement of science education, the empowerment to make autonomous and reflected decisions rather than adopting particular viewpoints (Aikenhead, 1985; Hodson, 2003; Hungerford, 2010; Jickling, 1992; McConnell, 1982; Pedretti, 2003; Ratcliffe \& Grace, 2003; Solomon \& Aikenhead, 1994).

When designing the learning environment of this study, all decisionmaking contexts were selected and modified so that each decision-making task required one specific decision-making strategy to adequately resolve the issue according to societal norms regarding sustainable development. However, despite a validation process in which the research group members discussed the fit of the decision-making context with the specific decision-making strategy and optimized it in several consecutive steps, only 39 to $55 \%$ of the participating students chose the expected strategy in each of the three tasks of the transfer phase. When evaluating these results, one should consider that these data were not collected after the intervention as part of the assessment, but during the learning process. A compelling result is that in both tasks with inherent knockout criteria based on societal norms (Task 2, the mixed strategy example (shipyard production site) and Task 3 , the non-compensatory strategy example (purchase of a bed)) approximately $80 \%$ of the students identified at least one of the knockout criteria. This result suggests that the students considered inherent norms and values, one requirement for the resolution of socioscientific issues (Jiménez-Aleixandre \& Pereiro-Muñoz, 2002; Kolstø, 2001; Ratcliffe, \& Grace, 2003; Sadler, 2004; Zeidler et al., 2005). However, in the task without knockout criteria, many students excluded options for reasons that were not based on societal norms. To investigate the reasons that the students did not select the expected strategy, two hypotheses were tested: first, selecting the strategy that fits best according 
to societal norms is associated with more elaborate metadecision explanations, whereas other strategies are justified in a less elaborate way; and second, the non-compensatory strategy was selected more often because it causes less cognitive load.

Contrary to our expectations, the students who selected the most adequate strategy did not provide higher level explanations than those who chose other strategies. Instead, the analyses revealed that the levels of explanations were quite similar across all contexts. Students who selected a compensatory strategy offered explanations regarding strategic aspects without linking them to specific task characteristics, whereas students who selected a non-compensatory strategy offered explanations that were more often linked to the decision-making task. This result suggests that the students found it easier to identify concrete knockout criteria than to illustrate why the disadvantages of one criterion can be compensated for by the advantages of another in a full trade-off. This outcome is plausible because it is less demanding to identify one aspect than to simultaneously take several aspects into account to describe why a trade-off between them would be appropriate.

Gresch et al. (2011) found that students who were familiar with decision-making strategies tended to overuse non-compensatory approaches. One possible explanation for this finding is that the noncompensatory decision-making strategy was associated with a lower cognitive load because it requires less evidence to be considered before reaching a conclusion than a compensatory strategy does (Hong \& Chang, 2004). The analyses of the process-related written data in the present study and the measurements of cognitive load revealed that for some students, the non-compensatory strategy is indeed a way to reduce the complexity of the decision-making situation, but the large majority of the 
students dealt with the socioscientific issues in an elaborate and reflective way.

\subsection{Implications for Science and Environmental Education}

In conclusion, the analysis of the process-related data from the intervention study revealed that the students did not randomly select a strategy in the transfer phase of the intervention, but did indeed exert elaborate and reflective metadecision skills. Because the students generally dealt adequately with the intervention tasks, two aspects should be considered when interpreting the finding that the students selected different strategies than expected. First, a closer examination of the presented contexts is necessary to draw conclusions for developing decision-making tasks of future trainings. All tasks consisted of three or four options, which were described according to four or five relevant criteria. Generally, the cognitive load was considered moderate for all tasks. This finding suggests that the complexity level was adequate for the trained students and that the quality was suitable to engage the students in the training. Another aspect is the presentation of the knockout criteria. When the contexts were selected and modified during the learning program development, options were considered non-sustainable if they had knockout criteria based on societal norms, such as devastating ecological, social or economic impacts. For the decision-making tasks with inherent knockout criteria, most students identified at least one of these characteristics, which suggests that these knockout criteria were presented in a way that allowed the students to recognize them. However, for the first task, an example of compensatory decision-making in which the students had to select a variety of apples for the school's cafeteria, many students selected the non-compensatory or mixed strategy. Because no societal norms demanded an exclusion of options in this task, personal 
criteria, such as the price of an apple or a strict avoidance of fruits that were not locally grown, prompted the selection of non-compensatory decision-making strategies. Hence, the individual decision-makers had different thresholds for eliminating options. We propose that consumer decisions are not optimal for introducing the application of decision-making strategies because thresholds determined by societal norms interfere with personal knockout criteria. Furthermore, consumer decisions are not ideal for assessing decision-making competence when considering the application of decision-making strategies. However, we recommend dealing with consumer decisions in a subsequent step in class to further differentiate between societal norms and personal values.

This leads to the second, more theoretical, implication, the balance between the students' autonomy when resolving socioscientific issues and the need, from a normative educational perspective, to confront students with the framework of sustainable development as the outcome of an international political consensus. In science and environmental education, it is widely acknowledged that teachers should not promote a particular point of view to avoid indoctrination (de Haan et al., 2008; Hodson, 2003; Hungerford, 2010; Jickling, 1992; Ratcliffe \& Grace, 2003). Instead, education should enable students to make elaborate decisions. In the present study, the autonomous selection of a decision-making strategy and a course of action allowed the students to express their procedural knowledge and their standpoint in an elaborate and independent way. Gresch et al. (2011) found that this combined teaching of decision-making strategies and metadecision activities not only enhanced the level of decision-making competence but also increased the students' perceived autonomy when dealing with socioscientific issues related to sustainable development. Furthermore, we observed that despite this autonomy, the majority of the students detected non-sustainable options based on societal norms in the transfer phase of the training. In addition, personal 
values, which are highly dependent on the decision-maker's attitudes, prior individual experiences and routines, were considered. This result supports the claim of Beach (1990) and Beach and Mitchell (1978) that the selection of a decision-making strategy depends on both the characteristics of the decision-making task, which involved both nonsustainable and sustainable options in this study, and on the decisionmaker's characteristics, because the perception of the task characteristics is a subjective process. Consequently, an evaluation of the quality of students' decision-making processes should involve an analysis of the metadecision explanations to gain further insights.

Generally, the concept of the fit of a strategy with the type of task is useful when designing learning environments. Strategic training in decision-making becomes meaningful only if the contexts are selected in a way that makes the application of the decision-making strategy plausible to the majority of the students. On the other hand, if societal norms and a multitude of personal values interfere, it provides a good opportunity to reflect on the development of societal norms. Moreover, it is vital from a normative educational viewpoint that students are able to reflect upon the norms that were negotiated and accepted by the majority of the world's societies to ensure sustainable development because this stimulates selfreflection (de Haan et al., 2008). Central efforts to yield a global consensus, such as Agenda 21 of the United Nations (UNCED, 1992) and subsequent global conferences, are important points of reference for classroom activities. The present study has revealed that thresholds are only considered explicitly for financial criteria. Consequently, ecological standards, e.g., minimum requirements for the water quality of limnological or marine ecosystems, or social standards, such as working conditions and social security, should be discussed in class. Such negotiations can be used to make the societal norm development process more transparent. This determination of thresholds could then be combined with 
strategic considerations to examine which options should be excluded in a non-compensatory approach because they do not reach the minimum thresholds. Consequently, the use of decision-making strategies to resolve socioscientific issues related to sustainable development offers opportunities to reflect on the distinction between societal norms and personal values and improve perspective-taking abilities. Therefore, future research should further elaborate on the development of suitable methods and appropriately framed decision-making tasks to stimulate this reflection process. Moreover, we suggest that the distinction between societal norms and personal values should not only be part of learning environments and curricula but also be assessed as a component of decision-making competence. Analyses of metadecision statements are one promising approach for this purpose. 


\section{$7 \quad$ Reflecting on the Use of Decision-making Strategies through Self-regulated Learning ${ }^{14}$}

\subsection{Abstract}

Thoughtful decision making to resolve socioscientific issues is central to STSE education. One approach for attaining this goal involves fostering the decision-making processes of students. Thus, the present study explores whether the application of three decision-making strategies, combined with reflections on the decision-making processes of others, enhances decision-making competence. In addition, it was examined whether this process is supported by elements of self-regulated learning, i.e. self-reflection regarding one's own performance and the setting of goals for subsequent tasks. Therefore, a computer-based training program, which involves the resolution of socioscientific issues related to sustainable development, was developed and its effects were analyzed using a pre-post-follow-up design ( $N=242$, upper high school students: grades 11-13). Decision-making competence was assessed using an open-ended questionnaire that focused on three facets: considered evidence, metadecision aspects and reflection on the decision-making processes of others. The findings suggest that although the amount of considered evidence did not change as a result of the trainings, students in both training groups (with and without elements of self-regulated learning) incorporated aspects of metadecision into their statements significantly more often than those in the control group. Furthermore, both training groups were more successful in reflecting on the decision-making processes of others. The students who received additional training in self-

\footnotetext{
${ }^{14}$ Source: Gresch, H., Hasselhorn, M. \& Bögeholz, S. (2011). Reflecting on the use of decision-making strategies through self-regulated learning. Manuscript submitted for publication.
} 
regulated learning showed greater effects in terms of several metadecision aspects and in reflection. Moreover, these effects remained significant two months after the training. Overall, our findings demonstrate that the application of decision-making strategies, combined with reflections on the decision-making processes of others, is a fruitful approach for STSE education.

Keywords: decision-making, STSE education, socioscientific issues, education for sustainable development, self-regulated learning

\subsection{Introduction}

In the democratic and pluralistic societies of the 21st century, all citizens should be provided with the resources that are necessary to enable their participation in personal and collective decisions pertaining to controversial issues (Aikenhead, 1985; Berkowitz \& Simmons, 2003; McConnell, 1982; Solomon \& Aikenhead, 1994; Zeidler et al., 2005). Therefore, the education of scientifically literate and responsible citizens who are capable of making thoughtful decisions based on scientific and societal considerations is central in the STSE movement (Aikenhead, 1985; McConnell, 1982; Pedretti, 2003; Pedretti \& Nazir, 2011; Solomon \& Aikenhead, 1994). Education for sustainable development is one field of STSE education (Pedretti, 2003) that focuses on empowering students to participate in actions that are designed to ensure sustainability (Eilam \& Trop, 2011). However, this goal can be reached only if thoughtful decisions and reflections regarding the possible benefits and drawbacks precede and accompany these actions (Eggert \& Bögeholz, 2006; Hodson, 2003). Therefore, science and environmental education teachers should not promote a particular view; rather, they should empower students to think critically (Hodson, 2003; Hungerford, 2010; Jickling, 1992; Ratcliffe \& Grace, 2003). Thus, the central focus should be on fostering high-quality 
decision-making processes (Hungerford, 2010; Potter, 2010; Sauvé, 2005; Siegel, 2006). Moreover, this objective has been included in many science education standards and curricula worldwide (AAAS, 1993; KMK, 2005; NRC, 1996; QCA, 2004).

Issues-based approaches are important in STSE education because they provide real and meaningful learning opportunities for the analysis of complex relationships and opportunities for assessment (Aikenhead, 1994, 2006; Bybee, McCrae, \& Laurie, 2009; Eggert \& Bögeholz, 2010; Fensham, 2009; Hodson, 2003; Kolstø, 2001; Pedretti, 2005; Sadler et al., 2007). Because real-world decisions frequently involve multiple fields, interdisciplinary approaches are vital for STSE education practices (Solomon \& Aikenhead, 1994). For environmental education in particular, the integration of ecological, social, economic, and political aspects is essential (Hungerford, 2010; Potter, 2010; UNESCO, 1978 (Tbilisi Declaration)). This interrelationship is even more strongly promoted by the education for sustainable development movement, which aims to integrate different interest groups in an attempt to solve various problems, such as the elimination of ecosystems, the loss of biodiversity and social injustice in a globalized world (Bourn, 2005; Eilam \& Trop, 2011; Herremans \& Reid, 2002; Marcinkowski, 2010; Sauvé, 1996, 2005; UNCED, 1992 (Agenda 21)). In consideration of this interdisciplinary approach, socioscientific issues are described as complex, open-ended, and contentious problems that lack simple and straightforward solutions (Sadler, 2004). To make thoughtful decisions aimed at resolving these issues, one must not only consider scientific evidence, but also the underlying values and societal norms because science itself is not valuefree and because societal contexts demand an integration of the values of the interest groups involved (Aikenhead, 1985; Eggert \& Bögeholz, 2006, 2010; Hodson, 2003; Kolstø, 2001; Ratcliffe \& Grace, 2003; Sauvé, 2005; Zeidler \& Sadler, 2007; Zeidler et al., 2005). In fact, value considerations 
have been shown to be included in the arguments of students (Bell \& Lederman, 2003; Grace \& Ratcliffe, 2002; Jiménez-Aleixandre \& PereiroMuñoz, 2002; Sadler \& Zeidler, 2004).

\subsection{Theoretical Framework}

\subsubsection{Decision-making and Argumentation in STSE Education}

Several STSE currents concern decision making, logical reasoning and argumentation (Pedretti \& Nazir, 2011; Sadler, 2004). The characteristics of high- and low-quality arguments have been identified in a number of studies (Driver et al., 2000; Kuhn, 1991; Toulmin, 1958; Zeidler, 1997) and interventions designed to enhance the quality of argumentation. These interventions were found to be successful in both short-term (Venville \& Dawson, 2010; Zohar \& Nemet, 2002) and long-term studies (Osborne et al., 2004). When engaged in reasoning, students often employ both rationalistic and emotive or intuitive patterns, and they frequently use heuristics (Arvai et al., 2004; Haidt, 2001; Sadler \& Zeidler, 2005; Zeidler, 1997). However, the use of heuristics may lead to a reduction in the complexity of a socioscientific issue (Arvai et al., 2004; Payne et al., 1998), and such simplification is inadequate from a normative perspective.

A significant amount of research has been conducted with the purpose of assessing and improving the presentation of the viewpoints of students in small-group or whole-class discussions; this research is primarily based on the argument pattern proposed by Toulmin (1958) (i.e. the connection between data, claims, warrants, backings and rebuttals when presenting one's position). Although this approach is useful for assessing the quality of arguments, especially in small-group discussions (Erduran et al., 2004), it does not reveal how the individual participants in a discussion reached their decision before the argument occurred. However, socioscientific issues often require both individual and collective decision making (Aikenhead, 1985; Zeidler et al., 2005; Eggert et al., 
2010). Moreover, because collective decision-making processes require individuals to agree on one final decision, individual decision making is part of the process of collective decision making (Aikenhead, 1985). Therefore, understanding and reflecting on the decision-making processes of oneself and of others is vital to reaching a group compromise. Consequently, reflections on the strengths and weaknesses of decisionmaking processes are considered a useful approach for critically judging the statements of others and for enhancing one's own reasoning (Arvai et al., 2004; Baron, 1994; Haidt, 2001; Hogan, 2002; Ratcliffe \& Grace, 2003; Zeidler, 1997).

The adequate evaluation of evidence is central to both decision making and argumentation. The main difference between these frameworks, however, is the role of the presented statements. Does a student elucidate how his/her decision was reached or defend his/her viewpoint after the decision has been made?

Few studies in science education have focused on understanding and optimizing decision-making processes. Therefore, the present study aims to foster decision-making competence that involves strategic considerations, i.e. the explicit use of a decision-making strategy, as well as a reflection on the underlying decision-making process (Eggert \& Bögeholz, 2006, 2010).

\subsubsection{Decision-making Strategies}

Due to the complexity of many decision-making tasks associated with several options and multiple attributes, there are a number of possible ways in which to approach a decision. Behavioral decision research has investigated the ways in which decision making actually occurs and the strategies that people apply when solving such problems. 
A decision-making strategy in which all advantages and disadvantages are considered in a full trade-off is called a compensatory strategy because all of the benefits and drawbacks compensate one another (Jungermann et al., 2005; Payne et al., 1998; Plous, 1993). One way of describing this decision-making process is through the weightedadditive-value model, which postulates that the outcomes of some decisions are best approximated by adding the values of all relevant attributes that characterize the options. The underlying value hierarchy is considered by weighting factors: important attributes contribute more to the final result than less important attributes. A decision maker selects the option with the highest overall value because this option best fulfills the pivotal demands.

However, decision-making situations often include unacceptable options. If the characteristics of an option do not reach a minimum threshold, decision makers may exclude such options without further consideration of the advantages. Because benefits and drawbacks are not compensated, such a strategy is referred to as non-compensatory (Jungermann et al., 2005; Payne et al., 1998; Plous, 1993). One example is the elimination-by-aspects rule (ibid.; Tversky, 1972), in which options are excluded if they do not reach the required cut-off levels associated with the most important criterion. Subsequently, the remaining options are examined with regard to the second most important criterion and, if necessary, are excluded and so forth.

These strategies are often combined to enable the remaining set of options to be compared in greater detail (e.g., through a complete tradeoff) after an initial screening phase, in which unacceptable options are excluded (Beach, 1990).

Generally, different types of decision-making tasks require different decision-making strategies (Eggert \& Bögeholz, 2006; Gresch et al., 
2011). Many routine decisions are best solved by applying heuristics, whereas other situations-especially complex socioscientific issues that affect various interest groups-require the use of more elaborate strategies (Arvai et al., 2004; Eggert \& Bögeholz, 2006, 2010; Gresch et al., 2011; Hogan, 2002). Regarding the framework of sustainable development, some situations suggest the use of a non-compensatory strategy, in which the options with attributes that would lead to unsustainable development are excluded (Gresch et al., 2011). Other issues may require a complete trade-off of all options. In conclusion, a high level of decision-making competence involves strategic considerations, i.e. the explicit use of a decision-making strategy, as well as a reflection on the underlying decision-making process (Eggert \& Bögeholz, 2006).

The values that underlie possible courses of action strongly influence the decision-making process. Therefore, an implicit or explicit value consideration is regarded as part of the decision-making strategy (Eggert \& Bögeholz, 2006; Jungermann et al., 2005; Payne et al., 1998). From a normative viewpoint, it is considered fruitful to explicitly reflect on underlying values (e.g., through a prioritization of values) to illuminate the implicit assumptions made during the process of creating judgments regarding socioscientific and environmental issues because this method is a possible means of avoiding an inappropriate reduction in complexity (Aikenhead, 1985; Arvai et al., 2004; Arvai \& Gregory, 2003; Eilam \& Trop, 2011; Gresch et al., 2011; Hodson, 2003; Kolstø, 2001; Sauvé, 2005).

Because the reasons behind poor decisions reflect not only a lack of information, but also shortcomings and flaws in the decision-making process (Arvai et al., 2004), it is recommended that decision making be taught through the application of decision-making strategies (Eggert \& Bögeholz, 2006; Gresch et al., 2011) or by addressing such flaws (Arvai et al., 2004; Gresch et al., 2011; Hogan, 2002; Ratcliffe \& Grace, 2003). 
Seethaler and Linn (2004), Ratcliffe (1997) and Eggert et al. (2010) trained students to make complete trade-offs by weighing all advantages and disadvantages. Gresch et al. (2011) showed that training students to apply compensatory, non-compensatory and mixed strategies enhanced their decision-making competence. Long-term effects, such as an explicit consideration of values, were observed. However, the frequent use of noncompensatory strategies was unintentionally triggered through the training: although all decision-making tasks on the questionnaire had been designed to ensure that no option had unsustainable characteristics, students in the training groups tended to exclude options more often and thus avoided full-tradeoffs, which are more cognitively demanding. Therefore, a desideratum for future research is to combine the application of decision-making strategies with the analysis of flaws in reasoning, especially a hasty exclusion of options, to yield improved training in decision-making competence.

\subsubsection{Self-regulated Learning}

Science education should prepare students for lifelong learning and thus provide them with strategies for independently completing new tasks. Unfamiliar socioscientific issues challenge the flexibility of students attempting to transfer such strategies to new issues. Self-regulated learning is a fruitful approach for achieving autonomy in science education (Schraw et al., 2006) because it combines the enhancement of cognitive and metacognitive strategies and motivational aspects (Boekaerts, 1999; Schraw et al., 2006; Zimmerman, 2000).

According to the model of self-regulated learning proposed by Zimmerman (2000), three subsequent phases of learning processes can be distinguished. Prior to processing a task, self-regulated learners set goals and select strategies that will assist them in completing the task (forethought phase). Self-monitoring and self-control ensure effective 
performance (performance phase). After completing the task, students reflect on the quality of their performance and draw conclusions for further tasks, e.g., by stating new goals (self-reflection phase). Hence, selfregulation is considered a cyclical process that demands metacognitive skills. In particular, the explicit self-reflection of students with regard to their progress requires metacognitive activity to scrutinize oneself and is thus considered important for critical thinking (Schraw et al., 2006). The authors acknowledge that reasoning activities are more complex than the completion of tasks described in Zimmerman's three phases. However, this model provides a suitable transparent framework for the design of an intervention.

Thus far, the integration of the aspects of self-regulated learning into research in science education has primarily focused on the effects of learning science content or improving inquiry-based activities and problem solving (Labuhn et al., 2008a, 2008b; Schraw et al., 2006). However, the inclusion of elements of self-regulated learning seems promising for the purposes of enhancing decision-making competence (Gresch et al., 2011).

\subsection{Research Questions}

Although the inclusion of results from behavioral decision research is a worthwhile endeavor to enhance decision-making competence in science and environmental education (Arvai et al., 2004; Eggert \& Bögeholz, 2006; Gresch et al., 2011), few studies have investigated the effects of such decision-making training on the management of socioscientific issues. Eggert et al. (2010) as well as Gresch et al. (2011) have shown that conducting decision-making strategy training fosters decision-making competence. However, some students tended to hastily exclude options in the non-compensatory approach (Gresch et al., 2011). Therefore, research is necessary to investigate whether an additional reflection on the strengths and weaknesses of the decision-making processes of others 
improves the decision-making competence of students. Such a reflection should focus on whether a suitable decision-making strategy is used to resolve a socioscientific issue and whether flaws in the application exist. Hence, the first hypothesis is as follows:

1. Training students in the application of decision-making strategies and reflection on the quality of the decision-making processes of others enhances decision-making competence.

Science education research pertaining to decision making has rarely focused on self-regulation although self-regulated learning is considered especially worthwhile because it induces metacognitive processes (Schraw et al., 2006) that are crucial for decision making (Eggert \& Bögeholz, 2006). Therefore, the second aim of the current study is to improve this reflection process through the use of self-regulation strategies. Thus, the second hypothesis is as follows:

2. A combination of reflections on the decisions of others with selfreflection on a student's own performance and the setting of goals for future tasks enhances decision-making competence at a higher rate.

To test these hypotheses, the authors developed a computer-based training program to train students in applying and reflecting on the use of decision-making strategies.

\subsection{Description of the Decision-making Training}

All participating students worked with a web-based training program consisting of two 45-minute sessions (see Table 7.1). At the beginning of the program, the framework of sustainable development - the interdisciplinary combination of ecological, social and economic facets - is introduced to provide students with the opportunity to reflect on inherent norms and personal values. 
Table 7.1

Structure of training program

\begin{tabular}{|c|c|c|c|}
\hline Training group 1 & Training group 2 & Control group & Contexts \\
\hline \multicolumn{4}{|l|}{ Session $1^{a}$} \\
\hline \multicolumn{2}{|l|}{$\begin{array}{l}\text { - Non-compensatory } \\
\text { - Compensatory stra } \\
\text { - Mixed strategy }\end{array}$} & $\begin{array}{l}\text { Decision making } \\
\text { with additional } \\
\text { ecological } \\
\text { information }\end{array}$ & $\begin{array}{l}\text { Decision } \\
\text { between } \\
\text { different } \\
\text { measures for } \\
\text { the protection } \\
\text { of coral reefs } \\
\text { - Land-use } \\
\text { decision after } \\
\text { brown coal } \\
\text { mining } \\
\text { Choice of an } \\
\text { aquaculture site }\end{array}$ \\
\hline \multicolumn{4}{|l|}{ Session 2} \\
\hline \multicolumn{2}{|c|}{$\begin{array}{l}\text { Reflecting on the decision-making } \\
\text { processes of others based on } \\
\text { strategic considerations }\end{array}$} & \multirow{2}{*}{$\begin{array}{l}\text { Decision making } \\
\text { from the } \\
\text { perspective of } \\
\text { other stakeholders. } \\
\text { without strategic } \\
\text { training }\end{array}$} & \multirow{2}{*}{$\begin{array}{l}\text { Choice of a } \\
\text { production site } \\
\text { for a shipyard } \\
\text { Decision } \\
\text { between } \\
\text { different } \\
\text { measures for } \\
\text { the renaturation } \\
\text { of a } \\
\text { limnological } \\
\text { ecosystem }\end{array}$} \\
\hline $\begin{array}{l}\text { Without training of } \\
\text { self-regulated } \\
\text { learning }\end{array}$ & $\begin{array}{l}\text { With integrated } \\
\text { training of self- } \\
\text { regulated } \\
\text { learning (self- } \\
\text { reflection on task } \\
\text { performance and } \\
\text { setting of goals } \\
\text { for the next task) }\end{array}$ & & \\
\hline
\end{tabular}

Note. ${ }^{\text {a Session }} 1$ as in Gresch et al. (2011). ${ }^{\mathrm{b}}$ Both training groups received the same training in session 1.

In the first session, all students respond to three decision-making tasks in which different courses of action must be compared before an option is selected. Students in the two training groups (TG1/TG2) arrive at their decisions by applying three decision-making strategies: a 
compensatory strategy, a non-compensatory strategy and a combination of both strategies (see Gresch et al., 2011).

For the first issue under consideration, measures that are designed to protect a coral reef in an impoverished southern region must be compared by considering the consequences for the ecosystem, local diving schools, and individuals who depend on income from diving tourism and the financial constraints of the local community. Because some options would have a strong negative effect on ecological or social factors or would create heavy financial burdens for the local community, students are encouraged to reflect on the question of which options may not be sustainable and should thus be excluded. The elimination-by-aspects rule is introduced as a non-compensatory approach, and its application is aided through buttons used to systematically eliminate options if the attributes do not reach the minimum threshold established by a student.

The second context is a land-use decision in which students must determine which form of land use they would promote after the end of brown coal mining. Again, ecological, social and economic consequences must be considered. In this task, all options are considered to be equally legitimate according to the sustainability framework. Consequently, students are encouraged to use a weighted-additive-value strategy, which is one type of compensatory decision-making strategy, by converting benefits and drawbacks into positive and negative scores. Subsequently, these scores are multiplied with the weighting factor chosen by the student and followed by a summation of all weighted attributes to determine an overall score for each option.

For the final issue in the first session, students must choose a site for an aquaculture (cf. Bayer et al., 2008) by applying a mixed strategy.

In all tasks, students are asked to reflect on the underlying values by prioritizing them or by weighting attributes. 
The second session consists of two decision-making tasks concerning the production site of a large enterprise that produces container ships (cf. Mühlenhoff, 2009) and a limnological ecosystem in which quality must be enhanced while ensuring the local population access to this recreational area (Eggert et al., 2008). In each task, two decisions of differing quality are presented to the students in the training groups. The general aims of this session are to avoid flaws in reasoning, such as an unreflected use of non-compensatory strategies (as in Gresch et al., 2011), and to stimulate reflection regarding the question of which strategy is most appropriate according to the characteristics of the decision-making task. The decision-making processes must be described and judged. One decision represents an intuitive judgment that lacks the consideration of counterevidence and other alternatives, whereas other decision makers use strategies explicitly, such as non-compensatory or compensatory approaches. Students are asked to reflect on whether the exclusion of options is justifiable based on the values relevant to the decision maker or whether the exclusion of options simply represents an inadequate reduction in complexity. After reflecting on the quality of the decisions presented, students in the training groups are shown a worked example completed by an "expert," who identifies the deficits in the decisions presented. Such worked examples have been found to enhance the performance of students in problem-solving tasks (van Gog, Paas, \& van Merriënboer, 2006; Ward \& Sweller, 1990). Students in TG2 are encouraged to compare and contrast their solutions with the completed example by marking the aspects that were mentioned in both their solution and the example solution. Following this self-reflection on their performance, students set their goals for working on future tasks, i.e. stating aspects on which they wish to focus.

Students in the control group (CG) work with the same sustainability issues. However, rather than receiving training in the use of decision- 
making strategies, they receive additional ecological information to inform their decisions in the first session. In the second session, they decide from the perspectives of relevant stakeholders rather than reflecting on the decision-making processes of others.

\subsection{Methods}

\subsubsection{Research Design}

To analyze the effects of the training program, the authors chose a prepost-follow-up control-group design. On the first day, students completed the pre-test and worked through the first session of the computer-based training program (see Table 7.1). On the second day, which occurred within a week of the first day, students finished the program and the posttest. A follow-up test was conducted two months after the intervention. All students were provided with a computer and were randomly assigned to one of two training groups or a control group when beginning to use the software.

\subsubsection{Sample}

A total of 242 students from 17 biology classes (grades 11-13, i.e. students in the last three years of high school) participated in the entire training program and the pre- and post-tests. Among these students, 204 also participated in the follow-up test. The mean age was 16.9 years, and $64 \%$ of the students were females. The groups did not differ with regard to sex, age, biology grade, years of education and number of biology periods per week. Furthermore, with regard to the pre-test results, no significant differences between the groups were found in any of the decision-making scales. 


\subsubsection{Measurement of Decision-making Competence}

Decision-making competence was assessed using an open-ended questionnaire (Eggert \& Bögeholz, 2010), which has been determined to be suitable for intervention studies (Eggert \& Bögeholz, 2010; Gresch et al., 2011). During a period of 45 minutes, students completed three realworld decision-making tasks related to sustainable development. In the first two tasks, they were instructed to compare and contrast possible courses of action and finally select one option. In the third task, the students reflected on the quality of the decisions made by three other individuals and offered suggestions for improvement. Each of the decisions presented was based on a different decision-making strategy.

The open answers were scored with regard to three major foci (see Table 7.2 for the scoring rubric). First, concerning each student's own decision, the scores for eight items (representing four options per task) reflected the extent to which a student considered advantages and disadvantages when judging the chosen option (one item per task) and the rejected options (three items per task; see considered evidence in Table 7.2). Second, three metadecision aspects were examined in six items: to what extent did students structure or plan their decision-making processes? Did they explicitly describe the aspects of the decision-making strategies that were utilized (e.g., the exclusion of options or an explicit trade-off)? Did they weight the criteria according to personal values? With regard to the personal values it was not coded, which particular value was considered or whether several values were of equal importance to the students. The only relevant aspect was whether the considerations of students regarding the weighting of criteria were stated explicitly. Third, the reflection task examined the ways in which students described the decision-making processes of others and offered suggestions for improvement (six items). Strategic descriptions and comments were considered elaborate reflections (Eggert \& Bögeholz, 2010). Because 
these items are polytomous with different maximum scores, they were equi-weighted to ensure that each item contributed equally to the scale.

Table 7.2

Scoring guide of the decision-making questionnaire

\begin{tabular}{|c|c|c|c|c|}
\hline Item description & Score 0 & Score 1 & Score 2 & Score 3 \\
\hline \multicolumn{5}{|c|}{ Considered evidence } \\
\hline $\begin{array}{l}\text { Chosen and } \\
\text { rejected options }\end{array}$ & $\begin{array}{l}\text { Does not } \\
\text { state } \\
\text { anything. }\end{array}$ & $\begin{array}{l}\text { States } \\
\text { either } \\
\text { positive or } \\
\text { negative } \\
\text { aspects. }\end{array}$ & $\begin{array}{l}\text { States both } \\
\text { positive and } \\
\text { negative } \\
\text { aspects. }\end{array}$ & \\
\hline
\end{tabular}

Metadecision aspects

\begin{tabular}{|c|c|c|}
\hline $\begin{array}{l}\text { Structuring and } \\
\text { planning of } \\
\text { decision-making } \\
\text { process }^{b}\end{array}$ & $\begin{array}{l}\text { Does not } \\
\text { explicitly } \\
\text { structure or } \\
\text { plan decision. }\end{array}$ & $\begin{array}{l}\text { Structures } \\
\text { and plans } \\
\text { decision } \\
\text { explicitly. }\end{array}$ \\
\hline $\begin{array}{l}\text { Description of } \\
\text { aspects of the } \\
\text { underlying } \\
\text { decision-making } \\
\text { strategy }^{b}\end{array}$ & $\begin{array}{l}\text { Does not } \\
\text { explicitly } \\
\text { describe } \\
\text { strategic } \\
\text { aspects. }\end{array}$ & $\begin{array}{l}\text { Describes } \\
\text { strategic } \\
\text { aspects } \\
\text { explicitly. }\end{array}$ \\
\hline $\begin{array}{l}\text { Weighting of } \\
\text { criteria according } \\
\text { to personal } \\
\text { values }^{b}\end{array}$ & $\begin{array}{l}\text { Does not } \\
\text { explicitly } \\
\text { weight } \\
\text { criteria. }\end{array}$ & $\begin{array}{l}\text { Weights } \\
\text { criteria } \\
\text { explicitly. }\end{array}$ \\
\hline
\end{tabular}




\begin{tabular}{|c|c|c|c|c|}
\hline Item description & Score 0 & Score 1 & Score 2 & Score 3 \\
\hline \multicolumn{5}{|l|}{ Reflection } \\
\hline $\begin{array}{l}\text { Description of } \\
\text { non- } \\
\text { compensatory } \\
\text { decision making }^{c}\end{array}$ & $\begin{array}{l}\text { No reference } \\
\text { to strategy. }\end{array}$ & $\begin{array}{l}\text { Reference } \\
\text { to one } \\
\text { aspect of } \\
\text { strategy. }\end{array}$ & $\begin{array}{l}\text { Reference } \\
\text { to two } \\
\text { aspects of } \\
\text { strategy. }\end{array}$ & $\begin{array}{l}\text { Reference } \\
\text { to at least } \\
\text { three } \\
\text { aspects of } \\
\text { strategy. }\end{array}$ \\
\hline $\begin{array}{l}\text { Description of } \\
\text { compensatory } \\
\text { decision making }^{c}\end{array}$ & $\begin{array}{l}\text { No reference } \\
\text { to strategy. }\end{array}$ & $\begin{array}{l}\text { Reference } \\
\text { to one } \\
\text { aspect of } \\
\text { strategy. }\end{array}$ & $\begin{array}{l}\text { Reference } \\
\text { to two } \\
\text { aspects of } \\
\text { strategy. }\end{array}$ & $\begin{array}{l}\text { Reference } \\
\text { to at least } \\
\text { three } \\
\text { aspects of } \\
\text { strategy. }\end{array}$ \\
\hline $\begin{array}{l}\text { Description of } \\
\text { intuitive decision } \\
\text { making }^{c}\end{array}$ & $\begin{array}{l}\text { No reference } \\
\text { to strategy. }\end{array}$ & $\begin{array}{l}\text { Reference } \\
\text { to one } \\
\text { aspect of } \\
\text { strategy. }\end{array}$ & $\begin{array}{l}\text { Reference } \\
\text { to at least } \\
\text { two aspects } \\
\text { of strategy. }\end{array}$ & \\
\hline $\begin{array}{l}\text { Suggestions for } \\
\text { improvement of } \\
\text { non- } \\
\text { compensatory } \\
\text { decision making }^{c}\end{array}$ & $\begin{array}{l}\text { No } \\
\text { suggestions } \\
\text { on strategic } \\
\text { level. }\end{array}$ & $\begin{array}{l}\text { Suggestions } \\
\text { on strategic } \\
\text { level with } \\
\text { one aspect. }\end{array}$ & $\begin{array}{l}\text { Suggestions } \\
\text { on strategic } \\
\text { level with at } \\
\text { least two } \\
\text { aspects. }\end{array}$ & \\
\hline $\begin{array}{l}\text { Suggestions for } \\
\text { improvement of } \\
\text { compensatory } \\
\text { decision making }^{c}\end{array}$ & $\begin{array}{l}\text { No } \\
\text { suggestions } \\
\text { on strategic } \\
\text { level. }\end{array}$ & $\begin{array}{l}\text { Suggestions } \\
\text { on strategic } \\
\text { level with } \\
\text { one aspect. }\end{array}$ & $\begin{array}{l}\text { Suggestions } \\
\text { on strategic } \\
\text { level with at } \\
\text { least two } \\
\text { aspects. }\end{array}$ & \\
\hline $\begin{array}{l}\text { Suggestions for } \\
\text { improvement of } \\
\text { intuitive } \\
\text { decision making }^{c}\end{array}$ & $\begin{array}{l}\text { No } \\
\text { suggestions } \\
\text { on strategic } \\
\text { level. }\end{array}$ & $\begin{array}{l}\text { Suggestions } \\
\text { on strategic } \\
\text { level with } \\
\text { one aspect. }\end{array}$ & $\begin{array}{l}\text { Suggestions } \\
\text { on strategic } \\
\text { level with at } \\
\text { least two } \\
\text { aspects. }\end{array}$ & \\
\hline
\end{tabular}

Note. Based on Eggert \& Bögeholz (2010); Eggert et al. (2010) and the results from the qualitative content analysis.

${ }^{a} 8$ items. ${ }^{b} 2$ items. ${ }^{c} 1$ item.

The scoring of the metadecision aspects of the answers of students was not originally included in the rubric of Eggert and Bögeholz (2010; cf. 
Eggert et al., 2010), with the exception of the item "weighting criteria according to personal values." However, Means and Voss (1996) suggest that the inclusion of metastatements is one element of strong informal reasoning. Because the intervention study focused on such strategic considerations during the decision-making process, the extension of the scoring rubric was valuable to describe the effects of the training in more detail. To determine which metadecision aspects were integrated by students, the authors developed categories in a qualitative content analysis using a deductive-inductive approach (Mayring, 2008). Thus, all categories were derived from behavioral decision-making theories (Jungermann et al., 2005; Payne et al., 1998), the works of Means and Voss (1996) and Eggert \& Bögeholz (2006, 2010). These categories were then refined according to the investigated data. For this development of additional scoring categories, approximately $25 \%$ of all pre- and post-tests $(n=100)$ were analyzed. A maximal variety of answers was sought by including both the training groups and the control group to represent different levels of competence before and after the training. The new scoring rubric (with examples and scoring definitions) was then used for the analysis of all questionnaires.

For motivational reasons, different contexts were used in the pretest compared with the post-test and the follow-up test. Although the structure and the scoring rubric were identical at all times of measurement, the difficulty of the questionnaires may have varied. Hence, all final scores were z-standardized according to the mean and standard deviation of the control group. These steps were conducted separately for each measurement time to generate an identical baseline for comparison.

For all analyses, the missing data were excluded listwise.

The reliability (Cronbach's alpha) of the dependent variables (posttest and follow-up) was satisfactory considering the heterogeneity of the 
constructs (considered evidence: .833/.798; reflection: .692/.572). However, the internal consistency of the follow-up test regarding the reflection was moderate. The metadecision aspects were analyzed on the item level. Hence, it was not possible to determine Cronbach's alpha.

Half of the questionnaires were recoded by a second rater, who was trained for this purpose. The interrater agreement (Cohen's Kappa; percentage of agreement) was substantial: consideration of advantages and disadvantages: $\mathrm{k}=.81$ (89\%); metadecision aspects: $\mathrm{k}=.68(90 \%)$; and reflection: $\mathrm{k}=.69$ (83\%). After determining the interrater agreement, all differing scores were discussed by the two raters before agreeing on a final score.

\subsection{Results}

Two hypotheses were examined in the present study. First, it was expected that the process of applying decision-making strategies and reflecting on the decision-making processes of other people would enhance decision-making competence. Second, it was hypothesized that self-regulation activities, i.e. reflecting on a student's own performance and setting goals for future tasks, foster decision-making competence at a higher rate. To test these hypotheses, the authors present results regarding three facets of decision-making competence: considered evidence, metadecision aspects and reflection (see Table 7.2).

\subsubsection{Considered Evidence}

Regarding the students' own decisions, the analysis of covariance of the post-test and follow-up results showed that the group had no effect on the number of integrated advantages and disadvantages when controlling for the number of advantages and disadvantages described in the pre-test. 


\subsubsection{Metadecision Aspects}

However, whether metadecision aspects were included in the decisions presented, differed among the groups (see Figure 7.1). For the analysis of these items, the scores from both decision-making tasks were summed for each category. The progression from pre-test to post-test was characterized by distinguishing between students who improved their scores and those who did not. Pairwise Chi-square analyses revealed that the training groups demonstrated more frequent improvements than did the control group: students from both training groups planned and structured their decision-making processes more frequently (TG1-CG: $\chi^{2}=5.1, d f=1, p<.05 ;$ TG2-CG: $\chi^{2}=10.5, d f=1, p<.01$ ) and explicitly described the strategic aspects of the underlying decision-making strategy (TG1-CG: $\chi^{2}=7.8, d f=1, p<.01 ;$ TG2-CG: $\chi^{2}=13.7, d f=1, p<.001$ ).

Furthermore, the criteria were more often weighted according to personal values (TG1-CG: $\chi^{2}=19.8, d f=1, p<.001$; TG2-CG: $\chi^{2}=9.7, d f=1$, $p<.01)$. However, training groups 1 and 2 did not differ significantly from one another.

The long-term progression is significant for the description of the aspects of the underlying strategy for TG1 (TG1-CG: $\chi^{2}=5.6, d f=1$, $p<.05)$ and the structuring and planning of the decision-making task for TG2 (TG2-CG: $\left.\chi^{2}=8.8, d f=1, p<.01\right)$. 


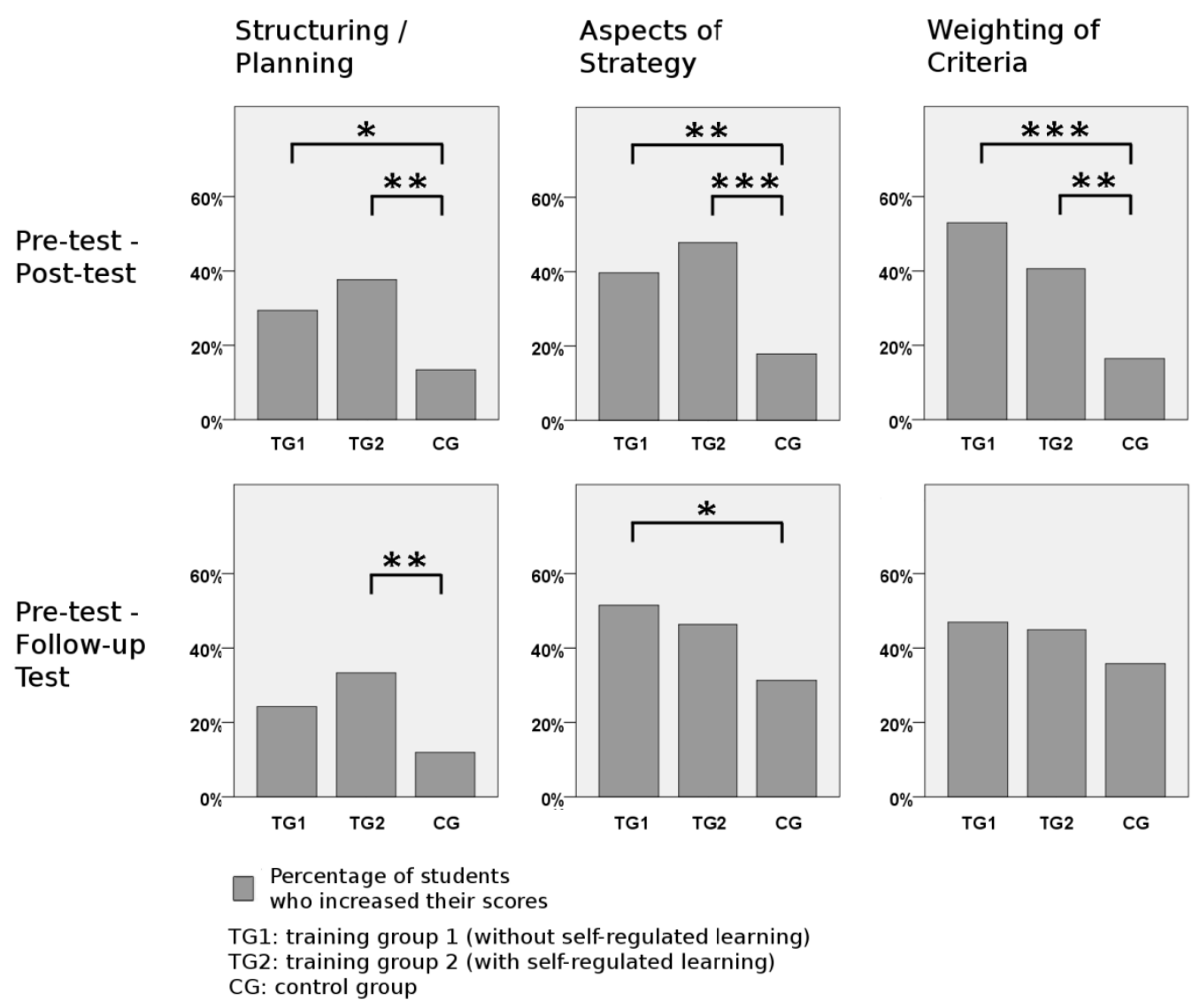

Figure 7.1. Metadecision in decision-making task: Percentage of students who increased their scores.

${ }^{*} p<.05 .{ }^{* *} p<.01{ }^{* * *} p<.001$.

\subsubsection{Reflection}

To investigate the effects of the training on the performance of students as they reflect on the decision-making processes of others, the authors conducted pairwise analyses of covariance of the post-test scores while controlling for pre-test scores (see Figure 7.2). In the comparisons of TG1 and TG2 with CG, the training groups were found to be significantly superior (TG1-CG: $F_{(1,96)}=11.810, p<.001$, partial $\eta^{2}=.110$; TG2-CG: $F_{(1,105)}=22.960, p<.001$, partial $\left.\eta^{2}=.179\right)$. 
The follow-up analysis did not reveal a significant effect in comparisons of TG1 and CG $\left(F_{(1,96)}=2.950, p=.089\right.$, partial $\left.\eta^{2}=.030\right)$, but TG2 was found to be significantly superior to CG (TG2-CG: $F_{(1,105)}=12.248, p<.001$, partial $\left.\eta^{2}=.104\right)$.

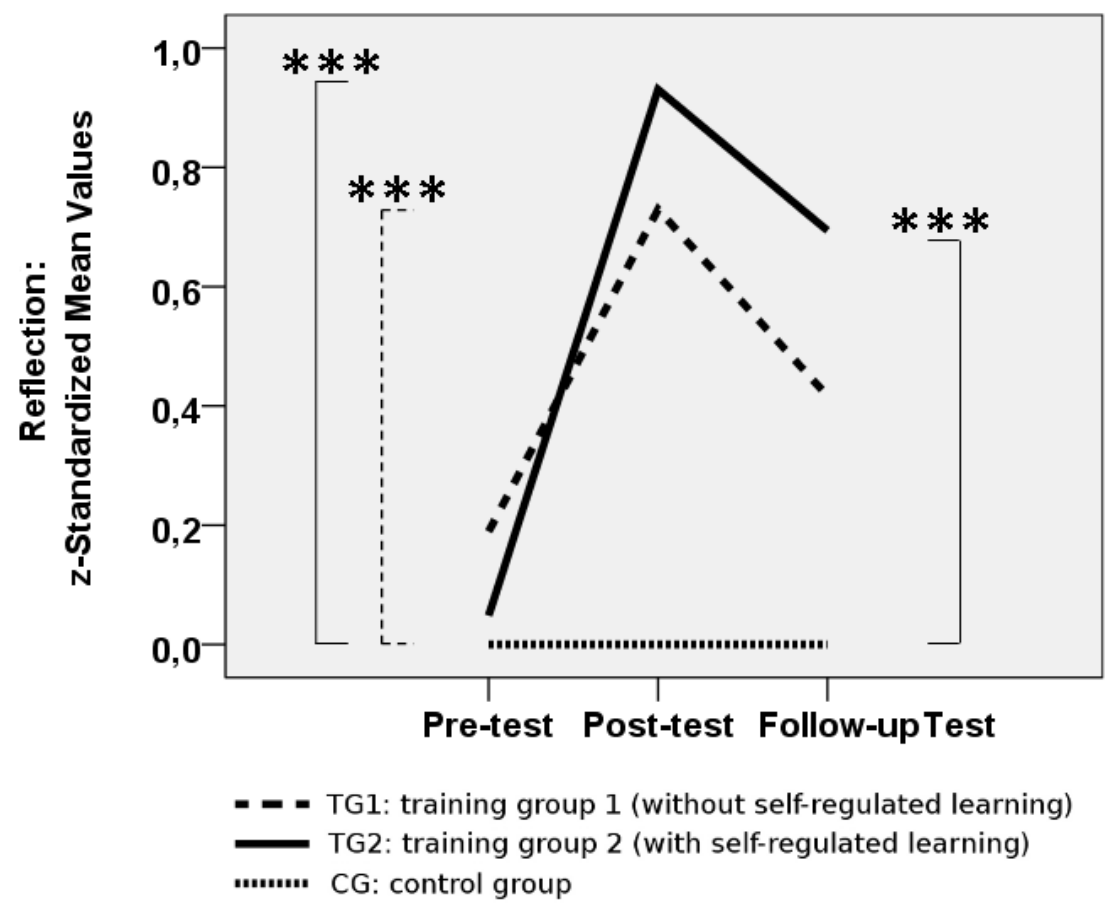

Figure 7.2. Reflection: Mean values (relative to $z$-standardized control group).

${ }^{*} p<.05 .{ }^{* *} p<.01 .{ }^{* * *} p<.001$.

In addition to these results on the scale level, the analyses of two items from this scale will be presented because the recognition of intuitive judgments and suggestions for improvement are of particular importance. Similar to our analyses of the items pertaining to metadecision, it was determined whether students increased their scores from the pre-test to the post-test (pre-test to follow-up test respectively). The percentage of students with scores that increased from the pre-test to the post-test is as follows: description of intuitive judgments: TG1: $30.2 \%$; TG2: $47.7 \%$; CG: 
$21.9 \%$; suggestions for improvement: TG1: $29.5 \%$; TG2: $39.1 \%$; CG: $18.0 \%$. In comparisons of TG2 and CG, Chi-square analyses revealed that TG2 showed significantly more improvement in the descriptions of the intuitive statements $\left(\chi^{2}=9.5, d f=1, p<.01\right)$ and in offering suggestions $\left(\chi^{2}=6.7, d f=1, p<.01\right)$. No significant effects were found in the comparisons of TG1 and CG. An examination of the difference between the training groups revealed that the group that received the selfregulation training (TG2) improved its score for the description of the intuitive judgments more frequently than TG1 $\left(\chi^{2}=4.1, d f=1, p<.05\right)$.

In the follow-up test, the percentage of students who increased their scores showed a similar pattern: description of intuitive judgment: TG1: $22.2 \%$; TG2: $43.3 \%$; CG: $26.6 \%$; suggestions for improvement: TG1: $24.6 \%$; TG2: $33.8 \%$; CG: $13.1 \%$. The performance difference observed between TG2 and CG remained stable during the two months following the intervention (description of intuitive judgment: $\chi^{2}=4.0, d f=1, p<.05$; suggestions for improvement: $\chi^{2}=7.5, d f=1, p<.01$ ). Again, the difference between TG1 and CG was not significant. In the comparisons of TG1 and TG2 the results in the follow-up test were similar to those observed for the post-test: TG2 obtained significantly higher scores than TG1 regarding the description of intuitive judgments $\left(\chi^{2}=6.5, d f=1\right.$, $p<.05)$.

\subsection{Discussion and Conclusions}

The aim of the present study was to examine whether decision-making competence is enhanced for students who receive training in decisionmaking strategies combined with reflections on the decisions of others based on strategic considerations.

The analysis of the decisions of students revealed that the training groups showed the most improvement in terms of including metadecision 
aspects: students in these groups structured and planned their decisionmaking processes more frequently than those in the control group and explicitly described aspects of their decision-making strategies. According to Means and Voss (1996), this use of metastatements is indicative of high-quality reasoning. Furthermore, the criteria that were relevant to the socioscientific issues were more frequently weighted according to personal values after the training. Hence, the program was successful in triggering the consideration of underlying values, which is beneficial for the resolution of socioscientific issues (Aikenhead, 1985; Hodson, 2003; Kolstø, 2001). However, the number of advantages and disadvantages of possible courses of action that students considered did not change as a result of the training. Based on a review of the structure of the training program, this result appears plausible because three decision-making strategies were applied. However, only the compensatory strategy required a full trade-off between all of the benefits and drawbacks, whereas the non-compensatory or mixed strategy allowed for the exclusion of options if courses of action were considered unsustainable with regard to ecological, economic or social consequences. Unlike the training program, the questionnaire was constructed in a way that each of the decision-making tasks required a full trade-off because no option was considered unsustainable according to the framework of sustainable development. Therefore, future research should focus on the development of test instruments designed to cover a wide range of decision-making situations and to require the use of different decision-making strategies.

Gresch et al. (2011) found that students who were trained in decision-making strategies without subsequent reflections on the shortcomings and flaws of decision-making processes tended to include less evidence than the control group. However, in the present study, the decisions of students became more transparent through metastatements on a strategic level without reducing the amount of evidence presented. 
Hence, the reflection on the hasty exclusion of options in the second session of the training program discouraged students from overusing noncompensatory strategies that can reduce the complexity of the decisionmaking task.

Regarding the reflection section of the questionnaire, in which students judged the decision-making processes of other people, the effect of the training was significant when the training groups were compared with the control group. This result indicates that the students in the training groups were more likely to describe the decisions on a level that involved the strategic aspects of the decision-making process. Furthermore, the suggestions regarding the improvement of the decisions included strategic considerations more frequently.

A limitation of this study is the moderate internal consistency (Cronbach's alpha) of the reflection scale for the follow-up test. Therefore, the effects should be evaluated with caution. However, one must consider that this construct is complex and heterogeneous: the decisions of three people were presented as solutions to the socioscientific issue, and each used different strategies to arrive at his/her decision. However, these aspects still belonged to the same construct from a theoretical point of view because they all represented important facets of an adequate reflection (Eggert \& Bögeholz, 2006, 2010). Thus, these factors should be evaluated in one scale. Even if these aspects are examined at the item level rather than the scale level, the finding that students from the selfregulation group improved significantly in reflecting intuitive judgments and offering suggestions for improvement is important. Moreover, these differences were stable during the two-month period between the intervention and the follow-up test. This result is noteworthy because the recognition that intuitive judgments lack the consideration of evidence and alternatives is important when judging the quality of the arguments of other 
people (Arvai et al., 2004; Baron, 1994; Haidt, 2001; Eggert \& Bögeholz, 2006).

When discriminating between the treatments with and without selfregulated learning, the authors found a significant difference only for the reflections on intuitive judgments. However, regarding other aspects of decision-making competence, the group that received self-regulation training had larger effect sizes than the group that did not receive this training. More importantly, key aspects, such as the structuring and planning of decision-making tasks and the reflection of the decisions of others, were still empirically observable two months after the training. These long-term effects were not significant for the group that did not receive training in self-regulated learning. Hence, the self-reflection on task performance and the setting of goals for future tasks were shown to be beneficial for gaining decision-making competence with regard to metadecision aspects and reflection. These findings show that selfregulated learning activities are not only valuable in enhancing problemsolving or knowledge acquisition (Schraw et al., 2004; Labuhn et al., 2008a), but also in fostering decision making.

In conclusion, the combination of decision-making strategies and reflections on reasoning flaws, enriched with exercises in self-regulated learning strategies, provides a fruitful approach for enhancing the decision-making competence of students and ensuring long-term effects.

In addition to the effects of the training program, a notable result of the present study is the extension of the scoring rubric by metadecision aspects (see Table 7.2). Metastatements are considered a component of high-quality reasoning (Means \& Voss, 1996) and could be coded with substantial interrater agreement. 


\subsection{Implications for STSE Education}

The present study demonstrates that a short intervention based on decision-making strategies is beneficial in enhancing the quality of the decisions of students in the long term. This outcome is comparable to the results of Zohar and Nemet (2002), who showed that short-term argumentation training improved the quality of the arguments of students. Consequently, these findings support the claim that both decision making and argumentation can be fostered in a short period of time. Nevertheless, the authors claim that decision-making and argumentation training should not be an addendum to science and environmental education; rather, such training should be a central part of this education.

One implication for STSE education is the necessity of reflecting on the strengths and weaknesses of the decision-making strategies that other people employ. Therefore, teachers should address the pitfalls of an inappropriate reduction of task complexity through an unjustified use of a non-compensatory strategy. The present study showed that strategic considerations regarding shortcomings and flaws in reasoning constitute a suitable approach for reaching this goal. Particularly in the area of education for sustainable development, it is vital that students be able to distinguish between decisions that involve unsustainable courses of action (and thus require non-compensatory strategies) and decisions that require full trade-offs. Although this study focused on education for sustainable development, the authors suggest that decision-making strategies are also applicable and useful in other STSE contexts. Future studies should examine the particular characteristics that socioscientific issues must possess to be suitable for acquiring and assessing decision-making competence.

Because the process of reflecting on the use of decision-making strategies requires metacognitive skills that develop as students mature, 
the influence of this development should also be investigated. Upper high school students were trained in the present study. Which aspects of this strategic training can be transferred to younger students? At which age are students capable of distinguishing between several possible decisionmaking strategies and reflecting on their adequate application? Which methods are suitable for encouraging effective decision making in different age groups?

Each student was individually trained in the current study. Therefore, future research should focus on two aspects to integrate individual and collective decision making. First, intervention studies that involve training teachers in the application of different decision-making strategies and reflections on flaws in decision-making processes are vital to the establishment of classroom activities as alternatives to computerbased programs. Eggert et al. (2010), for example, trained seventhgraders to apply a compensatory strategy in cooperative learning settings. Second, the relationship between individual and collective decision making should be illuminated: how can the use of different strategies and reflections based on strategic considerations be incorporated into group or whole-class discussions? The following approaches may enhance both individual and collective decision making: (1) discussions regarding the most suitable decision-making strategies and (2) the negotiation of thresholds that should be reached to ensure that possible courses of action meet the demands of different interest groups. 


\section{Summary and Discussion}

\subsection{Summary}

This empirical research project aims to foster systematic and thoughtful decision-making in the context of socioscientific issues pertaining to sustainable development. For this purpose, two research foci were examined in two computer-based intervention studies, one focusing on the application of decision-making strategies, the other investigating the effect of reflections upon decision-making processes on the students' decisionmaking competence. In addition, in both intervention studies, elements of self-regulated learning were integrated into the training program to unravel in which way this affects the acquisition of decision-making competence.

\section{Research focus 1: Application of decision-making strategies}

In the first intervention study, students from upper high school biology courses (grades 11 to $13, N=386$ ) were confronted with decision-making tasks related to sustainable development. During the intervention $(2 \times 45$ $\min$ ), the students of the training groups applied three decision-making strategies: a non-compensatory strategy, in which societal norms based on the framework of sustainable development require the exclusion of options (i.e., other benefits of the option cannot compensate for the deficits regarding knockout criteria), a compensatory strategy (all advantages and disadvantages are weighed in a full trade-off) and a mixed strategy. During the second phase of the intervention, the students were stimulated to use metadecision skills to select an appropriate strategy. The first training group selected a strategy directly, whereas the second training group was encouraged to conduct a task analysis to determine which strategy fits best with the decision-making task based on the forethought phase of Zimmerman's model of self-regulated learning (Zimmerman, 2000; see 
Figure 3.1) and Beach's metadecision framework (Beach, 1990; Beach \& Mitchell, 1978).

The effects of this intervention were investigated using a pre-postfollow-up control-group design and process-related data collected during the course of the computer-based program.

\section{Summative evaluation}

The effects of the intervention were assessed using a questionnaire on decision-making competence with open-ended items (Eggert \& Bögeholz, 2010) directly before and after the treatment and three months later. Two facets of decision-making competence were examined: the quality of the students' own decisions and the reflection on the decision-making processes of others. With regard to the quality of the students' own decisions, it was found that the training groups had a higher level of decision-making competence than the control group in the follow up, especially with regard to the weighting of criteria based on values. However, in the short-term analyses, a tendency to overuse noncompensatory strategies in the post-test negated the positive effects of an increase in value considerations so that the effects were only significant in the follow up.

Regarding the reflection task of the questionnaire, the students in the training groups improved at describing the decision-making processes as well as in making suggestions for improvement though this effect was not stable in the long-run for most aspects of the reflection.

For the second hypothesis regarding the additional effect of integrating self-regulated learning on decision-making competence, little evidence could be found. A difference between the training groups could be found only with regard to the suggestions for the improvement of the 
presented intuitive decision. Nevertheless, the result that the students who conducted the explicit task analysis as part of the self-regulation training perceived more autonomy in their decision-making processes is quite compelling.

\section{Process-related evaluation}

In addition to the analyses of the pre-post-follow-up tests, the metadecision activities, i.e., the task analyses conducted during the second session of the training, were examined in more detail $(n=120)$. Which explanations did the students offer to select a particular decisionmaking strategy? Which quality levels of explanations could be identified?

In a qualitative content analysis using a deductive-inductive approach (Mayring, 2008), the students' answers were categorized. Most of the students dealt with the question, whether a trade-off was possible or whether knockout criteria based on the framework of sustainable development existed to select one strategy. In addition, many students reflected on the importance of the inherent criteria. Those who considered particular criteria to be important based on societal norms or personal values identified these as knockout criteria and selected noncompensatory strategies to exclude options that did not reach ecological, social or economic standards. Other students who perceived all criteria to be equally important rather tended to use compensatory strategies to weigh all evidence. Three quality levels of these metadecision statements were derived. On the lowest level, the students did not make any reference to the strategy they selected or did not explain why they considered it most appropriate. On a basic level, the explanations referred to strategic considerations, whereas the highest level was characterized by explanations that explicitly linked strategic considerations to the specific task characteristics. 
Based on the quality levels, inferences were made about the performance of the students and the quality of the tasks of the intervention. The analyses of the study revealed that for the most part, students identified at least one of the knockout criteria in the tasks. However, in the task with equally legitimate options, many students excluded options based on personal values and did not employ the compensatory strategy although the compensatory strategy is considered best from a normative viewpoint. Contrary to the expectations, those students who offered high-quality metadecision statements did not choose the strategy that fits best according to societal norms. Instead, the pattern of quality levels was similar in each task regardless of the context and the expected decision-making strategy. Explanations for the selection of a compensatory strategy were mostly made on a basic level (strategic considerations), whereas those students who selected a noncompensatory strategy offered explanations on the highest level (strategic considerations linked to task characteristics). This is plausible because it is easier to identify one knockout criterion than to explain why several other criteria should be weighed in a complete trade-off.

Furthermore, the reasons for the overuse of non-compensatory strategies in the learning program were investigated. It could be shown that, as suggested by Hong and Chang (2004), the application of noncompensatory strategies causes less cognitive load than a compensatory strategy. However, these findings only explain the overuse to some extent. More importantly, the frequent deliberate use of non-compensatory strategies suggests that students were not able to distinguish between societal norms and personal values. 


\section{Research focus 2: Reflecting on decision-making processes}

In the second study, a different research focus was investigated regarding the reflection on decision-making processes $(N=242)$. In addition, the learning environment and the scoring rubric were optimized based on the results of the first study. As proposed by Ratcliffe and Grace (2003; cf. Eggert \& Bögeholz, 2010), the students were stimulated to reflect on the decision-making processes of other people that were presented to them in the second session of the training program. Two particular goals were pursued. In light of the result of the first research focus and the study of Hong and Chang (2004) showing that students frequently use noncompensatory strategies to solve decision-making tasks, the students were challenged to identify the non-reflective use of non-compensatory strategies. Moreover, the students had to contrast intuitive and systematic decisions by elaborating on the deficits and strengths of these decisionmaking processes.

The second training group received additional training in selfregulated learning based on the self-reflection phase of Zimmerman's model of self-regulated learning (Zimmerman, 2000; see Figure 3.1). After scrutinizing the quality of the presented decisions, the participating students reflected on their own performance: Which strengths and weaknesses of the decisions of other people did they identify? On which aspects should they focus in future tasks to improve their own performance? Hence, the cyclical character of self-regulated learning was emphasized through the self-reflection and goal setting for the resolution of future socioscientific issues.

The effect of this training was assessed with the decision-making questionnaire of Eggert and Bögeholz (2010) with additional metadecision items that were derived in a deductive-inductive approach (Mayring, 2008) based on the theoretical frameworks of Means and Voss (1996), Kuhn, 
(1999) and Eggert and Bögeholz (2006). Based on this evaluation scheme, it was shown that the students of the training groups planned their decisions more often in an explicit way and stated steps of their decision-making processes. This effect was still observable two months after the intervention for most aspects. However, the amount of considered evidence did not change as a result of the training. Regarding the reflection scale of the decision-making questionnaire, both training groups improved from the pre-test to the post-test. It is compelling that these gains in competence were stable in the follow up for the training group with additional elements of self-regulated learning who engaged in selfreflection and goal-setting for future tasks. In conclusion, the integration of self-regulated learning into a contextualized decision-making training that focused on the reflection of decision-making processes ensured long-run effects on decision-making competence.

\subsection{Training in Decision-making Strategies}

The presented studies focused on the application of decision-making strategies and reflections on the underlying decision-making processes. The results reveal that both approaches are suitable to foster individual decision-making competence, i.e., making systematic and elaborate decisions. From a normative educational perspective, structured and systematic decisions are superior to intuitive judgments because the decision-making process is more transparent and hence, open for debate (Eggert \& Bögeholz, 2006, 2010). In particularly, socioscientific issues pertaining to sustainable development demand elaborate decisions to deal with the factual and ethical complexity in an adequate way (Bögeholz \& Barkmann, 2005). Regarding moral judgments, Haidt (2001) and Baron (1998) claim that intuitive judgments do not produce optimal outcomes from a prescriptive standpoint. Consequently, findings from descriptive research concerning intuitive judgments should be used to help decision- 
makers avoid errors (Haidt, 2001). Sadler and Zeidler (2005) claim that intuitive and emotive reasoning patterns should be encouraged in classroom discourse to involve all students. However, they acknowledge that the basis of the students' reasoning should be challenged. In the second study of this dissertation, the participating students were stimulated to reflect upon the strengths and weaknesses of intuitive and more systematic decision-making processes. As a result, this approach has shown to be successful in fostering more systematic decisions.

Moreover, it is compelling that this short-term intervention of two periods (45 min each) yielded long-run effects that were still empirically observable in the follow up test. This finding is consistent with the results of the interventions of Zohar and Nemet (2002) and Venville and Dawson (2010) who improved argumentation skills within twelve and three periods, respectively. Kuhn (1999) argues that students already posses preliminary argumentation skills that can be elaborated on and fully expressed in argumentation trainings. Argumentation and decision-making are related constructs that both involve cognitive processes to structure relevant evidence and metacognitive skills to ensure a reflective execution. Therefore, the results of the presented studies indicate that, similar to argumentation, the use of decision-making strategies can be stimulated and elaborated on in a short training. However, whether classroom activities involving the reflective application of decision-making strategies are as efficient as computer-based training should be examined. The strategies of the intervention were derived from behavioral decision research (Jungermann et al., 2005; Payne et al., 1998; Plous, 1993). Thus, the presented study is based on the results of descriptive research, i.e., how people actually decide. While the results of behavioral decision research were gained through investigations of adults, the students' use of decision-making strategies has also been assessed from a normative 
educational viewpoint (Eggert \& Bögeholz, 2010). Consequently, the students were not trained to use artificial approaches to make decisions, but to make the premature strategies they may already execute implicitly more transparent and relate them to issues pertaining to sustainable development. This may explain how a decision-making training of two periods can be successful in yielding long-term effects on decision-making competence.

Because decision-making involves metacognitive processes to select an appropriate strategy based on the characteristics of the task and inherent societal norms, it is debatable at which age such decision-making training is useful. The presented studies focused on the selection between several decision-making strategies (study one) and a reflection upon the appropriateness of the decision-making strategies that other people applied (study two). Therefore, a high degree of metacognitive abilities was required during the course of the intervention. Thus, upper high school students (grades 11 to 13) were chosen because a high level of metacognitive skills was expected. However, the transferability of this strategic training to younger students should be investigated to determine at which age students are capable of using such metadecision aids effectively. Moreover, for classroom activities, it has to be investigated which specific methods are suitable for certain age groups. Eggert et al. (2010) have combined decision-making training with metacognitive structuring aids in the seventh grade. Although the decision-making training generally led to an increase in decision-making competence, the metacognitive structuring did not have an additional effect, which may be a result of the cognitive development of the students. Kuhn (1999) and Zeidler et al. (2005) describe and discuss developmental processes regarding critical thinking and the resolution of socioscientific issues. For the reflective use of decision-making strategies on a metadecision level, 
the development of the students should be taken into account to implement strategic trainings effectively. This requires theoretical elaborations and empirical research regarding cognitive development in relation to decision-making.

The results of the presented studies show that training decisionmaking strategies is successful in fostering individual decision-making competence. This is compelling because all citizens should be able to make thoughtful decisions regarding socioscientific issues, particularly in education for sustainable development (Bögeholz \& Barkmann, 2005; de Haan et al., 2008; Eggert \& Bögeholz, 2006; McConnell, 1982; Pedretti \& Nazir, 2011; Zeidler et al., 2005). While many decisions are made individually, e.g., consumer decisions, others require collective negotiations about the best course of action because a multitude of stakeholders are involved (Aikenhead, 1985; Bögeholz, 2006; Haan et al., 2008; Kyburz-Graber et al., 1997). Local environmental projects and global projects demand negotiations about possible outcomes. However, the conclusions made in this dissertation are restricted to individual decisionmaking because the intervention did not stimulate interactions among the students or discourse. This limitation should be addressed in future studies, for which the results of these studies represent a valuable starting point to transfer individual decision-making competence to collective negotiations. Aikenhead (1985) describes how individual and collective decision-making are intertwined. For a consensus, each group member has to reach the conclusion of the collective decision individually. Furthermore, each participant of a discussion may base his/her decision on personal values and pursue particular interests. In collective decisions, it is therefore vital that the individual decision-making process is transparent, i.e., it should be intersubjectively comprehensible to enable others to understand the perspective (Bögeholz \& Barkmann, 2003; 
Eggert \& Hößle, 2006). The summative assessment of the first study demonstrated that training in decision-making strategies combined with metadecision activities is useful to enhance the students' own decisionmaking competence, a prerequisite for collective decisions. Moreover, the process-related analyses of the metadecision explanations showed that the students were capable of making the societal norms and personal values, on which they based their decision, transparent and therefore open for debate. In the second research focus, the effect of an additional reflection on the deficits and strengths of the decision-making processes of other people was examined. This has shown to be beneficial not only for the students' own decision-making competence (an observed long-run increase in metastrategic planning of the decision) but also regarding the students' ability to describe other decision-making processes and to make suggestions for improvement (reflection scale of the questionnaire). While the inclusion of explicit metastatements is useful to make one's own decision-making process more transparent, a profound reflection is crucial for collective decisions because the identification of deficits in reasoning provides an adequate basis to engage in critical discourse with other stakeholders. Therefore, the question should be addressed in future studies, through which methods the principles of the presented intervention studies can best be transferred to small-group and wholeclass discussions about socioscientific issues. Such discussions can be combined with strategic considerations about the fit of decision-making strategies to the task characteristics and societal norms by the members of the group. On which thresholds do other group members base their decision to exclude options? Which common thresholds can be agreed on? Furthermore, whether courses of action are legitimate should be negotiated. For this purpose, the results of the presented studies are a suitable starting point because knowledge about the function of decision- 
making strategies and their successful application are considered valuable not only for individual but also for collective decision-making.

\subsection{Dealing with Societal Norms and Personal Values in Socioscientific Issues Pertaining to Sustainable Development}

Socioscientific issues in general and issues pertaining to sustainable development in particular demand an explicit consideration of values and norms in the decision-making process and a distinction from scientific facts (Bögeholz, 2011; Bögeholz \& Barkmann, 2003; Hogan, 2002; JiménezAleixandre \& Pereiro-Muñoz, 2002; Kolstø, 2001; Ratcliffe \& Grace, 2003; Zeidler et al., 2005). Non-sustainable options that do not meet requirements according to societal norms should be excluded. In addition, personal values should be taken into account when weighting criteria according to their perceived importance. The application of decisionmaking strategies that was investigated in this study is founded on normative considerations regarding sustainable development. As a consequence, students should be able to detect non-sustainable options with regard to ecological, social and economic standards (societal norms) and exclude them from further consideration using a non-compensatory decision-making strategy. The summative assessment of the first study revealed that the students who were trained in the application of decisionmaking strategies tended to exclude options in the post-test more often than the control group, although all the contexts were selected and adjusted in a way such that all the options were equally legitimate and required a full trade-off using a compensatory strategy. To unravel the reasons for this overuse of non-compensatory strategies, which has also been described by Hong and Chang (2004), three possible explanations were further scrutinized: the performance of the students, the quality of the 
tasks in the intervention and the structure of the decision-making questionnaire.

Regarding performance, it seemed plausible from a motivational perspective that the students used the non-compensatory strategy to avoid other cognitively more demanding strategies, which require the consideration of all evidence in a complete trade-off. However, the analyses of cognitive load measurements during the intervention and the examination of process-related metadecision explanations for the selection of a strategy suggest that the students did not hastily exclude options, but indeed demonstrated elaborate metadecision explanations to elaborate on why they considered the non-compensatory strategy to be most appropriate. It is compelling that the students mostly identified the nonsustainable options offered in the tasks during the training. However, in a task of the intervention with equally legitimate options, many students also used the non-compensatory strategy. As stated by Beach (1990; Beach \& Mitchell, 1978) in descriptive behavioral decision research, the selection of a decision-making strategy depends not only on the task characteristics but also on the characteristics of the decision-maker, who processes the information based on personal values and prior experiences. Therefore, the threshold to exclude one option differs from person to person. However, from a normative educational viewpoint, students should be able to reflect upon both personal values and societal norms.

The students' performance is closely related to the structure and quality of the intervention. The first study did not explicitly focus on a distinction between norms and values, which may have led to the overuse of non-compensatory strategies both in the post-test and during the intervention. A consumer decision triggered students to exclude options based on personal values. Based on this finding, the training program was optimized for the second study, particularly regarding the transfer phase. A 
problematic context was replaced and the participating students were stimulated to reflect on other people's decisions focusing on whether options were excluded precipitately or whether the exclusion was based on societal norms according to the sustainable development framework. As a result, this overuse of non-compensatory strategies due to the dominant consideration of personal values was not observed in the posttest and the follow up of the summative assessment in the second study.

Moreover, the structure of the decision-making questionnaire (Eggert \& Bögeholz, 2010) should be reviewed. The tasks of the questionnaire were considered equally legitimate according to the normative sustainability framework and, hence, required the application of a compensatory strategy. However, whether the options were indeed legitimate is debatable. Two courses of action may result in social injustice or involve ecological risks ${ }^{15}$ (post-test and follow up in the presented studies; Eggert \& Bögeholz, 2010). Although the options are courses of action in real-world scenarios that are actually pursued, it is still controversial whether this is desirable from a normative viewpoint considering the sustainability of the options. This lack of clarity regarding societal norms may have triggered the exclusion of options in the questionnaire used in both summative assessments. As a consequence, the way that the options were presented may have evoked responses that led to lower scores in the questionnaire because of the exclusion of options using a non-compensatory strategy, despite elaborate (meta)decision skills. Nevertheless, it is important to note that the overuse

\footnotetext{
${ }^{15}$ One option posed a threat on the employment in the fishing industry due to the radical measure to cease fishing entirely for three years (social injustice). The last task involved the consumption of chocolate made of milk from cows that were fed with genetically modified fodder (ecological risk).
} 
of decision-making strategies in the post-test of the study was only tendentially significant ${ }^{16}$, suggesting that the overall quality of the questionnaire is quite acceptable.

In the second study, a stronger focus on the adequacy of an exclusion of options regarding societal norms averted the unreflected use of non-compensatory strategies. However, from the considerations on the students' performance, the structure of the tasks of the training program and the decision-making questionnaire, it is suggested that further research is necessary to define and disentangle personal values and societal norms from a theoretical viewpoint, particularly with regard to the way students integrate them into their decision-making processes. Although the term "sustainable development" is broadly used in political debates and at the educational level, it is all but clear upon which norms and values scientists in the field or the society have agreed for particular issues. Due to these controversies, considerations about norms and values offer an opportunity to link socioscientific decision-making with reflections upon the nature of science involved in socioscientific issues. Debates among scientists concerning which indicators best represent sustainable development allow for reflections on science-in-the-making, which is considered essential for science education (Bingle \& Gaskell, 1994; Kolstø, 2001) because it demonstrates that science itself is not value-free and not based on scientific evidence alone. Consequently, it is essential to conduct empirical studies to train students to identify societal norms and personal values to integrate them in an elaborate decisionmaking process.

${ }^{16} p<.10$ 


\subsection{Fostering Decision-making through Self-regulated Learning}

In both of the studies described in this dissertation, elements of selfregulated learning were included in the decision-making training to make it more efficient. Therefore, self-regulation promoted the acquisition of complex competencies (cf. Perels et al., 2005) and is not only useful to enhance content knowledge or the execution of simple cognitive strategies (den Elzen-Rump \& Leutner, 2007; Labuhn et al., 2008a; Leutner \& Leopold, 2006). Moreover, the self-regulation training was not independent of the decision-making training but contextualized and linked to the main foci regarding the enhancement of decision-making competence. Two approaches have been selected based on Zimmerman's model of selfregulated learning (Zimmerman, 2000). A task analysis as part of the forethought phase was chosen to support students' metadecision processes when selecting a decision-making strategy in the first study. However, the inclusion of this metacognitive strategy did not result in higher gains in decision-making competence compared with the training of decision-making strategies without self-regulated learning, except for one item regarding reflection in the decision-making questionnaire. One possible way to explain this outcome in the summative assessment is a deficit in producing the new self-regulation strategy in the post-test and the follow up or an inefficient use thereof (Hasselhorn \& Gold, 2006). The process-related analyses revealed that the great majority of the students offered high-quality metadecision statements, which suggests the adequacy of the metacognitive strategy application during the training. However, the finding that the students were not able to distinguish personal values and societal norms may explain why the students did not efficiently conduct task analyses to select the strategy during the assessment. 
Nevertheless, the inclusion of task analyses as one element of selfregulated learning had beneficial effects on the resolution of socioscientific issues. During the training, the students reported higher levels of perceived autonomy. This is not only valuable from a motivational point of view (Deci \& Ryan, 1985, 2002) but also from a normative standpoint regarding the resolution of issues pertaining to sustainable development (de Haan et al., 2008). The selection and application of decision-making strategies offers an elaborate method to consider societal norms while still ensuring an independent choice of an option. Therefore, the explicit task analysis is beneficial for the educational goal to promote autonomous decisions.

In the second study, a different set of elements of self-regulated learning was included into the decision-making training. For the reflection on the quality of other people's decision-making processes, the selfreflection phase of Zimmerman's model of self-regulated learning (Zimmerman, 2000) was suitable from a theoretical point of view. Students were stimulated to self-reflect on their responses after critiquing the strengths and weaknesses of other decision-making processes, particularly with regard to the aspects they focused on during the task and the important aspects that they would concentrate on in future tasks when reflecting upon the quality of other decisions. Consequently, the students were triggered to formulate goals for future tasks. This takes the cyclical character of self-regulated learning into account. The results of the second study revealed that interlinking reflections on other decisions with selfreflection and goal setting successfully enhanced decision-making competence. Only the training group that was additionally trained in selfregulated learning yielded long-run effects with regard to essential components of decision-making competence, such as metastrategic 
planning of one's own decision-making process and reflections on other decisions.

While the cognitive and metacognitive components of self-regulated learning have successfully contributed to the enhancement of decisionmaking competence, motivational aspects were not included in the training because the presented studies focused on fostering systematic and structured decision-making processes, i.e., cognitive and metacognitive abilities, as in Bögeholz's definition of decision-making competence (2007; cf. Hartig \& Klieme, 2006). However, for future research, particularly with regard to linking individual decision-making with collective decisions and subsequent actions, incorporating motivational aspects will likely be beneficial. How cognitive and motivational constraints prevent students from implementing the outcome of their elaborate decisions and how they can be overcome should also be investigated (Ernst, 2008). Based on the self-determination theory (Deci \& Ryan, 1985, 2002), Darner (2009) describes how motivational factors can be linked to environmental actions. As a basis for motivation, three basic psychological needs should be satisfied: perceived autonomy, perceived competence and relatedness. The first study was successful at enhancing perceived autonomy when resolving socioscientific issues through elements of self-regulated learning. It should be determined how self-regulated learning and selfdetermination theory are linked from a theoretical point of view and in which way the other components that are necessary for self-determination could be fostered with regard to the decision-making process.

In conclusion, two facets of self-regulation have been successfully implemented into a decision-making training. While the elements of the self-reflection phase fostered long-run gains in decision-making competence, the task analysis to stimulate metadecision considerations as part of the forethought phase efficiently enhanced the level of perceived 
autonomy during the decision-making process (see Figure 3.1). In the presented studies, however, all students within one training group received the same treatment regardless of their self-regulation abilities or their previous levels of decision-making competence. To enhance the effectiveness of a decision-making training including elements of selfregulated learning, future research on developing adaptive trainings that focus on particular demands of students through feedback will be valuable. Feedback from experiences in prior tasks is essential to enhance the performance in future tasks and, hence, constitutes one central component of self-regulated learning (Zimmerman, 2000). In instructional research, feedback has shown to be one of the most powerful influences on learning and achievement (Hattie \& Timperley, 2007) and its inclusion into complex problem-solving environments was effective to develop problem-solving skills (Moreno, Reisslein, \& Ozugul, 2009). In particular, computer-based trainings offer the opportunity to include timely and adaptive feedback. How different types of feedback based on the three phases of self-regulated learning can enhance self-regulated decisionmaking should be investigated.

\subsection{Methodical Reflections}

The design of the studies was suitable to determine the effects of the intervention. The random assignment of the participating students within the same classroom to one of the two training groups or the control group at the beginning of the computer-based intervention ensured equal groups with regard to decision-making competence prior to training and other control variables, e.g., age or sex. Therefore, it was possible to determine the effects of the training by reducing the number of confounding variables, such as the influence of the class, the teacher or the school. Nevertheless, the study was conducted in biology courses at school to enhance the ecological validity. Furthermore, the control group dealt with 
the same decision-making tasks as the training groups, but received additional ecological information instead of strategic training or elements of self-regulated learning. Consequently, the choice of the control group is quite conservative and represents an authentic alternative, which is similar to currently used methods in biology classes. Therefore, the differences in decision-making competence between the training groups and the control group can be related to the effects of training in decision-making strategies. However, whether the level of competence actually increased from the pre-test to the post-test or follow up could not be determined because different versions of the questionnaire were used for the assessment. Although the structure of the decision-making tasks and the scoring rubric were identical at all measurement times, the varied contexts may have led to different degrees of difficulty in different test versions. Consequently, analyses of covariance of the post-test (follow up-test) scores that controlled for the pre-test scores were conducted rather than analyses of variance including different measurement times. Hence, the effects of the group were used to determine the outcome of the intervention instead of interaction effects of group and time.

The results of the summative assessments of decision-making competence revealed that the decision-making questionnaire of Eggert and Bögeholz (2010) was suitable to describe the effects of the intervention studies. Nevertheless, the statistical analyses showed that assessing the complex competence of decision-making with open-ended items is a challenging endeavor. In this respect, the low internal consistency of the scales of the questionnaire represents a limitation of the studies. In the first study, Cronbach's alpha values were observed within a range of .52 to .65 . for both observed scales, the students' own decision and reflection. Some items in the first scale were negatively correlated. Consequently, the homogeneity of the construct regarding item fit 
statistics ${ }^{17}$ reported by Eggert and Bögeholz (2010), who used the Rasch partial credit model based on item-response theory, could not be confirmed through statistical analyses based on classical test theory (Cronbach's alpha, correlations between items, correlation between items and scale). As a consequence, the reflection scale had to be evaluated at the item level rather than at the scale level in the first study. One reason for the moderate internal consistency is the heterogeneity of the theoretical construct. Regarding the students' own decision, the amount of considered evidence was assessed alongside the weighting of criteria based on values and norms. Although both aspects belong to the same construct from a theoretical point of view (Eggert \& Bögeholz, 2006), many students either described relevant evidence in detail to illustrate their decision or stated which values were important for them, and thus implied one option without fully describing all of the evidence. Similarly, the reflection scale involved descriptions of three different presented decision-making processes and suggestions for improvement, which are diverse facets of the same construct. Despite the low internal consistency of the scales, the questionnaire assesses central aspects of decision-making competence from a theoretical point of view and is hence considered adequate to determine the effects of the intervention.

Due to these limitations of the first study, the scoring rubric of the open-ended items was modified and extended to allow for a more sensitive assessment of the results of the second training. From a theoretical point of view, metastatements are considered valuable for decision-making and reasoning (Eggert \& Bögeholz, 2006; Kuhn, 1999;

\footnotetext{
${ }^{17}$ Eggert and Bögeholz (2010) reported Q-indices in the range of 0.10 to 0.25 for the items on the questionnaire. Furthermore, regarding the homogeneity of the participants' response behavior, the unidimensionality of the test was demonstrated.
} 
Means \& Voss, 1996). Consequently, the scoring rubric of Eggert and Bögeholz (2010, cf. Eggert et al., 2010) was extended using a deductiveinductive approach to derive new categories based on theoretical considerations (Mayring, 2008). These categories were subsequently refined according to the investigated data. The final scoring system involved metastrategic planning of the decision-making process as well as an explicit description of the single steps of the employed strategy. As a result, it was possible to describe whether the students made their decision in a more transparent way. Consequently, the extension of the scoring rubric was successful at evaluating the effects of training for upper high school students with statistical analyses at the item level based on classical test theory. However, it remains unclear whether these items can be included in scales for analyses based on item response theory or whether they are suitable to assess decision-making competence of younger students. Eggert and Bögeholz (2010; cf. Eggert, 2008) stated that the original set of items was appropriate for item response theorybased analyses regarding a wide range of students (grades 6 to 12). Therefore, future studies should investigate in which way these new categories are suitable to assess decision-making competence of younger students or whether the metadecision items can be integrated into one total scale of decision-making competence without violating the unidimensionality of the test ${ }^{18}$ described by Eggert and Bögeholz (2010).

In addition to the extension of the scoring rubric, the first scale was split into the facets considered evidence and value-based weighting, which solved the problem of the low Cronbach's alpha values in the second

\footnotetext{
${ }^{18}$ The data were modeled using a Rasch partial credit model based on item response theory.
} 
study (scale for considered evidence: Cronbach's alpha: .80 - .83; valuesbased weighting was analyzed at the item level). The internal consistency of the reflection scale improved slightly (Cronbach's alpha: .57 - .69). Generally, the categories to score the open answers were well-defined because the independent scoring of half the questionnaires by a second rater showed satisfying interrater-reliabilities in both studies (Cohen's kappa: .68 - .81). To improve the quality of the scoring further, all the different scores were discussed to agree on a final score.

Both intervention studies involved the reflective application of three decision-making strategies: a compensatory strategy, a non-compensatory strategy and a mixed strategy. Contrastingly, the questionnaire of Eggert and Bögeholz (2010) involved decision-making tasks with equally legitimate options that all required the application of a compensatory strategy, i.e., a full trade-off. The assessment of decision-making competence did not involve the resolution of issues with non-sustainable courses of action, which would require the application of a noncompensatory or mixed strategy. Consequently, the chosen test instrument did not ideally fit to assess the effects of the intervention. Until now, decision-making questionnaires that require the use of different strategies have not been developed. It can be assumed that an additional assessment of decision-making competence with a questionnaire involving tasks with non-sustainable options would reveal further insights into the effects of the training. However, it is compelling that strong effects have been demonstrated with the existing questionnaire involving one type of decision-making situation. For the purpose of developing a new questionnaire, the analyses of the process-related data may serve as a point of reference to design the tasks and the scoring rubric of such a questionnaire. A limitation of these analyses is that the students were explicitly asked to present metadecision statements, whereas the 
assessment of decision-making competence involves the entire decisionmaking process. As described above, it is vital to develop a theoretical model to further describe what the societal norms in the field of sustainable development are and conduct empirical studies about the students' understanding of norms and values and the integration into the decision-making process. In a subsequent step, questionnaires involving non-sustainable options should be developed. The use of these questionnaires may provide further insights into the mechanisms of the presented training studies.

\subsection{Concluding Remarks}

To summarize, the studies presented in this dissertation successfully fostered decision-making competence by training decision-making strategies combined with different facets of self-regulated learning. The summative and process-related analyses revealed valuable insights into the mechanisms involved when training systematic decision-making and with regard to the inherent considerations of societal norms and personal values. Furthermore, the presented studies give an example of how selfregulated learning can be contextualized and interlinked with training complex competencies.

The empirical results of the dissertation are compelling because training in decision-making strategies has been shown to be an effective method to enhance the quality of the students' decision-making processes as well as their reflection abilities. For STSE education in general and for education for sustainable development in particular, it is vital that students are able to make thoughtful decisions about controversial socioscientific issues (Aikenhead, 1985; de Haan et al., 2008; Eggert \& Bögeholz, 2006; McConnell, 1982; Pedretti \& Nazir, 2011; Zeidler et al., 2005). The urgent problems that the world society faces are complex with regard to scientific 
evidence and inherent norms and values. Therefore, they require all citizens to make elaborate and responsible decisions. In this study, the students were challenged to reflect upon inherent societal norms to determine whether options are non-sustainable with regard to ecological, economic or social standards using non-compensatory strategies. In contrast, other types of tasks with legitimate options required a full tradeoff to compare all pieces of evidence in a compensatory strategy. Although the decision-making training was contextualized for tasks pertaining to sustainable development, it is suggested that the application of decisionmaking strategies is also valuable to resolve other types of socioscientific issues. Further research should investigate in which way the reflective application of decision-making strategies can be transferred to other contexts and collective decision-making. Which methods are most suitable to incorporate the approaches of the presented computer-based interventions into classroom activities should be investigated. Adaptive trainings that integrate elements of self-regulated learning into decisionmaking are considered promising to ensure an effective acquisition of decision-making competence. 


\section{References}

Abelson, R. P., \& Levi, A. (1985). Decision making and decision theory. In G. Lindzey \& E. Aronson (Eds.), Handbook of Social Psychology (3rd ed., Vol. 1, pp. 231-309). Reading: Addisson-Wesley.

Ahlf-Christiani, C., Becker, I., Bernicke, B., Bögeholz, S., Dierks, H. G., Fischer, J., von Gadow, F. et al. (2003). Förderung der Urteilskompetenz im Fachunterricht der Sekundarstufe I und II. Werkstattmaterialien BLK-Programm „21“ Nr. 9, Partizipatives Lernen - Nachhaltigkeitsindikatoren entwickeln (Fostering judgment competence at secondary school level. Classroom materials developed in the BLK program „21", no. 9, participatory learning Developing indicators for sustainable development), retrieved from http://www.transfer-21.de.

Aikenhead, G. S. (1985). Collective decision making in the social context of science. Science Education, 69(4), 453-475.

Aikenhead, G. S. (1994). The social contract of science: Implications for teaching science. In J. Solomon \& G. S. Aikenhead (Eds.), STS education - International perspectives on reform. New York: Teachers College Press.

Aikenhead, G. S. (2006). Science education for everyday life. Evidencebased practice. New York: Teachers College Press.

American Association for the Advancement of Science (AAAS). (1989). Science for all Americans. Washington: Author.

American Association for the Advancement of Science (AAAS). (1993). Benchmarks for science literacy. New York: Oxford University Press.

Artelt, C. (1999). Lernstrategien und Lernerfolg - Eine handlungsnahe Studie (Learning strategies and performance - A process-related study). Zeitschrift für Entwicklungspsychologie und Pädagogische Psychologie, 31(2), 86-96.

Artelt, C. (2000). Wie prädiktiv sind retrospektive Selbstberichte über den Gebrauch von Lernstrategien für strategisches Lernen? (How predictive are retrospective self-reports on the use of learning strategies for strategic learning?). Zeitschrift für Pädagogische Psychologie, 14(2), 72-84. 
Artelt, C., Demmrich, A., \& Baumert, J. (2001). Selbstreguliertes Lernen (Self-regulated learning). In J. Baumert, E. Klieme, M. Neubrand, M. Prenzel, U. Schiefele, W. Schneider, P. Stanat, et al. (Eds.), PISA 2000 - Basiskompetenzen von Schülerinnen und Schülern im internationalen Vergleich (PISA 2000 - Key competencies of students in an international comparison) (pp. 271-298). Opladen: Leske + Buderich.

Arvai, J. L., Campbell, V. E. A., Baird, A., \& Rivers, L. (2004). Teaching students to make better decisions about the environment: Lessons from the decision sciences. The Journal of Environmental Education, 36(1), 33-44.

Arvai, J. L., \& Gregory, R. (2003). Testing alternative decision approaches for identifying cleanup priorities at contaminated sites. Environmental Science \& Technology, 37(8), 1469-1476.

Bandura, A. (1986). Social foundations of thought and action: A social cognitive theory. Englewood Cliffs: Prentice-Hall.

Barfod-Werner, I., Becker, G., Bese, A., Eggert, S., Goedeke, K., Grammel, U., Müller, K., et al. (2008). Kaufentscheidung Apfelsorte (Consumer decision: Buying a variety of apples). In M. Lücken \& B. Schröter (Eds.), Biologie im Kontext. Aufgaben-CD-ROM (Biology in context. $C D$ with classroom materials). Kiel: Leibniz-Institut für die Pädagogik der Naturwissenschaften (IPN).

Baron, J. (1994). Thinking and deciding (2nd ed.). Cambridge: Cambridge University Press.

Baron, J. (1998). Judgment misguided: Intuition and error in public decision making. New York: Oxford University Press.

Baron, J., \& Brown, R. V. (1991). Teaching decision making to adolescents. Hillsdale: Lawrence Erlbaum Associates.

Baumert, J., \& Köller, O. (1996). Lernstrategien und schulische Leistungen (Learning strategies and school performance). In J. Möller \& O. Köller (Eds.), Emotionen, Kognitionen und Schulleistung (Emotions, cognitions and school performance) (pp. 137-154). Weinheim: Beltz. 
Bayer, G., Eggert, S., Goldschmidt, H., Kiesel, G., Kratsch, S., Müller, E., \& Winterberg, A. (2008). Forellen züchten - Welche Standorte sind geeignet? (Cultivating trouts - Which locations are suitable?) In M. Lücken \& B. Schröter (Eds.), Biologie im Kontext. Aufgaben-CDROM (Biology in context. CD with classroom materials). Kiel: Leibniz-Institut für die Pädagogik der Naturwissenschaften (IPN).

Bayrhuber, H. (1992). Ethische Analyse der Gentherapie von Keimbahnzellen im Unterricht (Ethical analyses regarding germline therapy in the classroom). Friedrich-Jahresheft, 128-131.

Bayrhuber, H., Bögeholz, S., Eggert, S., Elster, D., Grube, C., Hößle, C., Linsner, M., et al. (2007). Biologie im Kontext - Erste Forschungsergebnisse (Biology in context - First research results). Der Mathematische und Naturwissenschaftliche Unterricht, 60(5), 304-313.

Bayrhuber, H., Bögeholz, S., Elster, D., Hammann, M., Hößle, C., Lücken, M., Mayer, J., et al. (2007). Biologie im Kontext - Ein Programm zur Kompetenzförderung durch Kontextorientierung im Biologieunterricht und zur Unterstützung von Lehrerprofessionalität (Biology in context - A program for the enhancement of competencies through context orientation in biology classes and for teacher professionalism). Der Mathematische und Naturwissenschaftliche Unterricht, 60(5), 282-286.

Beach, L. R. (1990). Image theory: Decision making in personal and organizational contexts. West Sussex: John Wiley and Sons.

Beach, L. R., \& Mitchell, T. R. (1978). A contingency model for the selection of decision strategies. Academy of Management Review, 3(3), 439-449.

Bell, R. L., \& Lederman, N. G. (2003). Understandings of the nature of science and decision making on science and technology based issues. Science Education, 87(3), 352-377.

Berkowitz, M. W., \& Simmons, P. (2003). Integrating science education and character education. In D. L. Zeidler (Ed.), The role of moral reasoning on socioscientific issues and discourse in science education (pp. 117-138). Dordrecht: Kluwer Academic Publishers. 
Bernholt, S., Eggert, S., \& Kulgemeyer, C. (in press). Capturing the diversity of students' competences in science classrooms: Differences and commonalities of three complementary approaches. In Proceedings of the IPN-York-Symposium, Kiel: Leibniz-Institut für die Pädagogik der Naturwissenschaften und Mathematik.

Betsch, T., \& Haberstroh, S. (2005). Current research on routine decision making: Advances and prospects. In T. Betsch \& S. Haberstroh (Eds.), The routines of decision making (pp. 359-376). Mahwah: Erlbaum.

Betsch, T., Haberstroh, S., \& Höhle, C. (2002). Explaining routinized decision making: A review of theories and models. Theory Psychology, 12(4), 453-488.

Bingle, W. H., \& Gaskell, P. J. (1994). Scientific literacy for decisionmaking and the social construction of scientific knowledge. Science Education, 78(2), 185-201.

Boekaerts, M. (1999). Self-regulated learning: Where we are today. International Journal of Educational Research, 31(6), 445-457.

Bögeholz, S. (2006). Explizites Bewerten und Urteilen. Beispielkontext Streuobstwiese (Explicit evaluation and judgment. Meadows with scattered fruit trees as an exemplary context). Praxis der Naturwissenschaften, 55(1), 17-24.

Bögeholz, S. (2007). Bewertungskompetenz für systematisches Entscheiden in komplexen Gestaltungssituationen Nachhaltiger Entwicklung (Decision-making competence for systematic decisions in complex issues pertaining to sustainable development). In D. Krüger \& H. Vogt (Eds.), Theorien in der biologiedidaktischen Forschung (Theories of research in biology education) (pp. 209220). Berlin: Springer. 
Bögeholz, S. (2011). Bewertungskompetenz im Kontext Nachhaltiger Entwicklung: Ein Forschungsprogramm (Decision-making competence in the field of sustainable development. A research program). In D. Höttecke (Ed.), Naturwissenschaftliche Bildung als Beitrag zur Gestaltung partizipativer Demokratie. Gesellschaft für Didaktik der Chemie und Physik. Jahrestagung in Potsdam 2010. (Contributions of science education to the development of a participatory democracy. National conference of chemistry and physics education in Potsdam, 2010) (pp. 32-46). Münster: LITVerlag.

Bögeholz, S., \& Barkmann, J. (2003). Ökologische Bewertungskompetenz für reale Entscheidungssituationen: Gestalten bei faktischer und ethischer Komplexität (Ecological decision-making competence in factually and ethically complex real-world situations). DGUNachrichten, 27/28, 44-53.

Bögeholz, S., \& Barkmann, J. (2005). Rational choice and beyond: Handlungsorientierende Kompetenzen für den Umgang mit faktischer und ethischer Komplexität (Rational choice and beyond: Action-oriented competencies for dealing with factual and ethical complexity). In R. Klee, A. Sandmann, \& H. Vogt (Eds.), Lehr- und Lernforschung in der Biologiedidaktik (Educational research in didactics of biology) (Vol. 2, pp. 211-224). Innsbruck: Studienverlag.

Bögeholz, S., Bittner, A., \& Knolle, F. (2006). Der Nationalpark Harz als Bildungsort (The national park Harz as an educational site). GAIA, 15(2), 135-143.

Bögeholz, S., Hößle, C., Langlet, J., Sander, E., \& Schlüter, K. (2004). Bewerten - Urteilen - Entscheiden im biologischen Kontext: Modelle in der Biologiedidaktik (Evaluating - judging - deciding in a biological context. Models in biology education). Zeitschrift für Didaktik der Naturwissenschaften, 10, 89-115.

Bourn, D. (2005). Education for sustainable development and global citizenship. The challenge of the UN-decade. Zeitschrift für internationale Bildungsforschung und Entwicklungspolitik, 28(3), 1519.

Bundesministerium für Bildung und Forschung (BMBF). (2009). Bericht der Bundesregierung zur Bildung für eine nachhaltige Entwicklung (Report of the government of the Federal Republic of Germany about education for sustainable development). Berlin: Author. 
Bundesministerium für wirtschaftliche Zusammenarbeit und Entwicklung (BMZ), \& Kultusministerkonferenz (KMK). (2007). Orientierungsrahmen für den Lernbereich Globale Entwicklung im Rahmen einer Bildung für nachhaltige Entwicklung (A framework for the educational field of global development within the framework of education for sustainable development). Bonn: Author.

Bund-Länder-Kommission für Bildungsplanung und Forschungsförderung (BLK). (1997). Gutachten zur Vorbereitung des Programms „Steigerung der Effizienz des mathematisch-naturwissenschaftlichen Unterrichts" (Report to prepare the initiation of the program „Enhancing the efficiency of mathematics and science education"). Bonn: Author.

Bund-Länder-Kommission für Bildungsplanung und Forschungsförderung (BLK). (1998). Bildung für eine nachhaltige Entwicklung Orientierungsrahmen (Education for sustainable development - A framework for orientation). Bonn: Author.

Bund-Länder-Kommission für Bildungsplanung und Forschungsförderung (BLK). (2005). Bildung für eine nachhaltige Entwicklung („21"): Abschlussbericht des Programmträgers zum BLK-Programm (Education for sustainable development: Final report on the BLKprogram „21“). Bonn: Author.

Bybee, R. W., McCrae, B., \& Laurie, R. (2009). PISA 2006: An assessment of scientific literacy. Journal of Research in Science Teaching, 46(8), 865-883.

Carroll, J. S., \& Johnson, E. J. (1990). Decision research - A field guide. London: Sage.

Colucci-Gray, L., Camino, E., Barbiero, G., \& Gray, D. (2006). From scientific literacy to sustainability literacy: An ecological framework for education. Science Education, 90(2), 227-252.

Darner, R. (2009). Self-determination theory as a guide to fostering environmental motivation. The Journal of Environmental Education, 40(2), 39-49.

Dawson, V. M., \& Venville, G. J. (2010). Teaching strategies for developing students' argumentation skills about socioscientific issues in high school genetics. Research in Science Education, 40(2), 133-148. 
de Haan, G. (2006). The BLK „21“ programme in Germany: A "Gestaltungskompetenz"-based model for education for sustainable development. Environmental Education Research, 12(1), 19-32.

de Haan, G. (2008). Gestaltungskompetenz als Kompetenzkonzept für Bildung für nachhaltige Entwicklung (Shaping competence as a conceptual framework for education for sustainable development). In I. Bormann \& G. de Haan (Eds.), Kompetenzen der Bildung für nachhaltige Entwicklung (Competencies in the field of education for sustainable development) (pp. 23-44). Wiesbaden: VS Verlag für Sozialwissenschaften, GWV Fachverlage.

de Haan, G. (2010). The development of ESD-related competencies in supportive institutional frameworks. International Review of Education, 56(2-3), 315-328.

de Haan, G., \& Gerhold, L. (2008). Bildung für nachhaltige Entwicklung Bildung für die Zukunft. Einführung in das Schwerpunktthema (Education for sustainable development - Education for the future. An introduction into a key issue). Umweltpsychologie, 12(2), 4-9.

de Haan, G., \& Harenberg, D. (1999). Expertise „Förderprogramm Bildung für nachhaltige Entwicklung " verfasst für die Projektgruppe „Innovation im Bildungswesen“ der Bund-Länder-Kommission für Bildungsplanung und Forschungsförderung im Auftrage des Bundesministeriums für Bildung, Wissenschaft, Forschung und Technologie (Expertise on the „program for the promotion of education for sustainable development" composed for the project "innovations in the educational system" of the commission of the Federal Republic of Germany and its federal states on educational strategies and the promotion of research on behalf of the (German) ministry for education, research and technology). Berlin: Freie Universität Berlin.

de Haan, G., Kamp, G., Lerch, A., Martignon, L., Müller-Christ, G., \& Nutzinger, H.-G. (2008). Nachhaltigkeit und Gerechtigkeit: Grundlagen und schulpraktische Konsequenzen (Sustainability and justice: Foundations and practical consequences for school education). Berlin: Springer.

Deci, E. L., \& Ryan, R. M. (1985). Intrinsic motivation and selfdetermination in human behavior. New York: Plenum Press.

Deci, E. L., \& Ryan, R. M. (2002). Handbook of self-determination research. Rochester: University of Rochester Press. 
den Elzen-Rump, V., \& Leutner, D. (2007). Naturwissenschaftliche Sachtexte verstehen - Ein computerbasiertes Trainingsprogramm für Schüler der 10. Jahrgangsstufe zum selbstregulierten Lernen mit einer Mapping-Strategie (Understanding science texts - A computer-based training program for students of the tenth grade for self-regulated learning based on a mapping strategy). In $M$. Landmann \& B. Schmitz (Eds.), Selbstregulation erfolgreich fördern (Fostering self-regulation successfully) (pp. 251-268). Stuttgart: Kohlhammer.

Deutscher Bundestag. (1998). Konzept Nachhaltigkeit. Vom Leitbild zur Umsetzung. Abschlußbericht der Enquete-Kommission „Schutz des Menschen und der Umwelt - Ziele und Rahmenbedingungen einer nachhaltig zukunftsverträglichen Entwicklung" des 13. Deutschen Bundestags (The concept of sustainability. From a guiding principle to its implementation. Final report of the commission "Protecting humans and the environment - Goals and conditions of a sustainable and future-oriented development" of the $13^{\text {th }}$ German Bundestag). Bonn: Author.

Dulitz, B., \& Kattmann, U. (1990). Bioethik. Fallstudien für den Unterricht (Bioethics. Case studies for teaching). Stuttgart: Metzler.

Driver, R., Newton, P., \& Osborne, J. (2000). Establishing the norms of scientific argumentation in classrooms. Science Education, 84(3), 287-312.

Eggert, S. (2008). Bewertungskompetenz für den Biologieunterricht - Vom Modell zur empirischen Überprüfung (Decision-making competence in in the biology classroom. From a theoretical model to its empirical verification. Göttingen: Niedersächsische Staats- und Universitätsbibliothek Göttingen.

Eggert, S., Barfod-Werner, I., \& Bögeholz, S. (2008). Entscheidungen treffen - Wie man vorgehen kann (Decision-making - How to proceed). Unterricht Biologie kompakt, 336, 13-18.

Eggert, S., Barfod-Werner, I., \& Bögeholz, S. (2010). Aufgaben zur Förderung der Bewertungskompetenz (Tasks for the enhancement of decision-making competence). In U. Spörhase \& W. Ruppert (Eds.), Biologie-Methodik (Methods in biology education) (pp. 231234). Berlin: Cornelsen-Scriptor. 
Eggert, S., \& Bögeholz, S. (2006). Göttinger Modell der Bewertungskompetenz - Teilkompetenz „Bewerten, Entscheiden und Reflektieren" für Gestaltungsaufgaben Nachhaltiger Entwicklung (Göttingen's model of decision-making competence - subcompetence "evaluating, deciding and reflecting" in tasks related to sustainable development). Zeitschrift für Didaktik der Naturwissenschaften, 12, 177-199.

Eggert, S., \& Bögeholz, S. (2010). Students' use of decision-making strategies with regard to socioscientific issues: An application of the Rasch partial credit model. Science Education, 94(2), 230-258.

Eggert, S., Bögeholz, S., Watermann, R., \& Hasselhorn, M. (2010). Förderung von Bewertungskompetenz im Biologieunterricht durch zusätzliche metakognitive Strukturierungshilfen beim Kooperativen Lernen - Ein Beispiel für Veränderungsmessungen (The effects of metacognitive instruction on students' socioscientific decision making - An exemplary procedure for measurement of change). Zeitschrift für Didaktik der Naturwissenschaften, 16 ,299-314.

Eggert, S., \& Hößle, C. (2006). Bewertungskompetenz im Biologieunterricht - Ein Überblick (Decision-making in biology education An overview). Praxis der Naturwissenschaften, 55(1), 1-10.

Eilam, E., \& Trop, T. (2011). ESD pedagogy: A guide for the perplexed. The Journal of Environmental Education, 42(1), 43-64.

Erduran, S., Simon, S., \& Osborne, J. (2004). TAPping into argumentation: Developments in the application of Toulmin's argument pattern for studying science discourse. Science Education, 88(6), 915-933.

Ernst, A. (2008). Zwischen Risikowahrnehmung und Komplexität: Über die Schwierigkeiten und Möglichkeiten kompetenten Handelns im Umweltbereich (Risk perception and complexity: About the challenges and possibilities of competent action in the field of environmental issues). In I. Bormann \& G. de Haan (Eds.), Kompetenzen der Bildung für nachhaltige Entwicklung (Competencies in education for sustainable development) (pp. 1522). Wiesbaden: VS Verlag für Sozialwissenschaften; GWV Fachverlage.

Fensham, P. J. (1988). Approaches to the teaching of STS in science education. International Journal of Science Education, 10(4), 346356. 
Fensham, P. J. (2009). Real world contexts in PISA science: Implications for context-based science education. Journal of Research in Science Teaching, 46(8), 884-896.

Fien, J., \& Tilbury, D. (2002). The global challenge of sustainability. In D. Tilbury, R. B. Stevenson, J. Fien, \& D. Schreuder (Eds.), Education and sustainability: Responding to the global challenge (pp. 1-12). Gland: International Union for Conservation of Nature and Natural Resources.

Gausmann, E., Eggert, S., Hasselhorn, M., Watermann, R., \& Bögeholz, S. (2010). Wie verarbeiten Schüler/innen Sachinformationen in Problem- und Entscheidungssituationen Nachhaltiger Entwicklung? - Ein Beitrag zur Bewertungskompetenz (How do students process information in issues pertaining to sustainable development? A contribution to the framework of decision-making competence). Zeitschrift für Pädagogik, Beiheft 56, 204-215.

Gigerenzer, G., \& Selten, R. (2001). Bounded rationality - The adaptive toolbox. Cambridge: MIT Press.

Gigerenzer, G., \& Todd, P. M. (2001). Fast and frugal heuristics: The adaptive toolbox. In G. Gigerenzer \& P. M. Todd (Eds.), Simple heuristics that make us smart (pp. 3-36). Oxford: Oxford University Press.

Grace, M. (2009). Developing high quality decision-making discussions about biological conservation in a normal classroom setting. International Journal of Science Education, 31(4), 551-570.

Grace, M., \& Ratcliffe, M. (2002). The science and values that young people draw upon to make decisions about biological conservation issues. International Journal of Science Education, 24(11), 11571169.

Gresch, H., Hasselhorn, M., \& Bögeholz, S. (2011). Training in decisionmaking strategies - An approach to enhance students' competence to deal with socioscientific issues. International Journal of Science Education, online first. 
Große, F., \& Bögeholz, S. (2005). Explizite Bewertung am Beispiel der Streuobstwiese - Zur Bedeutung von Entscheidungs- und Ökosystemkontexten (Meadows with scattered fruit trees as an example for explicit evaluations - About the relevance of contexts in decision-making regarding complex ecological systems). In $\mathrm{M}$. Schrenk \& W. Holl-Giese (Eds.), Bildung für nachhaltige Entwicklung. Ergebnisse empirischer Untersuchungen (Education for sustainable development. Results of empirical studies) (pp. 159173). Hamburg: Kovač.

Haidt, J. (2001). The emotional dog and its rational tail: A social intuitionist approach to moral judgment. Psychological Review, 108(4), 814834.

Hammond, K., Hamm, R. M., Grassia, J., \& Pearson, T. (1987). Direct comparison of the efficacy of intuitive and analytical cognition in expert judgment. IEEE Transactions on Systems, Man, and Cybernetics, 17(5), 753-770.

Hartig, J., \& Klieme, E. (2006). Kompetenz und Kompetenzdiagnostik (Competence and its methods of assessment). In K. Schweizer (Ed.), Leistung und Leistungsdiagnostik (Performance and its assessment) (pp. 127-143). Heidelberg: Springer Medizin.

Hasselhorn, M. (1992). Metakognition und Lernen (Metacognition and learning). In G. Nolde (Ed.), Lernbedingungen und Lernstrategien (Learning conditions and learning strategies) (pp. 35-64). Tübingen: Gunter Narr.

Hattie, J. \& Timperley, H. (2007). The power of feedback. Review of Educational Research, 77(1), 81-112.

Hasselhorn, M., \& Gold, A. (2006). Pädagogische Psychologie (Educational psychology). Stuttgart: Kohlhammer.

Hasselhorn, M., \& Labuhn, A. S. (2008). Metakognition und selbstreguliertes Lernen (Metacognition and self-regulated learning). In W. Schneider \& Hasselhorn (Eds.), Handbuch der Pädagogischen Psychologie (Handbook of educational psychology) (pp. 28-37). Göttingen: Hogrefe.

Herremans, I. M., \& Reid, R. E. (2002). Developing awareness of the sustainability concept. The Journal of Environmental Education, 34(1), 16-20. 
Herzig, B. (2005). Selbstreguliertes Lernen. Entwurf eines Konzeptes im Rahmen des Modellversuchs SINUS-Transfer NRW Projekt 3 (Selfregulated learning. Theoretical concepts in the project SINUSTransfer, North-Rhine Westfalia, project 3). Bochum.

Hesse, A. (2006). Big six - Die sechs wichtigsten globalen Herausforderungen für sustainable development im 21. Jahrhundert. (Big six - The six most important global challenges for sustainable development in the 21st century). Münster: SD-M Eigenverlag.

Hodson, D. (2003). Time for action: Science education for an alternative future. International Journal of Science Education, 25(6), 645-670.

Hogan, K. (2002). Small groups' ecological reasoning while making an environmental management decision. Journal of Research in Science Teaching, 39(4), 341-368.

Hogarth, R. M. (2005). Deciding analytically or trusting your intuition? The advantages and disadvantages of analytic and intuitive thought. In T. Betsch \& S. Haberstroh (Eds.), The routines of decision making (pp. 67-82). Mahwah: Erlbaum.

Hong, J.-L., \& Chang, N.-K. (2004). Analysis of Korean high school students' decision-making processes in solving a problem involving biological knowledge. Research in Science Education, 34(1), 97111.

Huckle, J., \& Sterling, S. (1996). Education for sustainability. London: Earthscan.

Hungerford, H. R. (2010). Environmental Education (EE) for the 21st century: Where have we been? Where are we now? Where are we headed? The Journal of Environmental Education, 41(1), 1-6.

Jickling, B. (1992). Why I don't want my children to be educated for sustainable development. The Journal of Environmental Education, 23(4), 5-8.

Jiménez-Aleixandre, M. P., Bugallo Rodríguez, A., \& Duschl, R. A. (2000). "Doing the lesson" or "doing science": Argument in high school genetics. Science Education, 84(6), 757-792.

Jiménez-Aleixandre, M. P., \& Pereiro-Muñoz, C. (2002). Knowledge producers or knowledge consumers? Argumentation and decision making about environmental management. International Journal of Science Education, 24(11), 1171-1190. 
Jungermann, H., Pfister, H.-R., \& Fischer, K. (2005). Die Psychologie der Entscheidung (The psychology of decision-making) (2nd ed.). Heidelberg: Elsevier, Spektrum, Akademischer Verlag.

Kauertz, A., Fischer, H. E., Mayer, J., Sumfleth, E., \& Walpuski, M. (2010). Standardbezogene Kompetenzmodellierung in den Naturwissenschaften der Sekundarstufe I (Classroom research on science education - Models of teaching and learning and the analysis of physics lessons). Zeitschrift für Didaktik der Naturwissenschaften, 16, 135-153.

King, P. M., \& Kitchener, K. S. (1994). Developing reflective judgment: Understanding and promoting intellectual growth and critical thinking in adolescents and adults. San Francisco: Jossey-Bass.

Klieme, E., Artelt, C., \& Stanat, P. (2001). Fächerübergreifende Kompetenzen: Konzepte und Indikatoren (Cross-curricular competencies: Concepts and indicators). In F. Weinert (Ed.), Leistungsmessungen in Schulen (Assessment of performance in schools) (pp. 203-218). Weinheim: Beltz.

Klieme, E., Avenarius, H., Blum, W., Döbrich, P., Gruber, H., Prenzel, M., Reiss, M., et al. (2003). Zur Entwicklung nationaler Bildungsstandards - Eine Expertise (Expertise on the development of national educational standars). Berlin: Bundesministerium für Bildung und Forschung.

Klieme, E., \& Leutner, D. (2006). Kompetenzmodelle zur Erfassung individueller Lernergebnisse und zur Bilanzierung von Bildungsprozessen. Beschreibung eines neu eingerichteten Schwerpunktprogramms der DFG (Developing competence models to assess individual learning outcomes and the development of the educational system. Description of a new priority program of the German research foundation). Zeitschrift für Pädagogik, 52(6), 876903.

Klieme, E., Leutner, D., \& Kenk, M. (2010). Kompetenzmodellierung. Zwischenbilanz des DFG-Schwerpunktprogramms und Perspektiven des Forschungsansatzes (Modelling competencies. Interim results of the priority program of the German research foundation and perspectives of the research approach), Zeitschrift für Pädagogik, Beiheft 56. 
Koeppen, K., Hartig, J., Klieme, E., \& Leutner, D. (2008). Current issues in competence modeling and assessment. Zeitschrift für Psychologie / Journal of Psychology, 216(2), 61-73.

Kolstø, S. D. (2001). Scientific literacy for citizenship: Tools for dealing with the science dimension of controversial socioscientific issues. Science Education, 85(3), 291-310.

Kolstø, S. D. (2006). Patterns in students' argumentation confronted with a risk-focused socio-scientific issue. International Journal of Science Education, 28(14), 1689-1716.

Kortland, K. (1996). An STS case study about students' decision making on the waste issue. Science Education, 80(6), 673-689.

Krombass, A., \& Harms, U. (2006). Ein computergestütztes Informationssystem zur Biodiversität als motivierende und lernförderliche Ergänzung der Exponate eines Naturkundemuseums (A computerbased information system about biodiversity as a motivating and beneficial supplement for the exhibits of a natural history museum). Zeitschrift für Didaktik der Naturwissenschaften, 12, 7-22.

Kuhn, D. (1991). The skills of argument. New York: Cambridge University Press.

Kuhn, D. (1993). Science as argument: Implications for teaching and learning scientific thinking. Science Education, 77(3), 319-337.

Kuhn, D. (1999). A developmental model of critical thinking. Educational Researcher, 28(2), 16-26.

Kuhn, D., Shaw, V., \& Felton, M. (1997). Effects of dyadic interaction on argumentative reasoning. Cognition and Instruction, 15(3), 287-315.

Kultusministerkonferenz (KMK). (2005a). Bildungsstandards im Fach Biologie für den Mittleren Schulabschluss ((German) educational standards in biology for middle school graduation). München: Wolters Kluwer Deutschland.

Kultusministerkonferenz (KMK). (2005b). Bildungsstandards im Fach Chemie für den Mittleren Schulabschluss ((German) educational standards in chemistry for middle school graduation). München: Wolters Kluwer Deutschland.

Kultusministerkonferenz (KMK). (2005c). Bildungsstandards im Fach Physik für den Mittleren Schulabschluss ((German) educational standards in physics for middle school graduation). München: Wolters Kluwer Deutschland. 
Kultusministerkonferenz (KMK), \& Bundesministerium für wirtschaftliche Zusammenarbeit und Entwicklung (BMZ) (2007). Orientierungsrahmen für den Lernbereich Globale Entwicklung im Rahmen einer Bildung für nachhaltige Entwicklung (Reference frame for the learning field of global development within the framework of education for sustainable development). Bonn: Author.

Kyburz-Graber, R., Rigendinger, L., Hirsch Hadorn, G., \& Werner Zentner, K. (1997). Sozio-ökologische Umweltbildung (Socio-ecological environmental education). Hamburg: Krämer.

Labuhn, A. S. (2008). Förderung selbstregulierten Lernens im Unterricht: Herausforderungen, Ansatzpunkte, Chancen (Enhancing selfregulated learning in a classroom context: An investigation of different approaches). Göttingen: Niedersächsische Staats- und Universitätsbibliothek Göttingen.

Labuhn, A. S., Bögeholz, S., \& Hasselhorn, M. (2008a). Lernförderung durch Anregung der Selbstregulation im naturwissenschaftlichen Unterricht (Enhancing learning through stimulating self-regulation in science education). Zeitschrift für Pädagogische Psychologie, 22(1), 13-24.

Labuhn, A. S., Bögeholz, S., \& Hasselhorn, M. (2008b). Selbstregulationsförderung in einer Biologie-Unterrichtseinheit (Fostering selfregulation in a biology teaching unit). Zeitschrift für Entwicklungspsychologie und Pädagogische Psychologie, 40(4), 167-178.

Lauströer, A. (2005). Förderung von Bewertungskompetenz durch Bildung für eine nachhaltige Entwicklung (Fostering decision-making competence through education for sustainable development). Kiel: Universitätsbibliothek.

Lauströer, A., \& Rost, J. (2008). Operationalisierung und Messung von Bewertungskompetenz (Operationalization and assessment of decision-making competence). In I. Bormann \& G. de Haan (Eds.), Kompetenzen der Bildung für nachhaltige Entwicklung (Competencies in the field of education for sustainable development) (pp. 89-102). Wiesbaden: VS Verlag für Sozialwissenschaften, GWV Fachverlage. 
Leopold, C., den Elzen-Rump, V., \& Leutner, D. (2006). Selbstreguliertes Lernen aus Sachtexten (Self-regulated learning when reading informational texts). In M. Prenzel \& L. Allolio-Näcke (Eds.), Untersuchungen zur Bildungsqualität von Schule. Abschlussbericht des DFG-Schwerpunktprogramms (Research on school education. Final report of the priority program of the German Research Foundation (pp. 268-288). Münster: Waxmann.

Leutner, D., \& Leopold, C. (2006). Selbstregulation beim Lernen aus Sachtexten (Self-regulation when learning from non-fictional texts). In H. Mandl \& Friedrich (Eds.), Handbuch Lernstrategien (Handbook about learning strategies) (pp. 162-171). Göttingen: Hogrefe.

Leutner, D., Leopold, C., \& den Elzen-Rump, V. (2007). Self-regulated learning with a text-highlighting strategy. Zeitschrift für Psychologie, 215(3), 174-182.

Marcinkowski, T. J. (2010). Contemporary challenges and opportunities in environmental education: Where are we headed and what deserves our attention? The Journal of Environmental Education, 41(1), 3454.

Mayring, P. (2008). Qualitative Inhaltsanalyse - Grundlagen und Techniken (Quantitative content analysis - Foundations and techniques) (10th ed.). Weinheim: Beltz.

McConnell, M. C. (1982). Teaching about science, technology and society at the secondary school level in the United States. An educational dilemma for the 1980s. Studies in Science Education, 9, 1-32.

McMackin, J., \& Slovic, P. (2000). When does explicit justification impair decision making? Journal of Applied Cognitive Psychology, 14(6), 527-541.

Meadows, D. H., Meadows, D. L., Randers, J., \& Behrens III, W. W. (1972). The limits to growth: A report for the Club of Rome's project on the predicament of mankind. New York: Universe Books.

Means, M. L., \& Voss, J. F. (1996). Who reasons well? Two studies of informal reasoning among children of different grade, ability, and knowledge levels. Cognition and Instruction, 14(2), 139-178. 
Menzel, S., \& Bögeholz, S. (2006). Vorstellungen und Argumentationsstrukturen von Schüler(inne)n der elften Jahrgangsstufe zur Biodiversität, deren Gefährdung und Erhaltung (Students' conceptions and argumentational structures regarding biodiversity, its threat and conservation). Zeitschrift für Didaktik der Naturwissenschaften, 12, 199-215.

Menzel, S., \& Bögeholz, S. (2009). The loss of biodiversity as a challenge for sustainable development: How do pupils in Chile and Germany percieve resource dilemmas? Research in Science Education, 39(4), 429-447.

Mittelsten Scheid, N., \& Hößle, C. (2008). Wie Schüler unter Verwendung syllogistischer Elemente argumentieren. Eine empirische Studie zu Niveaus von Argumentation im naturwissenschaftlichen Unterricht. (Students' skill of argument in terms of syllogisms. Levels of the skill of argument within science education - an empirical approach). Zeitschrift für Didaktik der Naturwissenschaften, 14, 145-165.

Moreno, R., Reisslein, M., \& Ozogul, G. (2009). Optimizing workedexample instruction in electrical engineering: The role of fading and feedback during problem-solving practice. Journal of Engineering Education, 98(1), 83-92.

Mühlenhoff, P. (2009). Umgang mit fragiler und konfligierender Evidenz im Biologieunterricht - Die Gestaltung der Unterems als Lernaufgabe (Dealing with fragile and conflicting evidence in biology education The constitution of the River Ems as a learning task). (unpublished master's thesis). Göttingen: University of Göttingen, Department of Biology Education.

National Research Council (NRC). (1996). National science education standards. Washington: National Academy Press.

Niedersächsisches Kultusministerium. (2007). Kerncurriculum für das Gymnasium, Schuljahrgänge 5-10. Naturwissenschaften (Curriculum for secondary school, grades 5 to 10. Science education). Hannover: Author.

Niedersächsisches Kultusministerium. (2009). Kerncurriculum für das Gymnasium - gymnasiale Oberstufe, die Gesamtschule gymnasiale Oberstufe, das Fachgymnasium, das Abendgymnasium, das Kolleg. Biologie (Curriculum for upper high school. Biology education). Hannover: Author. 
Organisation for Economic Co-operation and Development. (1999). Measuring student knowledge and skills: A new framework for assessment. Paris: Author.

Osborne, J., Erduran, S., \& Simon, S. (2004). Enhancing the quality of argumentation in school science. Journal of Research in Science Teaching, 41(10), 994-1020.

Oser, F., \& Althof, W. (1992). Wertklärung (Values clarification). In F. Oser \& W. Althof (Eds.), Moralische Selbstbestimmung: Modelle der Entwicklung und Erziehung im Wertebereich (Moral selfdetermination: Models of moral development and moral education) (pp. 475-516). Stuttgart: Klett-Cotta.

Paas, F. (1992). Training strategies for attaining transfer of problemsolving skill in statistics: A cognitive-load approach. Journal of Educational Psychology, 84(4), 429-434.

Paas, F. G. W. C., \& van Merriënboer, J. J. G. (1994). Instructional control of cognitive load in the training of complex cognitive tasks. Educational Psychology Review, 6(4), 351-371.

Payne, J. W., Bettmann, J. R., \& Luce, M. F. (1998). Behavioral decision research: An overview. In M. H. Birnbaum (Ed.), Measurement, judgment, and decision making (2nd ed., pp. 303-359). San Diego: Academic Press.

Pedretti, E. (1999). Decision making and STS education: Exploring scientific knowledge and social responsibility in schools and science centers through an issues-based approach. School Science and Mathematics, 99(4), 174-181.

Pedretti, E. (2003). Teaching science, technology, society and environment (STSE) education. In D. L. Zeidler (Ed.), The role of moral reasoning on socioscientific issues and discourse in science education (pp. 219-239). Dordrecht: Kluwer Academic Publishers.

Pedretti, E. (2005). STSE education: Principles and practices. Theoretical lenses and a spectrum of possibilities for practice. In S. Alsop, L. Bencze, \& E. Pedretti (Eds.), Analysing exemplary science teaching (pp. 116-126). Maidenhead: Open University Press.

Pedretti, E., \& Nazir, J. (2011). Currents in STSE education: Mapping a complex field, 40 years on. Science Education, 95(4), 601-626. 
Perels, F., Gürtler, T., \& Schmitz, B. (2005). Training of self-regulatory and problem-solving competence. Learning and Instruction, 15(2), 123139.

Pintrich, P. R., Smith, D. A. F., Garcia, T., \& McKeachie, W. J. (1993). Reliability and predictive validity of the motivated strategies for learning questionnaire (MSLQ). Educational and Psychological Measurement, 53(3), 801-813.

Plous, S. (1993). The psychology of judgment and decision making. New York: McGraw-Hill.

Potter, G. (2010). Environmental education for the 21st century: Where do we go now? The Journal of Environmental Education, 41(1), 22-33.

Prenzel, M., Carstensen, C. H., Senkbeil, M., Ostermeier, C., \& Seidel, T. (2005). Wie schneiden SINUS-Schulen bei PISA ab? Ergebnisse der Evaluation eines Modellversuchsprogramms. (How do the schools that participated in the SINUS program perform on the PISA tests? Results of an evaluation of the program). Zeitschrift für Erziehungswissenschaft, 8(4), 540-561.

Pressley, M., Borkowski, J. G., \& Schneider, W. (1987). Cognitive strategies: Good strategy users coordinate metacognition and knowledge. In R. Vasta \& G. Whitehurst (Eds.), Annals of child development (Vol. 5, pp. 89-129). New York: JAI Press.

Pressley, M., Borkowski, J. G., \& Schneider, W. (1989). Good information processing: What it is and how education can promote it. International Journal of Educational Research, 13(8), 857-867.

Qualifications and Curriculum Authority (QCA). (2004). Science: The national curriculum for England. London: Department for Education and Skills, Qualifications and Curriculum Authority.

Ratcliffe, M. (1997). Pupil decision-making about socio-scientific issues within the science curriculum. International Journal of Science Education, 19(2), 167-182.

Ratcliffe, M., \& Grace, M. (2003). Science education for citizenship Teaching socioscientific issues. Maidenhead: Open University Press.

Redclift, M. (1987). Sustainable development: Exploring the contradictions. London: RoutledgeFalmer. 
Reiss, M. (2008). The use of ethical frameworks by students following a new science course for 16-18 year-olds. Science \& Education, 17(8-9), 889-902.

Reitschert, K., \& Hößle, C. (2007). Wie Schüler ethisch bewerten. Eine qualitative Untersuchung zur Strukturierung und Ausdifferenzierung von Bewertungskompetenz in bioethischen Sachverhalten bei Schülern der Sek. I (How students judge ethically. A qualitative study on the structure and differentiation of competence of moral judgement with respect to bioethical issues concerning students of Sek. I). Zeitschrift für Didaktik der Naturwissenschaften, 13, 125-143.

Rieß, W., \& Mischo, C. (2010). Promoting systems thinking through biology lessons. International Journal of Science Education, 32(6), 705-725.

Roberts, D. A. (2007). Scientific literacy/science literacy. In S. K. Abell \& N. G. Lederman (Eds.), Handbook of research on science education (pp. 729-780). Mahwah: Law.

Roberts, L., Wilson, M. \& Draney, K. (1997). The SEPUP assessment system: An overview. BEAR report series, SA-97-1. Berkeley: University of California.

Rost, J. (2002). Umweltbildung - Bildung für eine nachhaltige Entwicklung: Was macht den Unterschied? (Environmental education education for sustainable development: What's the difference? Zeitschrift für internationale Bildungsforschung und Entwicklungspädagogik, 1, 1-10.

Rost, J., Lauströer, A., \& Raack, N. (2003). Kompetenzmodelle einer Bildung für Nachhaltigkeit (Models of competence regarding education for sustainable development). Praxis der Naturwissenschaften - Chemie in der Schule, 8(52), 10-15.

Sadler, T. D. (2004). Informal reasoning regarding socioscientific issues: A critical review of research. Journal of Research in Science Teaching, 41(5), 513-536.

Sadler, T. D. (2009). Situated learning in science education: Socioscientific issues as contexts for practice. Studies in Science Education, 45(1), 1-42.

Sadler, T. D. (2011). Socio-scientific issues in the classroom. Teaching, learning and research. Dordrecht: Springer. 
Sadler, T. D., Barab, S. A., \& Scott, B. (2007). What do students gain by engaging in socioscientific inquiry? Research in Science Education, 37(4), 371-391.

Sadler, T. D., \& Zeidler, D. L. (2004). The morality of socioscientific issues: Construal and resolution of genetic engineering dilemmas. Science Education, 88(1), 4-27.

Sadler, T. D., \& Zeidler, D. L. (2005). Patterns of informal reasoning in the context of socioscientific decision making. Journal of Research in Science Teaching, 42(1), 112-138.

Sauvé, L. (1996). Environmental education and sustainable development: A further appraisal. Canadian Journal of Environmental Education, 1, 7-34.

Sauvé, L. (2005). Currents in environmental education: Mapping a complex and evolving pedagogical field. Canadian Journal of Environmental Education, 10, 11-37.

Schecker, H., \& Parchmann, I. (2006). Modellierung naturwissenschaftlicher Kompetenz (Modelling competencies in the field of science education). Zeitschrift für Didaktik der Naturwissenschaften, 12, 45-66.

Schmitz, B. (2001). Self-monitoring zur Unterstützung des Transfers einer Schulung in Selbstregulation für Studierende - Eine prozessanalytische Untersuchung (Self-monitoring to support the transfer of training in self-regulation at college level - A process-related analyis). Zeitschrift für Pädagogische Psychologie, 15(3-4), 181197.

Schmitz, B., Schmidt, M., Landmann, M., \& Spiel, C. (2007). New developments in the field of self-regulated learning. Zeitschrift für Psychologie, 215(3), 153-156.

Schraw, G., Crippen, K. J., \& Hartley, K. (2006). Promoting self-regulation in science education: Metacognition as part of a broader perspective on learning. Research in Science Education, 36(1), 111139.

Schunk, D. H., \& Zimmerman, B. J. (1998). Conclusions and future directions for academic interventions. In D. H. Schunk \& B. J. Zimmerman (Eds.), Self-regulated learning: From teaching to selfreflective practice (pp. 225-235). New York: Guilford. 
Scott, W., \& Gough, S. (2003). Sustainable development and learning. London: RoutledgeFalmer.

Seethaler, S., \& Linn, M. (2004). Genetically modified food in perspective: An inquiry-based curriculum to help middle school students make sense of tradeoffs. International Journal of Science Education, 26(14), 1765-1785.

Senkbeil, M., Rost, J., Carstensen, C. H., \& Walter, O. (2005). Der nationale Naturwissenschaftstest PISA 2003. Entwicklung und empirische Überprüfung eines zweidimensionalen Facettendesigns (The national science test in PISA 2003. Development and empirical analysis of a two-facets design). Empirische Pädagogik, 19(2), 166-189.

Siegel, M. A. (2006). High school students' decision making about sustainability. Environmental Education Research, 12(2), 201-215.

Simon, H. A. (1955). A behavioral model of rational choice. Quarterly Journal of Economics, 69(1), 99-118.

Simon, S. B., Howe, L. W., \& Kirschenbaum, H. (1972). Values clarification: A handbook of practical strategies for teachers and students. New York: Hart.

Solomon, J., \& Aikenhead, G. S. (1994). STS education - International perspectives on reform. New York: Teachers College Press.

Souvignier, E., \& Rös, K. (2005). Lernstrategien und Lernerfolg bei komplexen Leistungsanforderungen - Analysen mit Fragebogen und Lerntagebuch (Learning strategies and performance in complex tasks - Analyses of questionnaires and diaries to support the learning progression). In C. Artelt \& B. Moschner (Eds.), Lernstrategien und Metakognition (Learning strategies and metacognition) (pp. 66-76). Münster: Waxmann.

Thillmann, H. (2007). Selbstreguliertes Lernen durch Experimentieren: Von der Erfassung zur Förderung (Assessing and fostering selfregulated learning through experimentation). Essen: Bibliothek Duisburg Essen.

Toulmin, S. (1958). The uses of argument. Cambridge: Cambridge University Press.

Tversky, A. (1972). Elimination by aspects: A theory of choice. Psychological Review, 79(4), 281-299. 
United Nations Conference on Environment and Development (UNCED). (1992). Rio declaration on environment and development. Retrieved from

http://www.un.org/documents/ga/conf151/aconf15126-1annex1.htm.

United Nations Educational, Scientific and Cultural Organization (UNESCO). (1978). Final report: Intergovernmental conference on environmental education. Paris. Retrieved from http://unesdoc.unesco.org/images/0003/000327/032763eo.pdf.

University of Rochester. (1996). Intrinsic motivation inventory. Retrieved from http://www.psych.rochester.edu/SDT/measures/IMI_scales.php.

van Gog, T., Paas, F., \& van Merriënboer, J. J. G. (2006). Effects of process-oriented worked examples on troubleshooting transfer performance. Learning and Instruction, 16(2), 154-164.

Venville, G. J., \& Dawson, V. M. (2010). The impact of a classroom intervention on grade 10 students' argumentation skills, informal reasoning, and conceptual understanding of science. Journal of Research in Science Teaching, 47(8), 952-977.

Ward, M., \& Sweller, J. (1990). Structuring effective worked examples. Cognition and Instruction, 7(1), 1-39.

Weinert, F. (1999). Concepts of competence (Contribution within the OECD project Definition and selection of competencies: Theoretical and conceptual foundations (DeSeCo)). Neuchâtel: DeSeCo.

Weinert, F. (2001a). Vergleichende Leistungsmessung in Schulen - eine umstrittene Selbstverständlichkeit (Comparative assessments in schools - A controversial matter of course). In F. Weinert (Ed.), Leistungsmessungen in Schulen (Assessment of performance in schools) (pp. 17-31). Weinheim: Beltz.

Weinert, F. (2001b). Concept of competence: A conceptual clarification. In D. S. Rychen \& L. H. Salganik (Eds.), Defining and selecting key competencies (pp. 45-65). Seattle: Hogrefe \& Huber.

Weinstein, C. E. (1988). Learning and study strategies: Issues in assessment, instruction, and evaluation. San Diego: Academic Press.

Whitehead, M. (2007). Spaces of sustainability. London: Routledge. 
Wilde, M., Bätz, K., Kovaleva, A., \& Urhahne, D. (2009). Überprüfung einer Kurzskala intrinsischer Motivation (KIM) (Testing a short scale of intrinsic motivation). Zeitschrift für Didaktik der Naturwissenschaften, 15, 31-45.

Wirth, J., \& Leutner, D. (2008). Self-regulated learning as a competence: Implications of theoretical models for assessment methods. Zeitschrift für Psychologie / Journal of Psychology, 216(2), 102-110.

World Commission on Environment and Development (WCED). (1987). Our common future. Oxford: Open University Press.

Zeidler, D. L. (1997). The central role of fallacious thinking in science education. Science Education, 81(1), 483-496.

Zeidler, D. L., \& Keefer, J. (2003). The role of moral reasoning and the status of socioscientific issues in science education. In D. L. Zeidler (Ed.), The role of moral reasoning on socioscientific issues and discourse in science education (pp. 7-38). Dordrecht: Kluwer Academic Publishers.

Zeidler, D. L., Osborne, J., Erduran, S., Simon, S., \& Monk, M. (2003). The role of argument during discourse about socioscientific issues. In D. L. Zeidler (Ed.), The role of moral reasoning on socioscientific issues and discourse in science education (pp. 97-116). Dordrecht: Kluwer Academic Publishers.

Zeidler, D. L., \& Sadler, T. D. (2007). Social and ethical issues in science education: A prelude to action. Science \& Education, 17(8-9), 799803.

Zeidler, D. L., Sadler, T. D., Applebaum, S., \& Callahan, B. E. (2009). Advancing reflective judgment through socioscientific issues. Journal of Research in Science Teaching, 46(1), 74-101.

Zeidler, D. L., Sadler, T. D., Simmons, M. L., \& Howes, E. V. (2005). Beyond STS: A research-based framework for socioscientific issues education. Science Education, 89(3), 357-377.

Zimmerman, B. J. (2000). Attaining self-regulation: A social cognitive perspective. In M. Boekaerts (Ed.), Handbook of Self-Regulation (pp. 13-39). Burlington: Elsevier Academic Press.

Zohar, A., \& Nemet, F. (2002). Fostering students' knowledge and argumentation skills through dilemmas in human genetics. Journal of Research in Science Teaching, 39(1), 35-62. 


\section{Curriculum Vitae}

Okt. 2008 - Jan. 2012 Promotionsstudium Biologie an der GeorgAugust-Universität Göttingen bei Prof. Dr. Bögeholz, Biologiedidaktik

Okt. 2008 - Okt. 2011 Stipendiat im DFG-Graduiertenkolleg 1195 Passungsverhältnisse schulischen Lernens

Okt. 2003 - Juni 2008 Studium an der Carl-von-Ossietzky-Universität Oldenburg: Biologie und Mathematik für das Lehramt an Gymnasien, 1. Staatsexamen $2006-2008$ studentische Hilfskraft bei Prof. Dr. Hößle

Aug. 2002 - Mai 2003 Zivildienst: Individuelle

Schwerstbehindertenbetreuung,

Diakoniestation Flensburg Ost

$1993-2002$

Fördegymnasium, Flensburg, Abitur

$1989-1993$

Grundschule Friedheim, Flensburg

\section{Auslandsaufenthalte}

Aug. 2010 - Nov. 2010 University of South Florida, Tampa, USA. Aufenthalt bei Prof. Dr. Zeidler

Sept. 2005 - März 2006 Universidad de Córdoba, Spanien

Sept. 1999 - März 2000 Cheltenham College, England

\section{Fremdsprachenkenntnisse}

Englisch, Spanisch, Französisch, Latein 